Angela Maria Ramos Lobo

\title{
Alteração dos ritmos diários de temperatura e atividade motora provocada pelo diabetes induzido por estreptozotocina em ratos wistar
}

Dissertação apresentada ao Programa de Pós-Graduação em Fisiologia Humana do Instituto de Ciências Biomédicas da Universidade de São Paulo, para obtenção do Título de Mestre em Ciências. 
Angela Maria Ramos Lobo

\section{Alteração dos ritmos diários de temperatura e atividade motora provocada pelo diabetes induzido por estreptozotocina em ratos wistar}

Dissertação apresentada ao Departamento de Fisiologia e Biofísica do Instituto de Ciências Biomédicas da Universidade de São Paulo, para obtenção do Título de Mestre em Ciências.

Área de concentração: Fisiologia Humana

Orientador: Prof. Dr. José Cipolla-Neto

Versão original

São Paulo

2013 
DADOS DE CATALOGAÇÃO NA PUBLICAÇÃO (CIP)

Serviço de Biblioteca e Informação Biomédica do

Instituto de Ciências Biomédicas da Universidade de São Paulo

reprodução não autorizada pelo autor

Lobo, Angela Maria Ramos.

Alteração dos ritmos diários de temperatura e atividade motora provocada pelo diabetes induzido por estreptozotocina em ratos wistar / Angela Maria Ramos Lobo. -- São Paulo, 2013.

Orientador: Prof. Dr. Jose Cipolla-Neto.

Dissertação (Mestrado) - Universidade de São Paulo. Instituto de Ciências Biomédicas. Departamento de Fisiologia e Biofísica. Área de concentração: Fisiologia Humana. Linha de pesquisa:

Neuroendocrinologia.

Versão do título para o inglês: Streptozotocin-induced diabetes disrupts body temperature and home cage activity daily rhythms in wistar rats.

1. Ritmos biológicos 2. Diabetes mellitus 3. Temperatura

4. Atividade motora 5. Insulina 6. Melatonina I. Cipolla-Neto,

Prof. Dr. Jose II. Universidade de São Paulo. Instituto de Ciências Biomédicas. Programa de Pós-Graduação em Fisiologia Humana III. Título. 
Candidato(a):

Título da Dissertação:

Orientador(a):
Angela Maria Ramos Lobo.

Alteração dos ritmos diários de temperatura e atividade motora provocada pelo diabetes induzido por estreptozotocina em ratos wistar.

A Comissão Julgadora dos trabalhos de Defesa da Dissertação de Mestrado, em sessão pública realizada a considerou
( ) Aprovado(a)
( ) Reprovado(a)

Examinador(a): Assinatura:

Nome:

Instituição:

Examinador(a): Assinatura:

Nome:

Instituição:

Presidente: Assinatura:

Nome:

Instituição: 


\section{CERTIFICADO}

Certificamos que o protocolo registrado sob n ${ }^{\circ} \mathbf{1 9 9}$ nas fls. $\mathbf{1 1 6}$ do livro 02 para uso de animais em experimentação, sob a responsabilidade do Prof(a) $\operatorname{Dr}(a))$ José Cipolla Neto, Coordenador (a) da Linha de pesquisa "O papel da melatonina no controle do metabolismo energético: ações centrais e a regulação circadiana da função metabólica" do qual participam o(s) aluno(s) Jéssica Andrade da Silva, Caroline Mendes, Rafael Maso Prévide, Ariane de Oliveira Turati, Angela Ramos Lobo, Rosana Fátima Dantas Ferreira, Ana Maria de Souza Lopes, Ronaldo Meira de Mello, Marco Taneda, Rafael Peres, Fernanda Gaspar do Amaral, Eliângela de Lima, Lia de Alencar Coelho,Daniella do Carmo Buonfiglio e os pesquisadores Fabio Bessa Lima, Silvana Bordin, Sara Schammah, Carla Roberta de Oliveira Carvalho, Solange Castro Afeche, Edson Amaro Jr., está de acordo com os Princípios Éticos de Experimentação Animal adotado pela Sociedade Brasileira de Ciência de Animais de Laboratório (SBCAL) e foi aprovado pela COMISSÃO DE ÉTICA NO USO DE ANIMAIS (CEUA) em 24.01.2012, com validade de 4 anos.

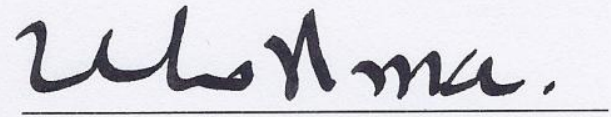

Prof.Dr.WOTHAN TAVARES DE LIMA

Coordenador

CEUA - ICB/USP
São Paulo, 27 de janeiro de 2012.

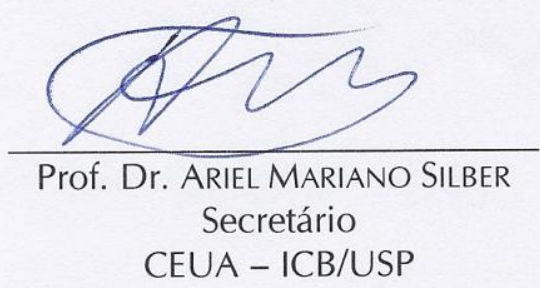


Dedico este trabajo a todos aquellos que contribuyeron para su desarrollo y me acompañaron durante este camino. En especial a mi familia por el apoyo y cariño incansables: mis padres Luis Manuel y Maria Lucia, y mis hermanos, Ana Amelia y José Luis. 


\section{AGRADECIMENTOS}

Finalmente chegou o momento tão esperado da culminação do mestrado. Essa experiência maravilhosa de mudar de vida, conhecer um novo país, uma nova cidade, um novo laboratório e novas pessoas. Ao chegar ao final, olhando para trás fico feliz de ter sido uma excelente escolha.

Gostaria de agradecer acima de tudo a Deus por guiar meu caminho e me permitir viver essa experiência maravilhosa de encontrar meu novo caminho em São Paulo e por todas as pessoas que acompanham a minha vida dia a dia.

Gracias a la mejor familia que podría haber pedido, que acompañan a la distancia pero siempre tan de cerca, estos años dándome coraje y fuerza para ir atrás de lo que me hace feliz. Gracias por la magia que tiene cada momento que pasamos los 5 juntos! Los quiero y los extraño demais.

A mis padres, Luis y Lucia, por apoyarme siempre, por todo lo que me enseñaron. Gracias por las charlas, los consejos, y la confianza depositada en mí. Por entender, aceptar y apoyarme en la búsqueda de mi camino, aunque sea un poco lejos de casa.

A mis hermanos Jose y Any, por apoyarme y acompañarme siempre. Por hacerme reir tanto y por cuidarme siempre. Por estar a mi lado y festejar cada pequeña alegría conmigo.

A mis amigos argentinos que me siguen acompañando en esta nueva etapa, compartiendo cada momento conmigo, aunque sea a la distancia.

Agradeço a minha família brasileira, meus tios e primos, por me apoiar e me fazer saber que posso contar com eles em qualquer momento.

Agradeço ao meu orientador, o Professor Cipolla, por ter aberto as portas do seu laboratório e me permitir cumprir meu sonho de trabalhar com Cronobiologia. Obrigada por me dar a liberdade, a confiança e as ferramentas para desenvolver meu trabalho, e por transmitir seu enorme conhecimento.

Agradeço a FAPESP e a CAPES pelo apoio financeiro para desenvolver meu mestrado.

A Daniellita, minha grande amiga. Um anjo que encontrei em São Paulo e que além de me ensinar grande parte do que aprendi no laboratório e de acompanhar de muito perto meu mestrado, se tornou numa amiga incrível com quem compartilhei esse tempo todo, muitas coisas boas, dentro e fora do laboratório. Obrigada por acreditar em mim ate quando eu não acredito.

A Ju, pelo grande apoio sempre nos experimentos e no dia a dia no laboratório. Obrigada pelo seu carinho e preocupação de mãe, pelas conversas e conselhos. 
Ao Rafa Prévide, com quem conheci muitos lugares legais em São Paulo, pelas conversas, as risadas e as saídas para comer coisas gostosas.

A Rosita, que além de ser uma grande amiga e companheira, me deu a possibilidade de dividir a casa com duas crianças fantásticas: o Schopen e a Penny.

A Moranguito, pelas conversas, as risadas, os jogos e a ajuda para resolver burocracias.

Aos meus colegas do laboratório, por terem me recebido tão bem e pelos experimentos circadianos compartilhados.

Um agradecimento especial ao José Maria, pela assistência e a ajuda sempre para resolver todos os tramites da pós-graduação.

Ao Anderson, pela alegria, por ter me ensinado a fazer Western Blot e por me ensinar uma nova forma de pensar a ciência.

Aos amigos que fiz aqui no Brasil, por todos os momentos legais que passei com vocês. Em especial ao Marcinho, meu primeiro amigo aqui, e o Matheus, com quem passei muitos momentos ótimos, por terem me recebido como colega de casa, pelas conversas e pelo interesse no que eu faço.

Ao Prof. Menna, por sua enorme predisposição para me ensinar Cronobiologia e discutir conceitos comigo. Obrigada pelas inúmeras contribuições na minha banca de qualificação, e pelo programa El Temps que foi fundamental para analisar meus dados.

Ao Dr. Mario Miguel, por ter me ensinado a trabalhar com o programa El Temps e pelas sugestões.

A Profa. Maria Tereza, por me transmitir a magia de ensinar, e por sempre ter as portas abertas para discutir qualquer assunto.

Finalmente, quero agradecer a todos aqueles que em maior ou menor medida acompanharam essa etapa durante esses dois anos, todos tiveram um papel importante. Obrigada! 


\section{RESUMO}

Ramos Lobo AM. Alteração dos ritmos diários de temperatura e atividade motora provocada pelo diabetes induzido por estreptozotocina em ratos Wistar. [dissertação (Mestrado em Ciências)] - São Paulo: Instituto de Ciências Biomédicas, Universidade de São Paulo; 2013.

Nos mamíferos, os núcleos supraquiasmáticos coordenam a ritmicidade biológica, regulando os ritmos circadianos e sazonais do organismo. A melatonina, hormônio produzido principalmente pela glândula pineal, é conhecida por ser um importante agente regulador dos ritmos endógenos, incluindo atividade motora (AM) e temperatura corporal (TC), sendo a sua produção influenciada por diversos fatores, como por exemplo, o diabetes mellitus tipo I (DM1). No rato, o DM1 promove a diminuição da TC, da AM e da síntese de melatonina, e o tratamento com insulina reverte tanto o efeito sobre a média da TC quanto sobre a síntese de melatonina, porem não reverte à diminuição da media da $\mathrm{AM}$. No entanto, ainda não são conhecidos, nesse modelo experimental, os perfis diários da TC e da AM, marcadores do sistema circadiano. $O$ objetivo do presente trabalho foi avaliar os efeitos do DM1 sobre os ritmos de TC e AM, seus parâmetros rítmicos (MESOR, amplitude e acrofase), peso e glicemia, assim como as modificações resultantes dos tratamentos tardios e precoces com insulina (6U/dia) (INSt e INSp), melatonina $(0,5 \mathrm{mg} / \mathrm{kg} / \mathrm{dia})$ (MELt e MELp) ou ambos (INS+MELt e INS+MELp). Ratos Wistar (200-250g), implantados com um transmissor tiveram sua temperatura e atividade motora registradas com um sistema de telemetria durante 55 dias. Após uma semana de registro, o diabetes foi induzido com estreptozotocina $(60 \mathrm{mg} / \mathrm{kg})$ e os animais divididos em seis grupos: INSt, MELt, INS+MELt iniciando os tratamentos após 33 dias de diabetes, e INSp, MELp, INS+MELp, tratados após de 3 dias da indução, passando por um intervalo de 15 dias sem tratamentos e restituídos por mais 15 dias. $\mathrm{O}$ grupo controle foi injetado com veiculo (tampão citrato).Trinta e três dias de diabetes levaram a ruptura do ritmo de TC junto com a redução da TC media, e a diminuição da AM com alteração do seu ritmo. Os tratamentos (INSt e INS+MELt) reverteram o quadro, sendo o INS+MELt mais eficiente. MElt restaurou apenas alguns parâmetros rítmicos, sendo mais eficiente sobre a AM. O grupo controle não apresentou modificações na TC nem na AM ao longo do experimento. Três dias de DM1 alteraram o ritmo da TC, mas não o de AM nem as medias de TC e AM. Os tratamentos precoces restauraram as alterações do diabetes no ritmo de TC. A interrupção dos tratamentos diminuiu as médias de temperatura e atividade $e$ alterou parcialmente os ritmos. A restituição dos tratamentos melhorou o quadro diabético, porem diferente do controle. Esses resultados mostram que, além da hipotermia, a redução de peso, a hiperglicemia e a diminuição na media da atividade motora, o estado diabético leva a uma ruptura do ritmo diário de TC e uma forte alteração no ritmo de AM. Os tratamentos INSt e INS+MELt revertem os efeitos deletérios, sendo mais eficiente quando combinado com a melatonina. A MElt atenua os efeitos deletérios, sendo mais evidente na AM. A ação da insulina é mais rápida, mais duradoura e mais eficiente do que a melatonina, a qual tem melhor ação sobre a atividade, e essas melhoras são dependentes da continuidade dos tratamentos.

Palavras-chave: Ritmos biológicos. Diabetes. Temperatura corporal. Atividade motora. Insulina. Melatonina. 


\begin{abstract}
Ramos Lobo AM. Streptozotocin-induced diabetes disrupts body temperature and home cage activity daily rhythms in Wistar rats. [Masters thesis in Human Physiology] - São Paulo: Instituto de Ciências Biomédicas, Universidade de São Paulo; 2013.

In mammals, body temperature (BT) and home cage activity (HCA) rhythms are two of the diverse rhythms in the body regulated by the circadian pacemaker located in the suprachiasmatic nuclei (SCN), and are considered "marker rhythms" of the circadian pacemaker. Melatonin, the pineal gland hormone, is a major regulator of the endogenous rhythms including BT and HCA. Its production is influenced by many factors, such as type 1 diabetes mellitus. In rats, T1DM leads to hypothermia and reduced melatonin synthesis and HCA; insulin treatment reestablishes normal BT and melatonin but not HCA. However, the BT and HCA rhythms, in this experimental model, remain unknown. The present work studied the effects of diabetes on the BT and HCA rhythms and the possible modifications resulting from early and late treatment with insulin (6U/day) (L-INS and E-INS), melatonin (daily $0.5 \mathrm{mg} / \mathrm{kg})(\mathrm{L}-\mathrm{MEL}$ and E-MEL), or both (L-INS+MEL and E-INS+MEL) on daily BT and HCA rhythms, its rhythmic parameters (MESOR, amplitude and acrophase), glycaemia and body weight on streptozotocin-induced $(60 \mathrm{mg} / \mathrm{kg})$ Wistar rats $(250 \mathrm{~g})$ for 55 days. After a week of control registration, diabetes was induced by a streptozotocin injection $(60 \mathrm{mg} / \mathrm{kg})$ and the animals were divided in six groups: L-INS, L-MEL, L-INS+MEL, starting treatments after 33 days of diabetes, and E-INS, E-MEL, E-INS+MEL, treated after 3 days of diabetes for 15 days, with an interval of 15 days off treatments and then restored for 15 more days. Control group was injected with citrate buffer. Thirty tree days of diabetes led to hypothermia and loss of BT rhythm, reduced HCA and its rhythm altered. L-INS and L-INS+MEL treatments reverted to normal, being LINS+MEL more efficient. L-MEL restored some of the rhythmic parameters but had no effect on body weight and glycaemia. BT and HCA rhythms were not modified in control group. Three day diabetes altered BT, but not HCA rhythms nor mean BT and HCA. All early treatments reverted alterations in BT rhythm; however E-MEL had no effect on body weight and glycaemia. Interruption of treatments reduced mean BT and HCA and altered their rhythms. Restitution of treatments attenuated the deleterious effects, but did not restore normal parameters. Taken together, T1DM leads to disruption of BT and alteration of HCA rhythms. Late treatments with insulin restore normal rhythms, being more efficient when combined with melatonin. Melatonin attenuates the deleterious effects, being more evident on HCA. Insulin effects are faster, last longer and are more efficient than melatonin, which are more evident in $\mathrm{HCA}$, and these effects depend on the maintenance of the treatments.
\end{abstract}

Keywords: Biological rhythms. Diabetes. Body temperature. Home cage activity. Insulin. Melatonin. 


\section{LISTA DE ILUSTRAÇÕES}

Figura 1 - Parâmetros que definem uma oscilação circadiana...............................20

Figura 2 - Sistema de temporização do sistema circadiano na síntese de

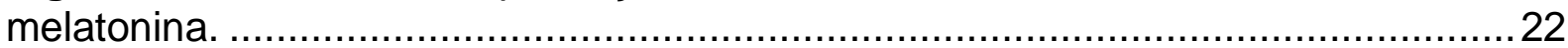

Figura 3 - Desenho experimental dos tratamentos tardios ...................................35

Figura 4 - Desenho experimental dos tratamentos precoces ................................36

Figura 5 - Perfil diário do ritmo de temperatura corporal de um animal do grupo

diabético tratado tardiamente com insulina ........................................................4 41

Figura 6 - Perfil diário do ritmo de atividade motora de um animal representativo do

grupo diabético tratado tardiamente com insulina. ...........................................43

Figura 7 - Média da temperatura dos períodos controle (CT), diabético (D) e tratado

com insulina (DI) do animal representado na figura 5 ..................................... 45

Figura 8 - Média da atividade motora dos períodos controle (CT), diabético (D) e tratado com insulina (DI) do animal representado na figura 6 ...............................4 45

Figura 9 - Perfil diário da temperatura corporal de um animal representativo do grupo diabético suplementado tardiamente com melatonina.....

Figura 10 - Perfil diário da atividade motora de um animal representativo do grupo diabético suplementado tardiamente com melatonina ........................................... 49

Figura 11 - Media da temperatura corporal dos períodos controle (CT), diabético (D) e suplementado com melatonina (DM) do animal representado na figura 9 .............51

Figura 12 - Média da atividade motora dos períodos controle (CT), diabético (D) e suplementado com melatonina (DM) do animal representado na figura $10 \ldots \ldots \ldots \ldots . .51$

Figura 13 - Perfil diário de temperatura corporal de um animal representativo do grupo diabético tratado tardiamente com insulina e melatonina ..............................53

Figura 14 - Perfil diário do ritmo de atividade motora de um animal representativo do grupo diabético tratado tardiamente com insulina e melatonina ..............................55

Figura 15 - Média da temperatura corporal dos períodos controle (CT), diabético (D) e tratado com insulina e melatonina (DIM) do animal representado na figura 13 .....57 Figura 16 - Média da atividade motora dos períodos controle (CT), diabético (D) e tratado com insulina e melatonina (DIM) do animal representado na figura 14 ........57 Figura 17 - Perfil diário do ritmo de temperatura corporal de um animal representativo do grupo diabético tratado precocemente com insulina ....................61 Figura 18 - Perfil diário do ritmo de atividade motora de um animal representativo do grupo diabético tratado precocemente com insulina

Figura 19 - Media da temperatura corporal dos períodos controle (CT), diabético (D1), tratamento precoce (DI1), tratamento interrompido (D2) e a restituição do tratamento com insulina (DI2) do animal representado na figura 17 .

Figura 20 - Média da atividade motora dos períodos controle (CT), diabético (D1), primeiro tratamento (DI1), tratamento interrompido (D2) e a restituição do tratamento

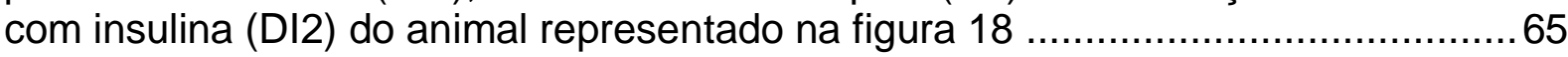

Figura 21 - Perfil diário do ritmo de temperatura corporal de um animal representativo do grupo diabético suplementado precocemente com melatonina ....67 Figura 22 - Perfil diário do ritmo de atividade motora de um animal representativo do grupo diabético suplementado precocemente com melatonina

Figura 23 - Média da temperatura dos períodos controle (CT), diabético (D1), primeira suplementação (DM1), suplementação interrompida (D2) e a restituição da suplementação com melatonina (DM2) do animal representado na figura 21 ...........71 
Figura 24 - Média da atividade dos períodos controle (CT), diabético (D1), primeira suplementação (DM1), suplementação interrompida (D2) e restituição da suplementação com melatonina (DM2) do animal representado na figura 22

Figura 25 - Perfil diário do ritmo de temperatura corporal de um animal representativo do grupo diabético tratado precocemente com insulina e melatonina73 Figura 26 - Perfil diário do ritmo de atividade motora de um animal representativo do grupo diabético tratado precocemente com insulina e melatonina.

Figura 27 - Média da temperatura dos períodos controle (CT), diabético (D1), primeiro tratamento (DIM1), tratamento interrompido (D2) e restituição do tratamento com insulina e melatonina (DIM2) do animal representado na figura 25 .77 Figura 28 - Média da atividade dos períodos controle (CT), diabético (D1), primeiro tratamento (DIM1), tratamento interrompido (D2) e restituição do tratamento com insulina e melatonina (DIM2) do animal representado na figura 26

Figura 29 - Variação de peso corporal e glicemia de animais diabéticos tratados precoce ou tardiamente com insulina....

Figura 30 - Variação de peso corporal e glicemia de animais diabéticos

suplementados precoce ou tardiamente com melatonina.

Figura 31 - Variação de peso corporal e glicemia de animais diabéticos tratados precoce ou tardiamente com insulina e melatonina.

Figura A1 - Perfis diários dos ritmos de temperatura e de atividade motora de um animal controle. 103

Figura A2 - Perfis diários dos ritmos de temperatura de animais diabéticos tratados tardiamente. 104

Figura A3 - Perfis diários dos ritmos de temperatura de animais diabéticos tratados precocemente.

Figura A4 - Perfis diários dos ritmos de atividade motora de animais diabéticos tratados tardiamente. 106

Figura A5 - Perfis diários dos ritmos de atividade motora de animais diabéticos tratados precocemente. 


\section{LISTA DE TABELAS}

Tabela 1 - Parâmetros rítmicos da temperatura corporal nos diferentes tratamentos tardios. 58 Tabela 2 - Parâmetros rítmicos da atividade motora nos diferentes tratamentos tardios.................................................................................................. 59

Tabela 3 - Parâmetros rítmicos da temperatura corporal nos diferentes tratamentos

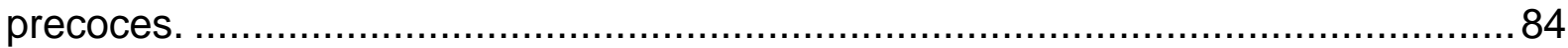
Tabela 4 - Parâmetros rítmicos da atividade motora nos diferentes tratamentos precoces. .85 


\section{LISTA DE ABREVIATURAS}

AANAT - Arialquilamina $\mathrm{N}$-acetiltransferase

ANOVA - Método de Analise de variância

AM - Atividade motora

ATP - Adenosina tri-fosfato

CEEA - Comissão de Ética em Experimentação Animal

COBEA - Colégio Brasileiro de Experimentação Animal

DM1 - Diabetes mellitus do tipo I

DM2 - Diabetes mellitus do tipo II

DNA - Ácido desoxirribonucleico

EPM - Erro Padrão Médio

GLUT - Transportador de glicose

GLUT2 - Transportador de glicose tipo 2

HIOMT - Hidroxindol-oxi-metiltransferase

ICB - Instituto de Ciências Biomédicas

IDF - Federação Internacional de Diabetes

IML - Coluna Intermediolateral

MESOR - Valor médio da função biológica ajustada a uma curva Coseno

$\mathrm{NAD}^{+}$- Nicotinamida Adenina Dinucleotídeo

NO - Óxido nítrico

NSQ - Núcleos Supraquiasmáticos

PARP - Enzima poli-ADP-ribose polimerase 
PI3K - Fosfatidil Inositol 3 Quinase

PVN - Núcleo Paraventricular

SIDA - Sindrome de imunodeficiência adquirida

STZ - Estreptozotocina

T3 - Triiodotironina

T4 - Tiroxina

TAM - Tecido Adiposo Marrom

TC - Temperatura Corporal

TPH - Triptofano Hidroxilase

ZT - Zeitgeber Time 


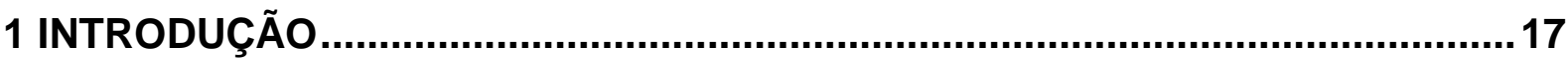

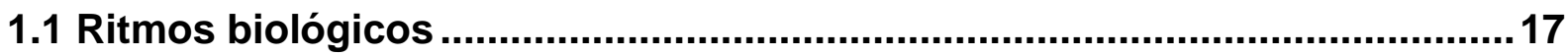

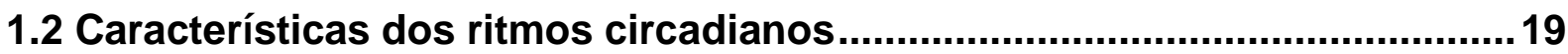

1.3 Controle neural da síntese de melatonina......................................................

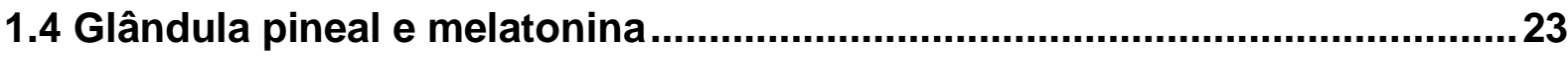

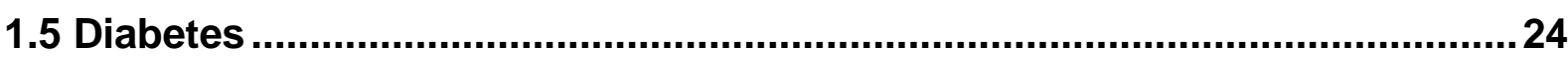

1.6 Diabetes, atividade motora, temperatura corporal e melatonina..................26

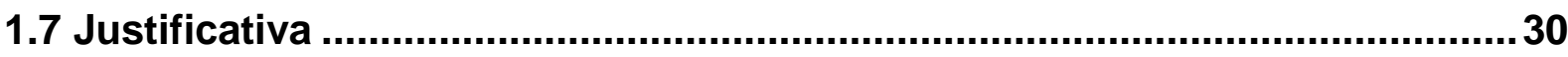

2 OBJETIVOS

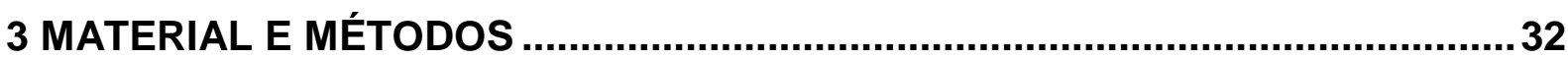

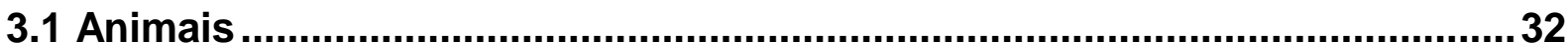

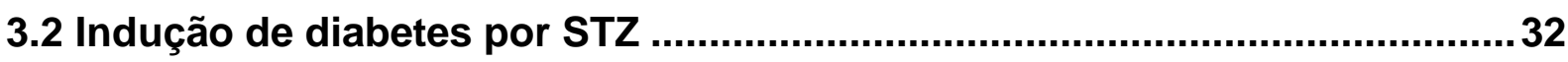

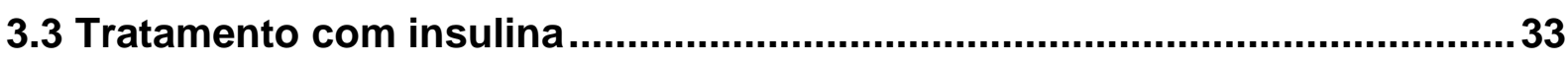

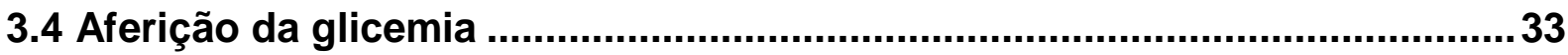

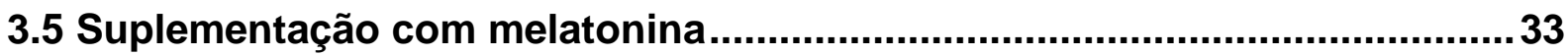

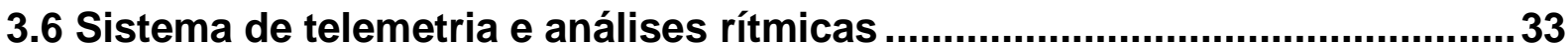

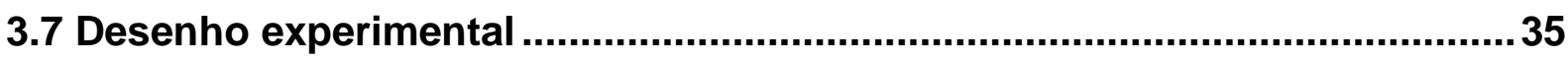

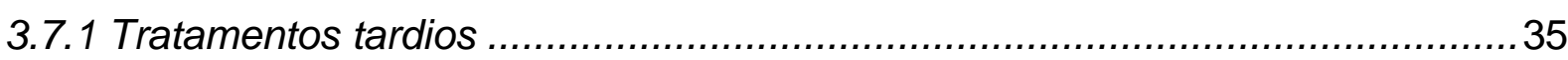

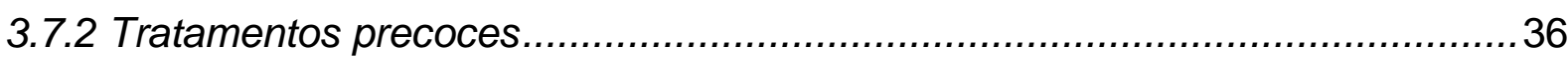

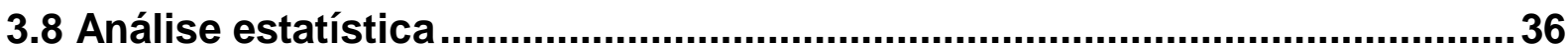

4 RESULTADOS

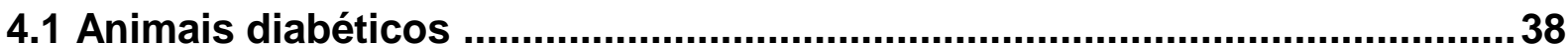

4.1.1 Perfis diários dos ritmos de temperatura corporal e de atividade motora.........38

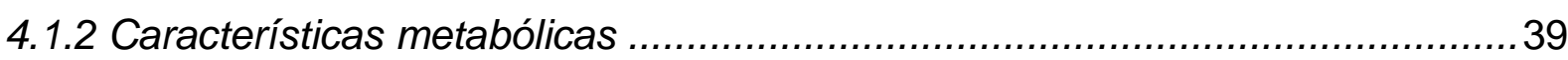

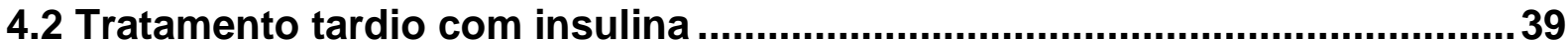

4.2.1 Perfis diários dos ritmos de temperatura corporal e de atividade motora.........39

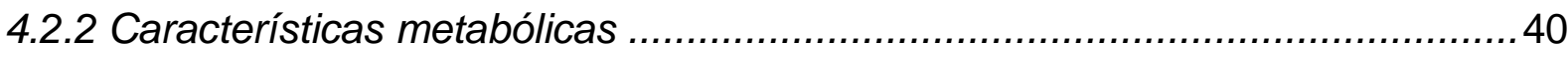

4.3 Suplementação tardia com melatonina ........................................................46

4.3.1 Perfis diários dos ritmos de temperatura corporal e de atividade motora.........46

4.3.2 Características metabólicas ................................................................... 47

4.4 Tratamento tardio com insulina e melatonina.............................................52

4.4.1 Perfis diários dos ritmos de temperatura corporal e de atividade motora.........52 
4.4.2 Características metabólicas .53

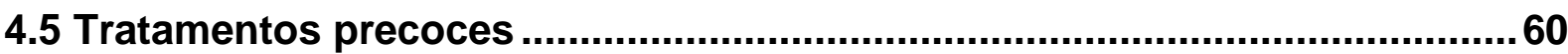

4.6 Tratamento precoce com insulina ............................................................60

4.6.1 Perfis diários dos ritmos de temperatura corporal e de atividade motora.........60

4.6.2 Características metabólicas ...............................................................61

4.7 Suplementação precoce com melatonina ................................................66

4.7.1 Perfis diários dos ritmos de temperatura corporal e de atividade motora.........66

4.7.2 Características metabólicas .............................................................. 66

4.8 Tratamento precoce com insulina e melatonina ...........................................72

4.8.1 Perfis diários dos ritmos de temperatura corporal e de atividade motora........72

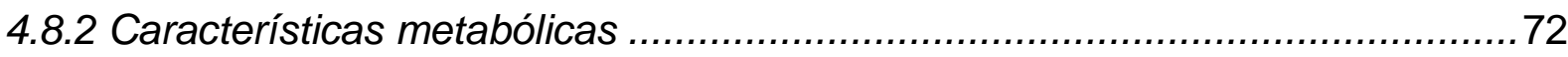

4.9 Interrupção dos tratamentos precoces .........................................................78

4.10 Restituição do tratamento com insulina....................................................78

4.10.1 Perfis diários dos ritmos de temperatura corporal e de atividade motora ......78

4.10.2 Características metabólicas ............................................................. 79

4.11 Restituição da suplementação com melatonina .......................................79

4.11.1 Perfis diários dos ritmos de temperatura corporal e de atividade motora ......79

4.11.2 Características metabólicas .................................................................. 80

4.12 Restituição do tratamento com insulina e melatonina ............................... 80

4.12.1 Perfis diários dos ritmos de temperatura corporal e de atividade motora ......80

4.12.2 Características metabólicas ................................................................ 81

5 DISCUSSÃO.................................................................................................. 86

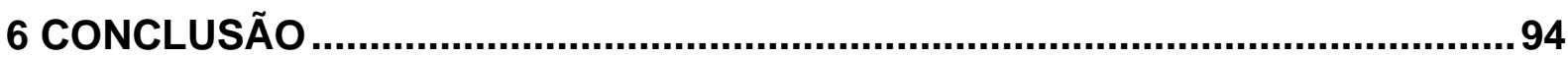

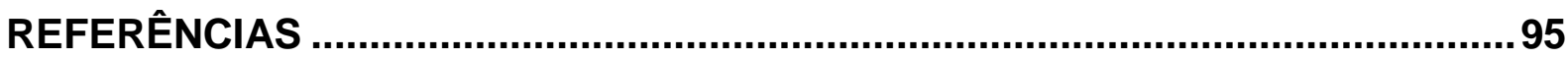

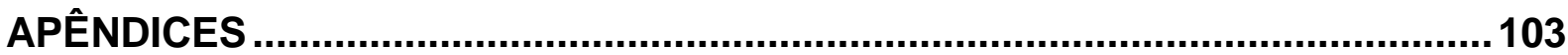

APÊNDICE A - Figuras suplementares ........................................................... 103

APÊNDICE B - Artigos de periódicos ................................................................ 108 


\section{INTRODUÇÃO}

\subsection{Ritmos biológicos}

Os ritmos biológicos circadianos, ubíquos nos seres vivos, constituem uma adaptação altamente eficiente uma vez que garantem a relação temporal entre os seres vivos e seu meio ambiente, em geral sincronizada pelo ciclo claro escuro do dia e da noite. Para isso, o sistema de temporização circadiana, organiza temporalmente todos os processos fisiológicos e comportamentais de forma que os sistemas funcionais no organismo se expressam com intensidades e qualidades diferentes de acordo com a hora do dia, garantindo, assim, essa relação temporal vital entre os seres vivos e seu ambiente, contribuindo com a sobrevivência individual e da espécie (Cipolla-Neto, 1988).

A persistência da ritmicidade circadiana em um ambiente carente de pistas externas sugere a existência de um sistema que mantém a organização temporal interna, chamado de oscilador interno (Benstaali et al., 2001).

A capacidade do oscilador interno de ajustar sua frequência a dos ritmos ambientais é chamada de sincronização. Os diversos ciclos ambientais capazes de regular o período e a fase dos osciladores internos são chamados de Zeitgebers, em alemão, "doador de tempo" (Zeit=tempo; Geber=doador), "sincronizadores", ou "agentes arrastadores" (Cipolla-Neto, 1988).

Para a maioria dos organismos, e principalmente os roedores, o agente sincronizador mais importante é o ciclo claro/escuro, porem outros fatores ambientais periódicos também podem cumprir o papel de agentes sincronizadores, como a temperatura ambiental, os ciclos de disponibilidade de alimento, fatores sociais, etc (Cipolla-Neto, 1988).

Apesar dos vários ritmos de um organismo estarem sincronizados entre si, eles apresentam uma dispersão de fase ao longo do dia. Assim, diversos ritmos biológicos exibem seus picos de máximo (hora do dia em que é mais provável que a variável estudada atinja seu valor máximo na oscilação) em diferentes momentos do ciclo de 24 h. No entanto, a relação de fase entre eles é estável, garantindo a manutenção da ordem temporal interna circadiana (Cipolla-Neto, 1988). Isto significa que os ritmos de sistemas e órgãos de um organismo mantêm relações de fase 
estáveis entre si e com o ciclo claro escuro ambiental (Marques, Menna-Barreto, 2003).

A nível sistêmico, a ritmicidade circadiana (circa = aproximadamente; diana $=$ referente a um dia) depende do oscilador central, capaz de impor sua frequência de oscilação aos outros osciladores presentes no organismo. Os marca-passos circadianos podem ser únicos como os núcleos supraquiasmáticos (NSQ) em roedores, ou múltiplos, como os NSQ e a pineal em aves (Cipolla-Neto, 1988). O fato dos osciladores centrais serem capazes de impor seu período aos osciladores secundários caracteriza uma hierarquia funcional dentro da estrutura multioscilatória dos vertebrados. A ablação neonatal dos NSQ em ratos elimina permanentemente os ritmos de atividade locomotora e de ingestão de água, o que sugere que outras áreas do cérebro não têm a capacidade de reorganizar e suprir a função desempenhada pelos NSQ (Marques et al., 1997). Por outro lado, várias secreções endócrinas podem, por sua vez, influenciar o período e a sincronização do oscilador central. Isso indica que osciladores subordinados, como algumas glândulas endócrinas, podem retroagir, modulando a função dos osciladores centrais. A hierarquia da estrutura multioscilatória dos vertebrados mencionada acima depende da modulação por retroalimentação dos outros osciladores periféricos para que se dê a sua expressão funcional.

Em nível comportamental, a estrutura circadiana dos surtos de atividade e de repouso é fundamental para observar as outras distribuições temporais. Atividade e repouso são categorias definidas, em geral, a partir da observação comportamental. Desta forma, distinguem-se da vigília e o sono, cuja caracterização básica provém, principalmente, da análise de parâmetros fisiológicos (atividade elétrica cerebral, muscular, ocular, parâmetros neurovegetativos, etc.). Nem sempre a categoria atividade, comportamentalmente definida, corresponde a um estado fisiológico de vigília; assim como o repouso comportamental nem sempre corresponde a estados de sono, fisiologicamente definidos (Cipolla-Neto, 1988). Por outro lado, o ritmo de temperatura é um dos diversos ritmos no organismo regulado pelo sistema oscilador circadiano. Devido a sua robustez e a facilidade relativa para seu monitoramento, foi estabelecido como um dos "ritmos marcadores" do marca-passo circadiano (Hanneman, 2001; Kelly, 2006; Minors et al., 1996). Scheer et al. (2005) descreveram um efeito dual dos NSQ na termorregulação de ratos, levando a 
diminuição da temperatura corporal durante a fase clara e ao aumento durante a fase escura, independentemente da atividade motora. Além disso, os NSQ são fundamentais para a determinação dos ritmos metabólicos tais como as mudanças na glicemia, no cortisol e melatonina plasmáticos (Goncharova et al., 2005; Korkmaz et al., 2009; la Fleur et al., 2001a,b; Peschke et al., 2006, 2007; Reiter et al., 2009).

$\mathrm{Na}$ década de 60 se acreditava que, em roedores noturnos, o aumento na atividade durante a fase escura do ciclo claro/escuro poderia ser responsável pelo pico diário da temperatura (Abrams, Hammel, 1965). Contudo, De Castro (1978) concluiu que no rato a variação diária da temperatura central é produto do ciclo diário de atividade e do ciclo diário do limite superior da termorregulação; o limite inferior é mantido constante. Atualmente ainda está em discussão se os ritmos de temperatura e atividade dos ratos são controlados pelo mesmo oscilador ou por osciladores diferentes no NSQ.

\subsection{Características dos ritmos circadianos}

O termo ritmo biológico é aplicado a qualquer oscilação de uma variável biológica, seja qual for o nível de organização considerado, que se repete com o mesmo período. O período é então o intervalo de tempo em que um ciclo se completa (Figura 1). Cada um dos valores que a variável assume durante um ciclo define uma fase do ritmo. Apesar de fase significar cada um dos momentos de um ritmo, esse termo é empregado para exprimir os estados de um processo ou de um ciclo ambiental. Assim, no ritmo de atividade fala-se de "fase de repouso" e "de atividade"; no ciclo de um dia, designa-se a "fase clara" e "escura"; no ciclo de temperatura, distingue-se a "fase quente" da "fase fria" (Marques et al., 1997). 
Figura 1 - Parâmetros que definem uma oscilação circadiana.

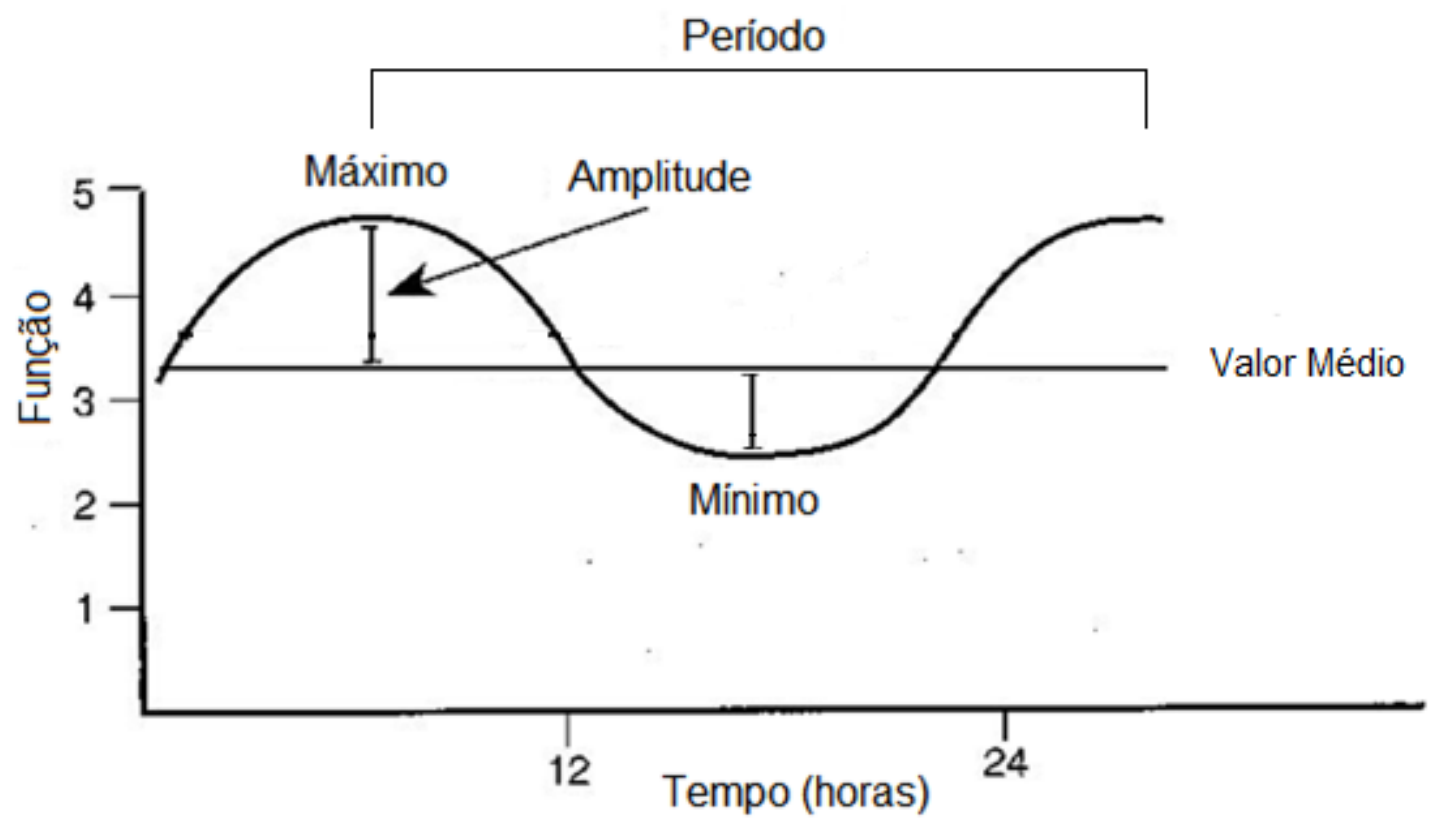

Oscilação de uma função biológica hipotética ajustada a uma curva coseno e os parâmetros rítmicos que a definem. A duração do ciclo completo (período) é aproximadamente de $24 \mathrm{~h}$. A amplitude é uma medida do grau de variação dentro da oscilação, ou seja, é a diferença entre o valor máximo (ou mínimo) e o valor médio.

Fonte: Adaptado de Cardinali et al., 1994.

Para poder estudar a variável biológica desejada, são utilizadas funções matemáticas como o ajuste da oscilação a uma função coseno, conhecido como o método do Coseno ou Cosinor. Na curva ajustada, o valor médio da oscilação é chamado de MESOR (Midline Estimating Statistic Of Rhythm), e a medida do tempo transcorrido entre um instante de referencia e o instante no qual é maior a probabilidade de ser encontrado o máximo é chamada de acrofase. A duração da oscilação é definida como período e a medida do grau de variação dentro da oscilação (entre o valor máximo ou mínimo e o MESOR) é chamada de amplitude. Com esses parâmetros rítmicos (MESOR, amplitude, acrofase) e a curva ajustada é possível definir qualquer função biológica no tempo. No caso das variáveis com oscilação diária que estão sincronizadas ao ciclo claro-escuro, o período é definido e de $24 \mathrm{~h}$.

Um organismo sadio é caracterizado por um alto grau de ordem temporal na sua organização circadiana, também chamado de acoplamento, entre os osciladores 
do organismo, que resulta em seu funcionamento coordenado ou ordem temporal interna (Marques, Menna-Barreto, 2003). Os desvios desta ordem temporal interna (desacoplamento) podem caracterizar uma doença crônica. Um indicador da alteração cronobiológica consiste na diminuição da amplitude dos ritmos (Cardinali et al., 1994).

A adaptação temporal envolve diversas etapas, todas elas mediadas pelo oscilador interno, permitindo ao organismo organizar recursos e atividades antes da ocorrência do momento em que sejam necessários (Pittendrigh, 1960). Assim, as transições entre estados, como do sono à vigília ou do jejum à alimentação, na verdade, são preparadas progressivamente, antes que o indivíduo acorde ou se alimente. Por sua parte, também é observado esse fenômeno de antecipação nas migrações sazonais.

\subsection{Controle neural da síntese de melatonina}

Em mamíferos, a informação das condições de luminosidade ambiental chega às retinas sendo captada pelas células ganglionares e levada até a glândula pineal, que na fase escura tem um aumento do seu produto de secreção, o hormônio melatonina (Figura 2).

O sistema neural responsável pela síntese de melatonina envolve o núcleo paraventricular (PVN), na sua porção parvicelular, que através de vias diretas e indiretas, projeta-se sobre a coluna intermediolateral (IML) da medula espinhal. As fibras pré-ganglionares simpáticas projetam-se sobre o gânglio cervical superior que, por sua vez se projeta sobre a glândula pineal.

A produção de melatonina se dá de forma rítmica e circadiana devido a um controle direto dos núcleos supraquiasmáticos sobre o PVN. Os NSQ orquestram os ritmos circadianos através da informação temporal por vias neurais e humorais.

Nos mamíferos de hábito diurno, os NSQ modulam o sistema nervoso autonômico e permitem o controle simpático do metabolismo, fenômeno do amanhecer. Nesse momento, o conteúdo plasmático de epinefrina, norepinefrina, e o cortisol estão elevados. O sistema de temporização circadiana faz com que, no período de maior atividade e alimentação, os tecidos sejam mais tolerantes à glicose além de aumentar a sensibilidade à insulina. No final dessa fase, as retinas são expostas à escuridão e tem início o processo de síntese de melatonina pela glândula 
pineal. Ao mesmo tempo, os NSQ bloqueiam a tonicidade simpática e permitem o controle parassimpático do metabolismo, fenômeno do entardecer. A presença de luz durante a fase escura induz uma reação de alerta com mobilização do sistema simpático, sendo este um efeito mascarador (neste caso, tratando-se de um processo externo que produz a modificação da expressão do ritmo biológico, chamase mascaramento externo). Os NSQ inibem a secreção de melatonina da pineal e, dependendo do momento da noite em que ocorre a foto-estimulação, atrasa o pico da melatonina se for ao começo da noite ou adianta-o no dia seguinte se ocorrer no fim da noite (Korkmaz et al., 2009). Dado que a melatonina é produzida sempre na fase escura independente dos organismos serem de hábitos diurnos ou noturnos, nesses últimos a regulação do metabolismo se da de forma inversa, ou seja, na fase escura ocorre o controle simpático do metabolismo e na fase clara, o controle do parassimpático do metabolismo.

Figura 2 - Sistema de temporização do sistema circadiano na síntese de melatonina.

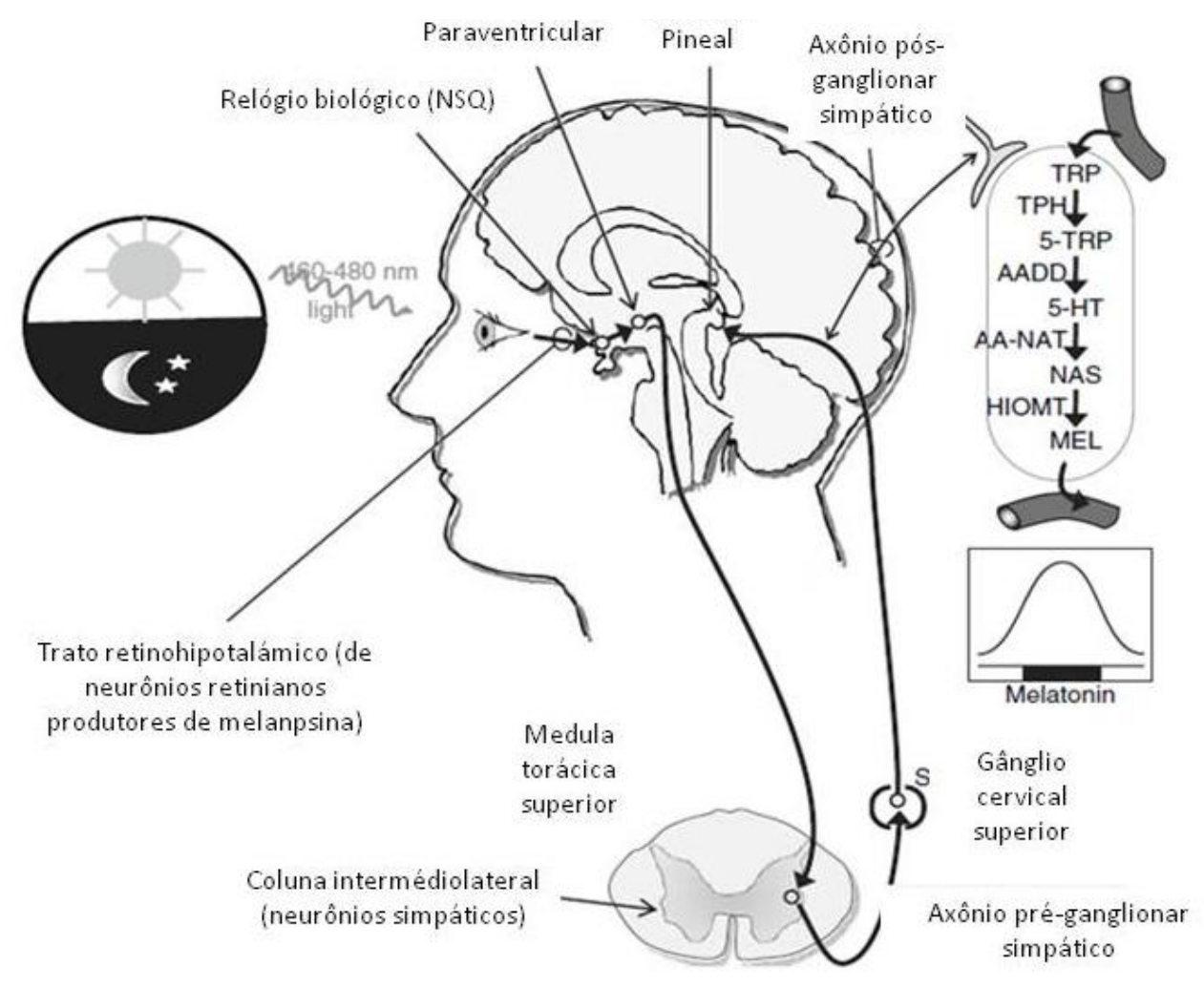

Controle neural da síntese de melatonina, e as estruturas que participam desse processo. Fonte: Adaptado de Kormaz et al., 2009. 


\subsection{Glândula pineal e melatonina}

A melatonina, hormônio produzido pela glândula pineal, é sintetizada exclusivamente na fase escura em resposta ao estímulo noradrenérgico proveniente do gânglio cervical superior, que por sua vez está subordinado aos núcleos paraventriculares hipotalâmicos. Esse sistema neural é temporizado circadianamente pelos NSQ que, por sua vez, sincronizam-se ao claro-escuro ambiental pela via retino-hipotalâmica. A síntese de melatonina envolve uma cascata enzimática que começa na hidroxilação do aminoácido essencial triptofano pela triptofano hidroxilase (TPH), gerando 5-hidroxitriptofano. Este por sua vez é transformado em 5-hidroxitriptamina (serotonina) por uma descarbolixase inespecífica de aminoácidos aromáticos. A serotonina é então $\mathrm{N}$-acetilada pela enzima arilalquilamina $\mathrm{N}$-acetiltransferase (AANAT), gerando $\mathrm{N}$-acetilserotonina, que é transformada em melatonina pela hidroxindol-oxi-metiltransferase (HIOMT). A secreção de melatonina dá-se por um mecanismo de difusão simples e por ser uma molécula anfifílica difunde-se em meios aquosos ou lipídicos, não sendo armazenada em vesículas. A vida média da melatonina circulante é de aproximadamente 20 minutos em ratos, e sua metabolização periférica se dá essencialmente pela transformação hepática (aproximadamente $90 \%$ da melatonina circulante) em 6-hidroximelatonina que após conjugação com sulfatos (a maior parte) ou com glucoronídeos é excretada na urina. No sistema nervoso central e na própria glândula pineal a melatonina pode ser transformada em quinuraminas sob a ação da 2,3 indolamina dioxigenase (Castro Afeche, Cipolla-Neto, 2008).

A administração farmacológica de melatonina é capaz de sincronizar ritmos circadianos em ratos em livre-curso (Rebolledo et al., 1983), e esse efeito depende da integridade dos NSQ (Cassone et al., 1986). Parece claro que a melatonina atua diretamente sobre os NSQ, pois a administração do hormônio durante a noite subjetiva deprime a atividade metabólica do NSQ (Cassone et al., 1988) e provoca deslocamentos de fase na atividade elétrica do NSQ in vitro (McArthur et al., 1991). Além disso, Vanecek et al. (1987) e Reppert et al. (1988) encontraram uma alta densidade de receptores de melatonina nos NSQ de roedores.

A duração das fases de claro e de escuro é fundamental para 0 desencadeamento da resposta fotoperiódica e também para a regulação dos ritmos diários. A duração da noite pelo organismo é avaliada a partir de um sinal humoral 
dado pela melatonina (Arendt, 1988, 1995; Armstrong, Redman, 1985; Brown et al., 1981; Cardinali, 1981; Cardinali, Vacas, 1981; Goldman, 1983; Vollrath, 1981; Pevet, 1987; Reiter, 1983, 1987). A pineal nos mamíferos tem propriedades de transdutor neuroendócrino, pois a informação fótica canalizada através de um sinal da via simpática chega à glândula e regula a secreção de melatonina. A pineal é o principal mediador da mudança fotoperiódica ambiental na preparação da resposta fisiológica nos ritmos circanuais e um poderoso modulador dos ritmos circadianos. Ela é a principal interface entre o ciclo claro/escuro ambiental e os sistemas nervoso central e endócrino. Uma característica notável da bioquímica da pineal é a capacidade de suas enzimas responderem imediatamente a mudanças fóticas ambientais, apresentando uma atividade maior na fase escura e uma atividade inibida pela luz. Essa regulação aloca a síntese de melatonina exclusivamente na fase escura, proporcionando ao organismo um sinal circulante indicativo da duração da fase escura (Cardinali, 1981; Honma et al., 1992).

É importante ressaltar que dentre suas ações, a melatonina promove a sincronização das funções centrais (Gillette, Mitchell 2002) e periféricas (Alonso-Vale et al., 2006, 2008; Lima et al., 1998; Picinato et al., 2002a), desempenhando um papel importante no metabolismo energético, na ação (Anhê et al., 2004, Lima et al., 1994) e secreção (Picinato et al., 2002a,b, 2008) da insulina, assim como na função do tecido adiposo (Alonso-Vale et al., 2004a,b, 2005).

\subsection{Diabetes}

O diabetes mellitus é um grupo de doenças metabólicas crônicas que se manifesta quando o pâncreas não produz insulina adequadamente ou quando o corpo não consegue utilizar apropriadamente a insulina que produz e, portanto impede que as células incorporem glicose do sangue e a use para convertê-la em energia, ocorrendo em ambos os casos um aumento da glicemia. A condição diabética está associada a dano em longo prazo em vários órgãos e sistemas de todo o organismo (Federação Internacional de Diabetes, IDF, 2012). Existem evidências que indicam que a destruição das células $\beta$ do pâncreas (responsáveis pela síntese e secreção da insulina), por meio de mecanismos autoimunes, seria a causa predominante do diabetes mellitus de tipo I (Andersson et al., 2001). 
O diabetes mellitus constitui um problema de saúde mundial. A IDF (2012) estima que $8 \%$ da população mundial padecem de diabetes (371 milhões de pessoas). O número de mortes atribuídas ao diabetes em 2012 foi de 4.8 milhões. Em 2007 a mesma instituição mostrou que no Brasil havia uma prevalência do diabetes de $5.8 \%$ (6.913.300 pessoas) com idades entre 20-79 anos e estimou que em 2025 haveria 11.4\% de prevalência. Em 2012 os estudos da IDF mostraram que existem 13.8 milhões de pessoas diabéticas no Brasil (IDF, 2012).

Em 1997, a Associação Americana de Diabetes (ADA) estabeleceu novos critérios de classificação para cada tipo de diabetes e diagnóstico. Essa classificação do diabetes inclui quatro classes clínicas (ADA, 2009):

- Diabetes do tipo I (DM1) - que resulta da destruição das células $\beta$ pancreáticas, geralmente levando a uma deficiência absoluta de insulina, pode ser de origem autoimune ou idiopática;

- Diabetes do tipo II (DM2) - graus variados de diminuição da secreção e resistência à insulina;

- Outros tipos específicos devido a outras causas - defeitos genéticos da função da célula $\beta$, defeitos genéticos da ação da insulina, doenças do pâncreas exócrino (ex. fibrose cística) e indução por drogas ou produtos químicos (como no tratamento da SIDA ou após transplante de órgão);

- Diabetes gestacional - diabetes diagnosticada durante a gravidez.

Quando a hiperglicemia se torna crônica, o substrato que normalmente é utilizado como fonte de energia se torna tóxico. Cronicamente, a alta concentração de glicose é a maior causa de retinopatias, nefropatias, neuropatias e doenças macrovasculares (Gul et al., 2008).

É por essa razão que o estudo de modelos em animais diurnos e noturnos que permitam conhecer mais a respeito dessa patologia resulta de uma ajuda inestimável.

A indução experimental do diabetes é feito por drogas químicas que agem através da destruição seletiva das células $\beta$ nas ilhotas pancreáticas. As principais substâncias utilizadas são a estreptozotocina (STZ) e a aloxana, que podem induzir tanto diabetes do tipo1 como diabetes do tipo II (Szkudelski, 2001). A STZ é uma alquil-nitrosourea isolada a partir da bactéria Streptomycetes achromogenes. Devido a sua semelhança com a glicose essa molécula entra seletivamente na célula $\beta$ 
através do transportador de glicose GLUT2 (Karunanayake et al., 1976; Tjälve et al., 1976). A ação intracelular tóxica da STZ é devido à atividade alquilante do seu grupamento metil-nitrosurea, que transfere o seu grupo metil para a molécula de DNA, resultando em fragmentação do DNA. Em resposta aos danos causados ao DNA, a enzima poli-ADP-ribose polimerase (PARP) tem sua ativação aumentada, resultando na diminuição de NAD+e dos estoques de ATP. Essa depleção no estoque de energia celular resulta em necrose das células $\beta$ (Lenzen, 2008; Rakieten et al., 1963).

Uma hipótese alternativa propõe que parte do efeito diabetogênico da STZ se deve a sua capacidade doadora de óxido nítrico (NO), porém o agente alquilante metil-metanosulfonato, que possui a maior toxicidade em células produtoras de insulina, não é uma molécula doadora de NO, indicando que o NO não é um prérequisito para a obtenção da ação tóxica da família dos agentes alquilantes à qual a STZ pertence (Delaney et al., 1995). O tratamento de ratos jovens com STZ produz um estado diabético caracterizado pela perda de peso, polidipsia, poliúria, glicosúria, polifagia, hipoinsulinemia e hiperglicemia (Hakim et al., 1997). A ação coletiva da STZ resulta na destruição das células $\beta$ e consequentemente na hipoinsulinemia e hiperglicemia resultantes. (Szkudelski, 2001).

\subsection{Diabetes, atividade motora, temperatura corporal e melatonina}

Evidências na literatura mostram que o diabetes induzido por uma única injeção de STZ é capaz de produzir modificações tanto na temperatura corporal, quanto na média da atividade motora e na frequência cardíaca. Ele age diminuindo os três parâmetros em curto prazo e perdura até dez dias após a injeção de STZ. O efeito do diabetes experimental sobre esses parâmetros foi agudo, porém atingiram um estado estável aproximadamente 10 dias após a indução do diabetes. A redução na atividade precedeu as reduções no batimento cardíaco e temperatura corporal (Howarth et al., 2005a, b).

Além disso, também existem evidências da ação do diabetes a longo prazo, observadas em até 5 meses. Após 4 semanas da indução do diabetes, tanto a atividade física, quanto a temperatura foram significativamente menores do que as observadas nos animais controles. A glicemia permaneceu elevada mesmo após 22 
semanas da indução. Esses efeitos são parcialmente normalizados pelo tratamento com insulina, em um período de três semanas (Howarth et al., 2005b). Em outro trabalho do grupo de Howarth et al. (2006) foi demonstrado que o tratamento com insulina foi capaz de reverter a diminuição da temperatura média mas não a diminuição na atividade motora média provocada pelo diabetes. A captação de glicose durante $o$ tratamento com insulina produz substratos necessários para gerar energia e promover o subsequente aumento da temperatura corporal (Howarth et al., 2006). Além disso, o hipotireoidismo é uma doença associada com os modelos mais comuns de diabetes (STZ e aloxana) (Katovitch et al., 1993; Rodgers et al., 1991; Rondeel et al., 1992; Schroder-Van Der Elst, Van Der Heide, 1992; Sochor et al., 1987; Sundaresan et al., 1984). Mais recentemente foi demonstrado que o diabetes induzido por STZ provoca um verdadeiro hipotiroidismo (valores diminuídos de T3 e T4 livres, junto com os sinais clínicos de hipotiroidismo, como frequência cardíaca diminuída, intervalo Q-T aumentado e menor temperatura retal), além de uma queda significativa na temperatura com oito semanas de diabetes, porém, não com duas semanas. Foi demonstrada uma correlação negativa entre a glicemia e o conteúdo de T3 e T4 livre. O tratamento com insulina preveniu todos os sinais de hipotireoidismo e restaurou os conteúdos de T3 e T4 livre. Já o tratamento com T3 normalizou a temperatura, a frequência cardíaca e o intervalo Q-T, mas não teve efeito sobre a glicemia. Esse dado sugere que esses efeitos observados nos animais diabéticos seriam decorrentes do hipotireoidismo secundário ao diabetes induzido pela STZ (Zhang et al., 2002).

Dados da literatura mostram que o diabetes experimental provoca uma redução na síntese e nos níveis circulantes de melatonina. Outros dados também mostram certa controvérsia, Herichová et al., (2005) não encontraram diminuição na síntese de melatonina pineal em ratos Wistar após 7 dias de indução de diabetes com uma única dose de STZ (100 mg/kg) e outro trabalho mostra concentração aumentada de melatonina plasmática pós-indução com STZ (Peschke et al., 2008). No caso de animais com diabetes tipo II, uma maior concentração de insulina está acompanhada da redução de melatonina (Peschke et al., 2008). Contudo, dados do grupo (Amaral, 2009) indicam que o diabetes induzido por STZ causa uma diminuição $(50 \%)$ na produção de melatonina pela glândula pineal. Essa perda não é por necrose ou apoptose dos pinealócitos e reflete um desarranjo no metabolismo 
pineal. A menor concentração de melatonina circulante pode ser um fator contribuinte para o desenvolvimento da doença, não só por diminuir a capacidade do organismo de combater o estresse oxidativo, mas também por provocar alterações na organização rítmica circadiana e prejudicar o importante papel exercido pela melatonina na potenciação da ação da insulina in vitro (Garcia et al., 2008).

Além disso, nosso grupo de pesquisa demonstrou que a insulina atua na glândula pineal de ratos potencializando a síntese de melatonina dependente de noradrenalina, através da regulação da atividade das enzimas envolvidas na síntese de melatonina e que esse efeito de potencialização tem a participação da PI3K. Esse efeito potencializador está restrito a dois períodos específicos da fase escura, um no começo e outro no fim, portanto a glândula pineal apresenta duas janelas de sensibilidade à ação da insulina durante a fase noturna, quando há a presença de noradrenalina (Garcia et al., 2008, 2010).

Embora os efeitos da melatonina na modulação da glicemia em humanos não estejam totalmente estabelecidos, pacientes com diabetes mellitus do tipo II (DM2) apresentam uma diminuição no conteúdo plasmático de melatonina e um aumento dos receptores de melatonina pancreáticos (Peschke et al., 2006; Tutuncu et al., 2005). Além disso, Barone e Menna-Barreto (2011) demonstraram, em pacientes com diabetes do tipo I, uma correlação negativa entre a hiperglicemia e a produção de melatonina avaliada pela 6-sulfatoximelatonina urinária.

A diminuição da amplitude circadiana do sinal de melatonina endógena (devido ao envelhecimento ou à luz durante a fase escura) pode resultar em um aumento da massa corporal, da adiposidade visceral e as consequências metabólicas adversas. Existem evidências na literatura de que a suplementação com melatonina em ratos de meia idade consegue melhorar algumas respostas reguladoras do metabolismo energético como a diminuição da massa corporal, da adiposidade intra-abdominal, e das concentrações plasmáticas de insulina e leptina sem alterar o consumo alimentar nem a adiposidade total, assim como aumentar a temperatura corporal, a atividade física e o conteúdo plasmático de corticosterona, que são características de indivíduos jovens (Rasmussen et al., 1999; WoldenHanson et al., 2000; Zanuto et al., 2013).

A suplementação em horários inapropriados (durante a fase clara) pode reduzir sua habilidade de controlar a massa corporal (Wolden-Hanson et al., 2000). 
A suplementação no horário apropriado (na fase escura) pode potencialmente funcionar como uma terapia ou prevenção para a resistência à insulina, o aumento na gordura intra-abdominal e para patologias resultantes do envelhecimento (Mendes et al., 2013; Rasmussen et al., 1999). 


\subsection{Justificativa}

Com todas essas evidências descritas, ainda não é conhecido o efeito do diabetes sobre o perfil diário da temperatura corporal, nem sobre o ritmo de atividade motora. Sabe-se que na falta de insulina e consequentemente no desenvolvimento do diabetes a síntese de melatonina diminui, sendo restaurada no tratamento com insulina exógena. Além disso, o tratamento com insulina restabelece os parâmetros metabólicos dos animais diabéticos. Por outro lado, e levando em consideração que existe uma forte relação entre a melatonina, insulina e o metabolismo, é de suma importância estudar os efeitos da insulina e da melatonina sobre os distúrbios causados na ritmicidade de animais diabéticos, e se existe uma ação complementar dos dois hormônios, assim como avaliar a ação desses hormônios em animais tratados no inicio da doença. 


\section{OBJETIVOS}

O objetivo deste projeto foi estudar, em ratos Wistar, os efeitos provocados pelo diabetes induzido por STZ sobre os ritmos diários de temperatura corporal e de atividade motora, dois ritmos marcadores da estrutura temporal circadiana, seus parâmetros rítmicos (MESOR, amplitude e acrofase) e período, assim como a glicemia e o peso corporal. Também estudamos as possíveis modificações resultantes dos tratamentos tardios com insulina e/ou melatonina, e se existe efeito precoce quando os tratamentos são administrados logo no início da doença. 


\section{MATERIAL E MÉTODOS}

\subsection{Animais}

Para a realização do experimento foram utilizados ratos albinos da linhagem Wistar $(250 \mathrm{~g})$. Os animais foram mantidos em biotério com ciclo claro-escuro de 12:12 (ZT0 07:00) e temperatura controlada de $21 \pm 2{ }^{\circ} \mathrm{C}$ pelo período aproximado de duas semanas, para adequada adaptação ao ciclo, antes do início dos procedimentos experimentais. Os animais receberam água e comida ad libitum. ZT é uma nomenclatura utilizada para uniformizar os horários do ciclo circadiano sincronizado pelo claro-escuro ambiental, sendo que em ciclos $12 \mathrm{~h} / 12 \mathrm{~h}$ claro/escuro convencionou-se que o ZT0 representa a transição do escuro para o claro (o início do claro) e que o ZT12, a transição do claro para o escuro (o início do escuro), independentemente do horário em que o biotério apaga ou acende suas luzes. Todos os procedimentos estão de acordo com os Princípios Éticos de Experimentação Animal adotado pelo Colégio Brasileiro de Experimentação Animal (COBEA) e foram aprovados pela Comissão de Ética em Experimentação Animal (CEEA) do ICB.

\subsection{Indução de diabetes por STZ}

Os animais utilizados nesse experimento receberam dose única de $60 \mathrm{mg} / \mathrm{kg}$ de STZ (Sigma Chemical Co., St. Louis, MO, EUA). A STZ foi preparada em tampão citrato de sódio ( $\mathrm{NaCl}$ 0,9g, $\mathrm{H}_{2} \mathrm{O}$ destilada $100 \mathrm{~mL}$, citrato de sódio $\left.294 \mathrm{mg}\right) 10 \mathrm{mM}$, pH 4,5. Sua administração foi realizada via intraperitoneal na fase clara. Foram considerados diabéticos aqueles que apresentaram a glicemia equivalente ou maior que $200 \mathrm{mg} / \mathrm{dL}$. Tal verificação ocorreu no dia seguinte à indução do quadro e os indivíduos que não ficaram diabéticos foram retirados do experimento. Os animais do grupo controle receberam apenas solução veículo (tampão citrato de sódio), em quantidade condizente com sua massa corporal (Figura A1). Deve-se ressaltar que nenhum animal esteve em jejum no momento referente à indução do diabetes. 


\subsection{Tratamento com insulina}

Após três dias da injeção de STZ, os animais diabéticos tratados com insulina receberam, de forma subcutânea, 2 unidades de insulina de ação prolongada (Glargina/Lantus $\AA$, Sanofi Aventis, Alemanha) no começo do dia e uma mistura de 2 unidades de insulina de ação prolongada (Glargina/Lantus $\circledast$, Sanofi Aventis) e de 2 unidades de insulina regular (Humulin $\AA$, Lily, EUA) no começo da noite (do Carmo Buonfiglio et al., 2011).

Durante esse período foram feitas medições da glicemia para comprovação do controle do diabetes.

\subsection{Aferição da glicemia}

A aferição da glicemia foi realizada obtendo-se uma gota de sangue da cauda dos animais. A gota foi então colocada na tira reagente (Optium Blood Glucose Test Strips, Medisense $\AA$, Bedford, MA, EUA) conectada ao glicosímetro Optium Xceed®(Medisense ${ }^{\circledR}$ Bedford, MA, EUA) que afere a glicemia após 5 segundos. $O$ aparelho foi previamente calibrado de acordo com as instruções do fabricante e a cada troca de lote de tiras reagentes.

\subsection{Suplementação com melatonina}

No grupo de animais suplementados, a melatonina foi administrada na água somente na fase escura, na concentração que resulte na aquisição pelo animal de uma dose de $0,5 \mathrm{mg} / \mathrm{kg}$ de peso corpóreo. Para isso, cada animal teve o volume ingerido na noite anterior medido e a concentração foi corrigida diariamente em função desse volume.

\subsection{Sistema de telemetria e análises rítmicas}

A aquisição dos dados de atividade motora e temperatura corporal foi feita por um sistema de telemetria (RESPIRONICS, Mini Mitter, Oregon, USA), com um transmissor individual (E-mitter, $23 \mathrm{~mm} \times 8 \mathrm{~mm} / 1.6 \mathrm{~g}$ ) implantado na cavidade abdominal que emite frequências a uma placa receptora (ER-4000) localizada na 
base de cada gaiola (Harkin et al, 2002). O intervalo de aquisição de dados foi de 30 segundos utilizando o software VitalView (Mini Mitter, Oregon, USA). Os termogramas e actogramas individuais foram realizados utilizando o software EI Temps (Diez-Noguera, Barcelona, España). Para o termograma foram plotados os dados brutos, e para o actograma foi realizada uma somatória dos dados a cada hora. Cada animal foi registrado durante 55 dias ao longo do experimento todo. Dessa forma, cada animal foi seu próprio controle.

Para a análise do período dentro de cada tratamento foi realizado o periodograma utilizando o software El Temps. Cada serie temporal (55 dias de registro) foi dividida nos diferentes tratamentos e a média a cada 1 hora (no caso da temperatura) ou somatória a cada hora (no caso da atividade motora) foram realizadas. O periodograma foi realizado utilizando o método de Sokolov-Bushell em cada série temporal dividida segundo os tratamentos $(7 \mathrm{~d}, 15 \mathrm{~d} 33 \mathrm{~d}$ no caso que correspondesse), analisando períodos entre 20 h (1200 min) e 28 h (1680 min) e expressado em minutos (1440 $\mathrm{min}=24 \mathrm{~h}$ ).

Para a análise dos parâmetros rítmicos foi utilizado o software Cosana (Benedito Silva, São Paulo, Brasil), que ajusta cada dia da serie temporal (55 dias) a uma função coseno pelo método do Cosinor, dando os valores diários de MESOR, amplitude e acrofase para cada dia que apresenta uma oscilação significativa de 24 h. Para a análise da temperatura foi realizada a média a cada hora dos dados brutos, e para a atividade motora foi realizada a somatória a cada hora durante os 55 dias do protocolo obtendo assim, para cada ritmo, uma curva ajustada a função coseno a partir dos parâmetros rítmicos (MESOR, a amplitude e acrofase) de cada dia e para cada animal. 


\subsection{Desenho experimental}

\subsubsection{Tratamentos tardios}

Os animais foram distribuídos de maneira aleatória em três grupos $(\mathrm{n}=3 \mathrm{em}$ cada grupo), segundo o desenho experimental mostrado na Figura 3:

I) Animais diabéticos tratados tardiamente com insulina;

II) Animais diabéticos suplementados tardiamente com melatonina;

III) Animais diabéticos tratados tardiamente com insulina e suplementados com melatonina.

Figura 3 - Desenho experimental dos tratamentos tardios

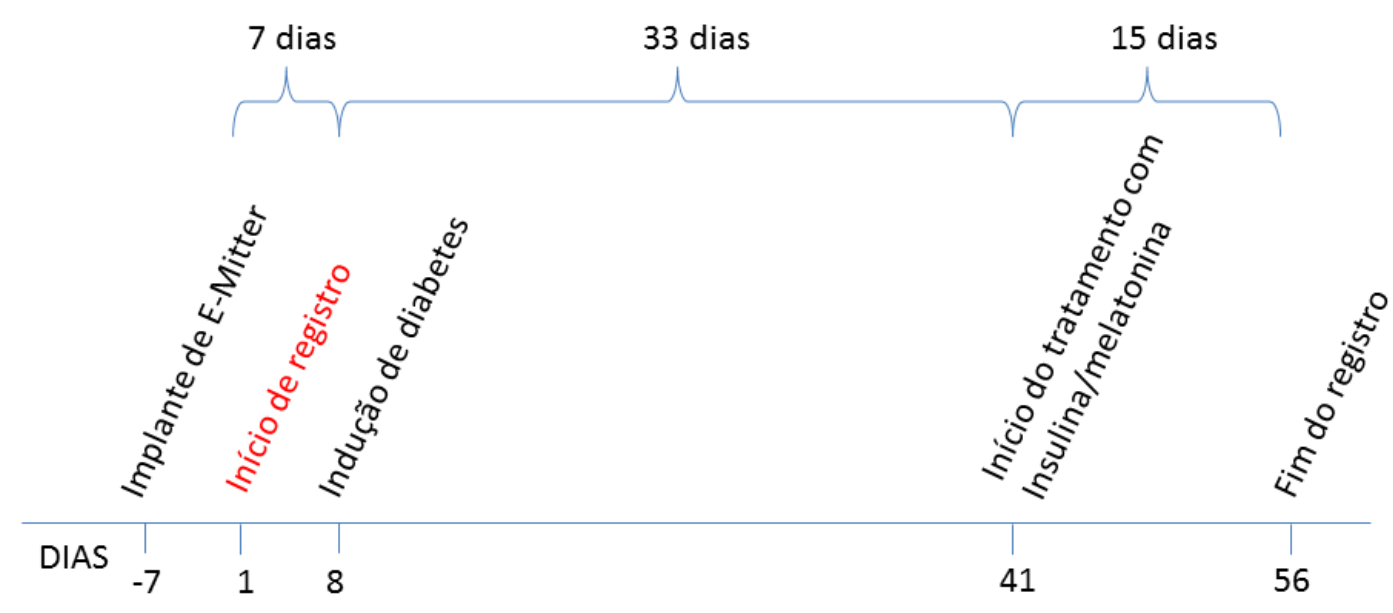

Os animais foram implantados com o transmissor (E-mitter) e após uma semana de recuperação da cirurgia, os dados de temperatura e atividade motora foram coletados como especificado acima, durante 7 dias. No oitavo dia, o diabetes foi induzido com uma injeção intraperitoneal única de STZ e os parâmetros continuaram a ser registrados por 33 dias. Após os trinta e três dias de registro seguindo-se à injeção de STZ, os animais do grupo I foram tratados com insulina, os animais do grupo II foram suplementados com melatonina e os do grupo III foram tratados com insulina e melatonina diariamente durante mais 15 dias. No dia 56 o registro e os tratamentos foram interrompidos. 


\subsubsection{Tratamentos precoces}

Os animais foram distribuídos de maneira aleatória em três grupos ( $\mathrm{n}=3$ em cada grupo), segundo o desenho experimental mostrado na Figura 4:

IV) Animais diabéticos tratados precoce e tardiamente com insulina;

V) Animais diabéticos suplementados precoce e tardiamente com melatonina;

VI) Animais diabéticos tratados precoce e tardiamente com insulina e suplementados com melatonina.

Figura 4 - Desenho experimental dos tratamentos precoces

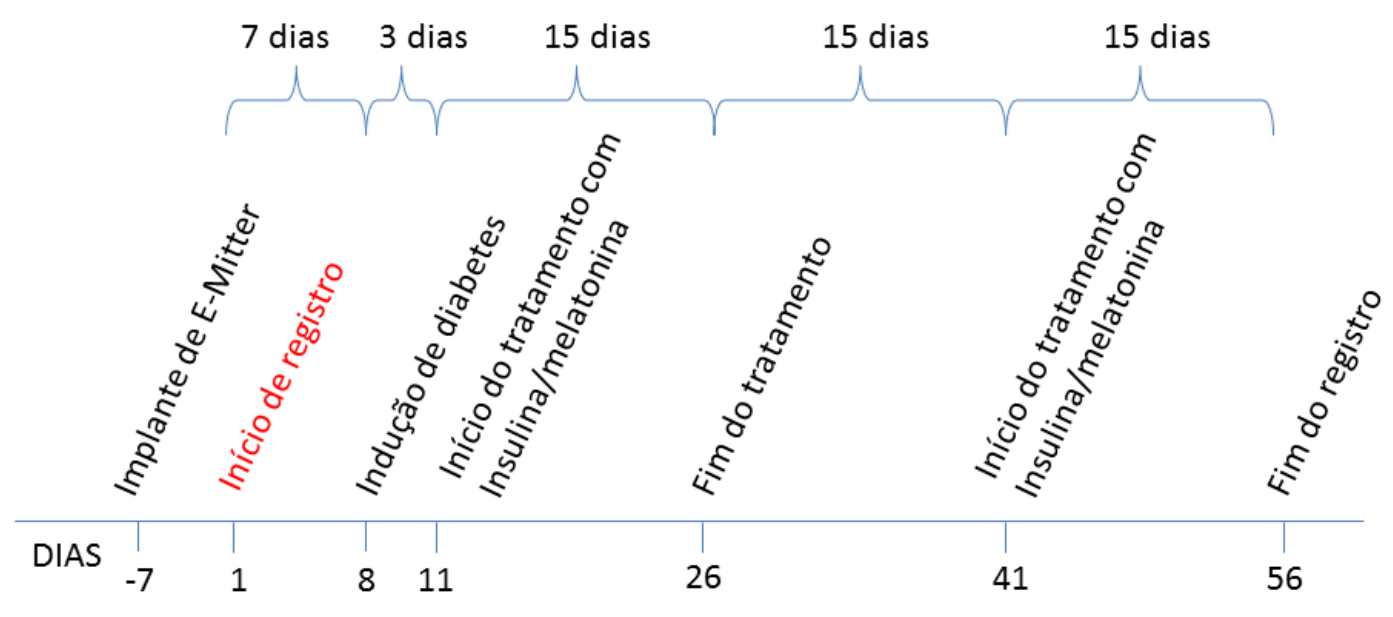

Os animais foram implantados com o transmissor (E-mitter) e após uma semana de recuperação da cirurgia, os dados de temperatura e atividade motora foram coletados como especificado acima, durante 7 dias. No oitavo dia, o diabetes foi induzido com uma injeção intraperitoneal única de STZ e os parâmetros continuaram a ser registrados por 3 dias. Após os três dias de registro seguindo-se à injeção de STZ, os animais do grupo IV foram tratados com insulina, os animais do grupo V foram suplementados com melatonina e os do grupo $\mathrm{VI}$ foram tratados com insulina e melatonina diariamente durante mais 15 dias. No dia 26, todos os tratamentos foram interrompidos e os parâmetros registrados por mais 15 dias, até o dia 40. No dia seguinte, os respectivos tratamentos foram recomeçados durante 15 dias. No dia 56 , o registro e os tratamentos foram interrompidos.

\subsection{Análise estatística}

Dos três animais utilizados em cada grupo, um animal foi escolhido para representa-lo nas análises rítmicas, dado que todos os animais de cada grupo responderam de forma similar a cada tratamento (Termogramas de tratamentos 
tardios na Figura A2 e de tratamentos precoces na Figura A3, Actogramas de tratamentos tardios na Figura A4, e de tratamentos precoces na Figura A5). Os dados das médias foram classificados por período de tratamento e foram expressos como a média \pm erro padrão médio (EPM). As análises estatísticas foram realizadas utilizando o software GraphPad PRISM (GraphPad Prism Software, Inc., LA Jolla, CA, USA). Os parâmetros rítmicos (MESOR, amplitude e acrofase) só foram analisados pelo método do Cosinor em dias que resultaram significativos na análise de ANOVA de uma via. As análises comparativas dentro de cada grupo entre os diferentes períodos de tratamento foram realizadas usando ANOVA de uma via seguida do teste de Bonferroni para comparação entre os tratamentos. 


\section{RESULTADOS}

Para cada grupo, foram estudados 3 animais, dos quais somente um foi utilizado como representativo de cada grupo. O critério de escolha foi baseado no ritmo do período controle de cada animal. Sendo assim, o animal que apresentasse um período controle mais estável foi utilizado para mostrar as análises rítmicas. Os termogramas e actogramas de todos os animais se mostram nas figuras suplementares (Figuras A2 - A5).

\subsection{Animais diabéticos}

\subsubsection{Perfis diários dos ritmos de temperatura corporal e de atividade motora}

Como foi descrito previamente, (Howarth, 2005a, b) o diabetes do tipo I leva à hipotermia. No presente trabalho demonstramos que o diabetes não só leva à hipotermia (Figuras 7, 11, e 15, segunda coluna), mas também leva à alteração da organização rítmica diária da temperatura corporal, caracterizada por dias em que há ausência da ritmicidade de $24 \mathrm{~h}$, dias em que apesar da presença do ritmo de $24 \mathrm{~h}$ há alterações dos parâmetros rítmicos representadas por frequentes deslocamentos de fase (adiantamentos ou atrasos), associados a uma redução do MESOR e aumento da amplitude (Figuras 5, 9, e 13 e Tabela 1).

Após 5 dias da injeção da indução do diabetes, houve uma diminuição rápida da temperatura, junto com alterações nos parâmetros rítmicos como aumento da amplitude devido à diminuição da temperatura mínima. A progressão do quadro de diabetes levou à prevalência de dias arrítmicos, diminuição do MESOR e aumento da amplitude.

A análise do periodograma, realizada no conjunto temporal de 33 dias, mostrou que o diabetes causou perda do período de $24 \mathrm{~h}$, característico dos animais prévio à injeção de STZ, assim como de qualquer período compreendido entre $20 \mathrm{e}$ $28 \mathrm{~h}$ (Figuras 5, 9, e 13, painel médio).

No caso da atividade motora, se bem que o diabetes não levou à perda total do ritmo diário (Figuras 6, 10 e 14 A e C), se observou uma forte alteração do mesmo, caracterizado por dias apresentando adiantamento de fase, e dias sem 
ritmo de 24 h (Figuras 6, 10, e 14 B) predominantemente, e a média das acrofases resultou significativamente adiantada (Tabela 2). Assim como observado na temperatura corporal, a média do MESOR diminuiu significativamente, porém diferente do observado para a temperatura, a amplitude do ritmo de atividade também diminuiu por causa do diabetes (Figuras 6, 10, e 14 E, Tabela 2). Ou seja, observou-se uma redução geral da atividade motora uma vez que sua média diminuiu (Figuras 8, 12, e 16).

No caso da atividade, as análises de periodograma no conjunto da série temporal, mostraram que os 33 dias de diabetes não provocaram a perda do período de 24 h, o qual não foi alterado (Figuras 6, 10, e 14, painel do meio).

\subsubsection{Características metabólicas}

Os animais diabéticos apresentaram redução progressiva no peso corporal com o passar das semanas e hiperglicemia, como era esperado (Figuras 29, 30, e $31, B$ e D).

\subsection{Tratamento tardio com insulina}

4.2.1 Perfis diários dos ritmos de temperatura corporal e de atividade motora

O tratamento com insulina, instituído 33 dias após a instalação do quadro diabético, restaurou o período de $24 \mathrm{~h}$ do ritmo de temperatura corporal, que havia sido perdido (Figura 5, painel inferior). A perda do ritmo diário de temperatura causada pelos 33 dias de diabetes foi revertida junto com o MESOR, como é observado no termograma e na curva ajustada pelo método do Cosinor (Figura $5 \mathrm{~A}$, $C$ e $D$, Tabela 1), porém as acrofases e a amplitude não foram revertidas ao normal (Figura 5 B e E, Tabela 1). O resultado foi um ritmo diferente ao ritmo existente previamente a injeção de STZ.

O tratamento tardio com insulina causou um aumento na média da temperatura corporal revertendo a hipotermia e atingindo valores próximos dos valores no período controle, porém não atingiu a significância estatística (Figura 7 , terceira coluna). 
No caso da atividade motora o período de $24 \mathrm{~h}$, que não tinha sido alterado pelo diabetes, continuou mantido durante o tratamento com insulina (Figura 6, painel inferior). As alterações na ritmicidade da atividade motora causadas pelo diabetes não foram revertidas pelo tratamento tardio com insulina, como se observa no actograma e na curva ajustada, sendo estes caracterizados por maioria de dias sem ritmo de $24 \mathrm{~h}$ (Figura 6 A e C). O mapa de acrofases apresentou três dias com ritmicidade de $24 \mathrm{~h}$, aparentemente as acrofases tendendo a voltar à fase escura (Figura $6 \mathrm{~B}$ ), mas mesmo assim a média das acrofases mostrou avanços de fase relativamente ao período controle (Tabela 3). Nem o MESOR nem a amplitude, diminuídos durante o período diabético, foram revertidos pelo tratamento com insulina, continuando ambos diminuídos (Figura 6 D e E, Tabela 3).

$\mathrm{O}$ tratamento tardio com insulina não foi suficiente para reverter à queda na média da atividade motora causada pelo diabetes (Figura 8, terceira coluna).

\subsubsection{Características metabólicas}

Também, como esperado segundo a literatura, durante o tratamento com insulina os animais ganharam peso e a glicemia retornou aos valores controle (Figura 29 B e D). 
Figura 5 - Perfil diário do ritmo de temperatura corporal de um animal do grupo diabético tratado tardiamente com insulina

A

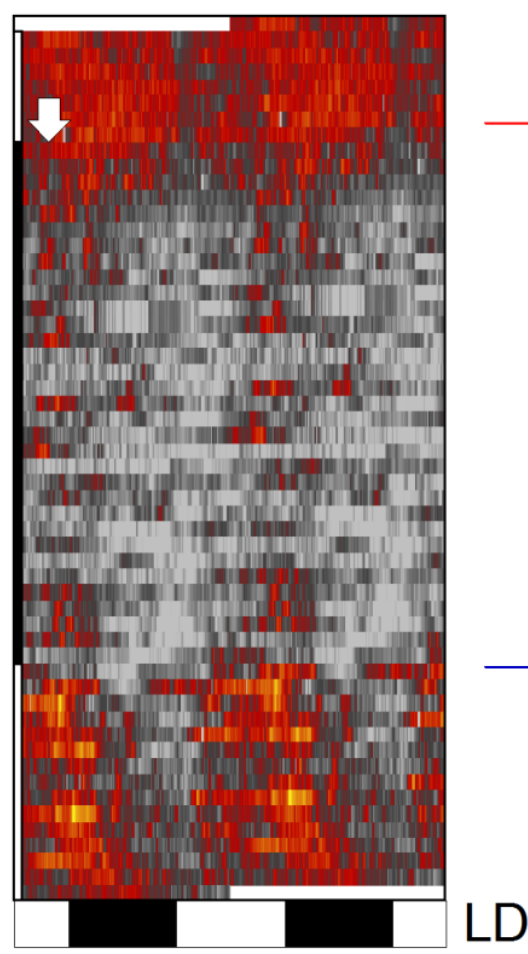

LD
B

$36 \quad$ ZT
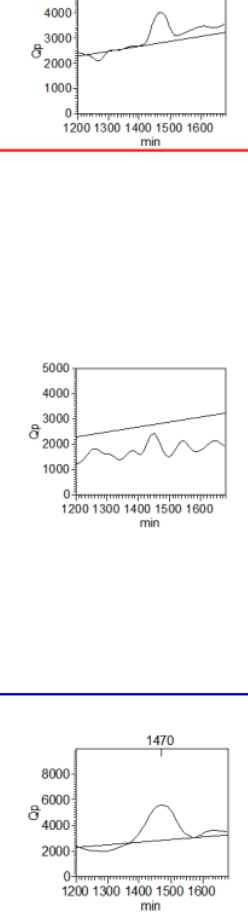

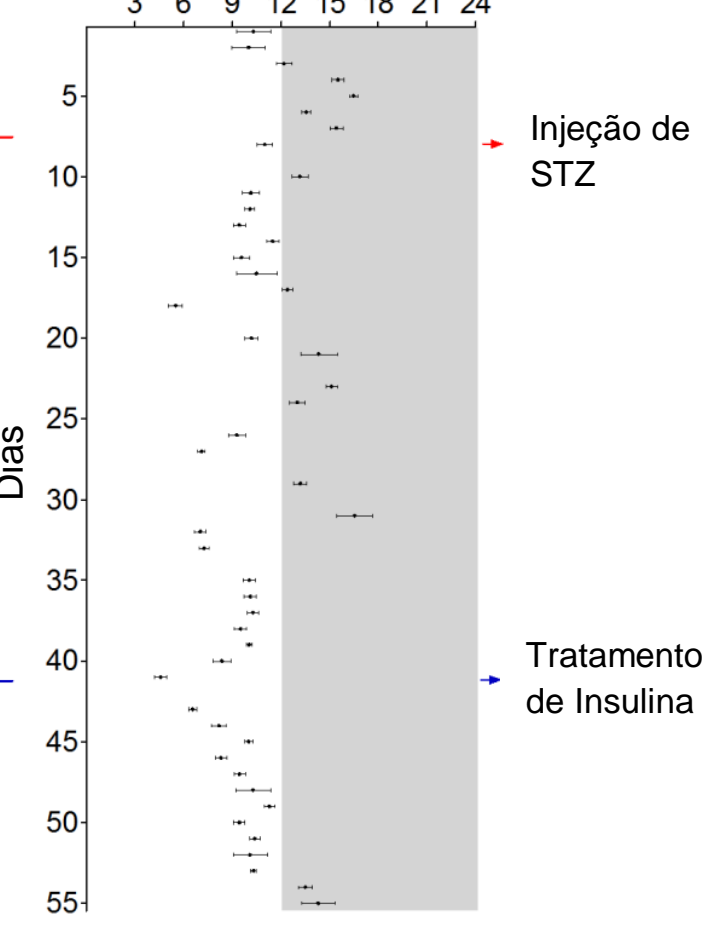




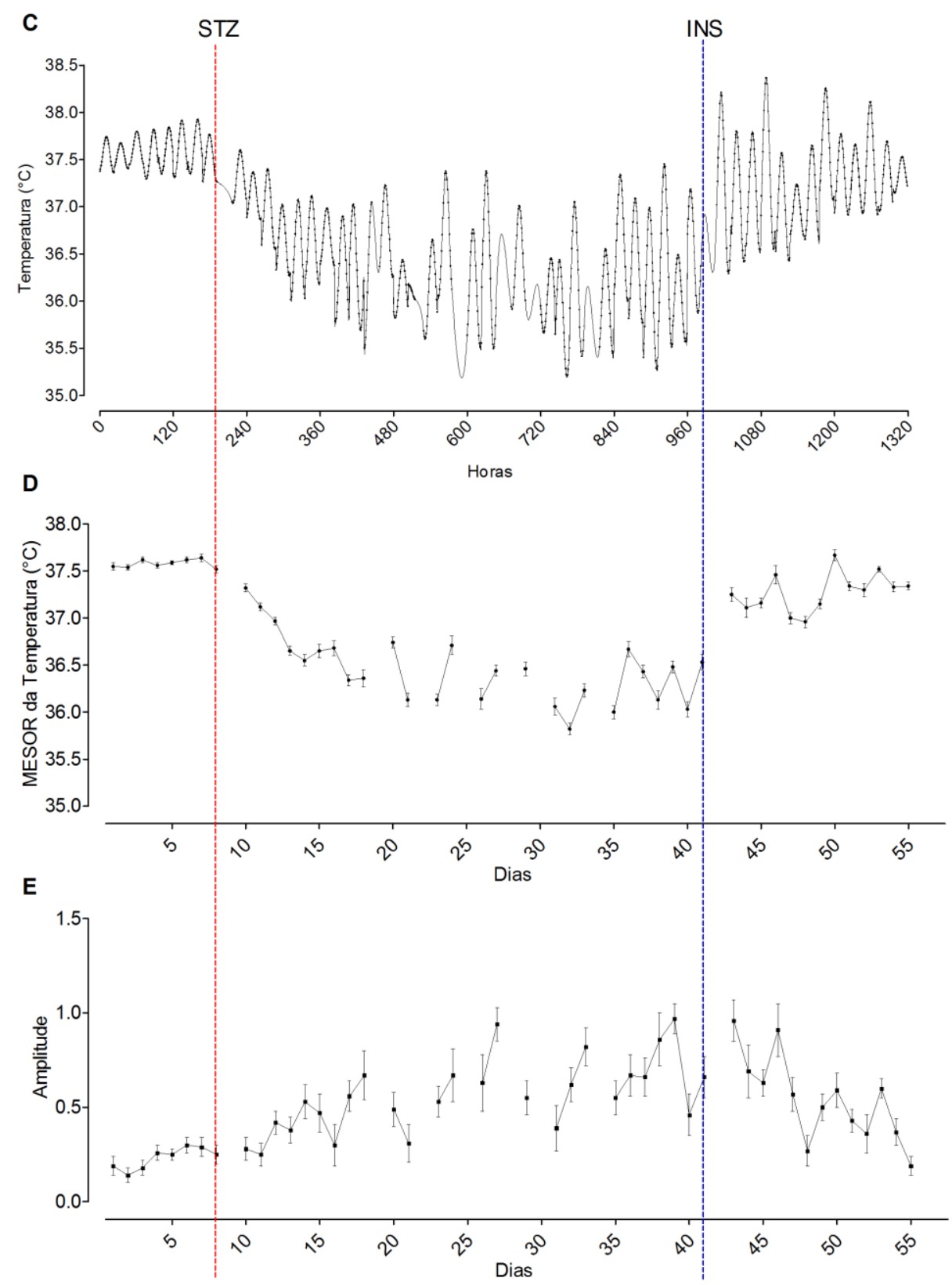

(A) Termograma representado por colorações vermelhas à amarelas indicando temperaturas maiores e gris a preto indicando temperaturas menores. Cada linha representa um dia de registro. Retângulos brancos e pretos no inferior do termograma indicam o regime de luminosidade durante os experimentos. Barra lateral branca superior indica o período controle, barra preta indica período diabético e a barra branca inferior indica o período do tratamento. (B) Mapa de acrofases da temperatura corporal. Para gerar o mapa, as acrofases resultantes da análise pelo Cosinor (média de $1 \mathrm{dia}$ ) foram plotadas segundo o ZT correspondente para gerar o padrão diário (média \pm EPM). A fase escura (ZT12 a ZT24) esta representada pela área cinza do gráfico. As setas e barras laterais indicam o início dos períodos diabético (vermelha) e tratado (azul). Os painéis centrais mostram os periodogramas correspondentes a cada período (controle, painel superior; diabético, painel médio; tratado, painel inferior), indicando o período predominante, quando estiver por cima do limiar (1440 $\min =24 \mathrm{~h}$ ). (C) Curva ajustada a cada $24 \mathrm{~h}$ pelo Cosinor e plotada dia a dia durante o experimento. (D) MESOR resultado das análises pelo Cosinor dia a dia da temperatura. (E) Amplitude resultado das análises pelo Cosinor dia a dia da temperatura. Para todos os parâmetros rítmicos (MESOR, amplitude, acrofase e a curva ajustada) somente foram considerados os dias que apresentaram oscilações de $24 \mathrm{~h}$ na análise de ANOVA unifatorial. 
Figura 6 - Perfil diário do ritmo de atividade motora de um animal representativo do grupo diabético tratado tardiamente com insulina.

A

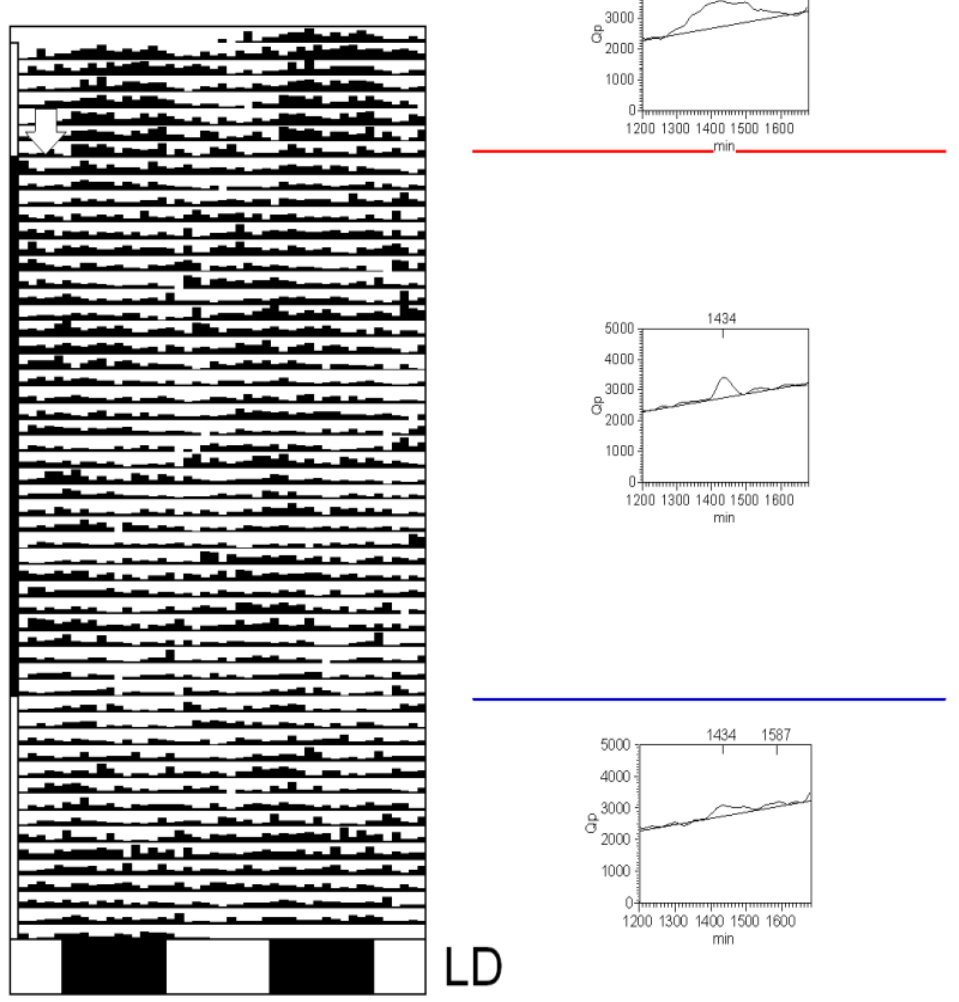

B

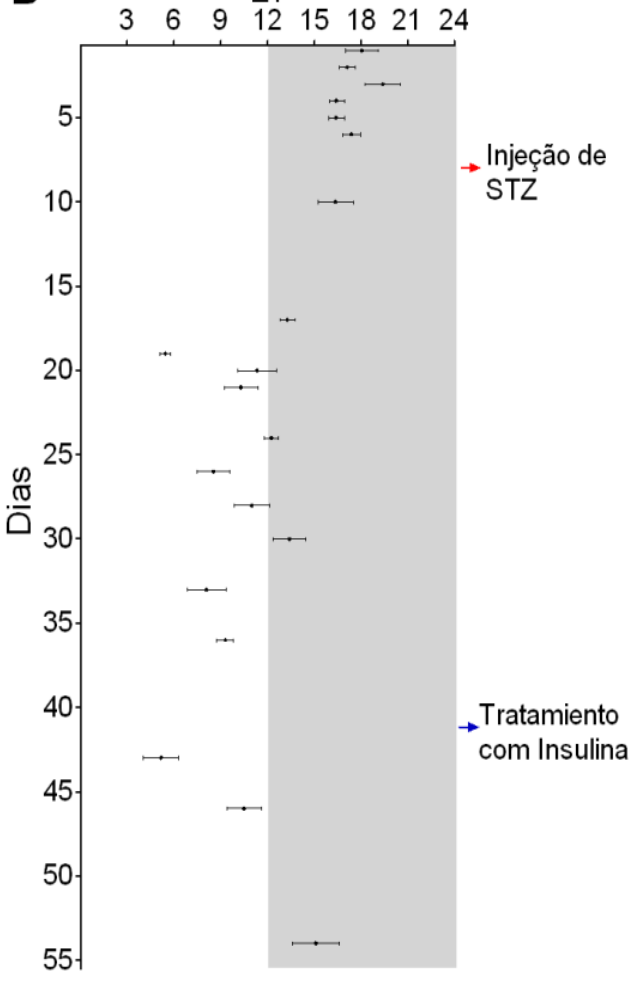




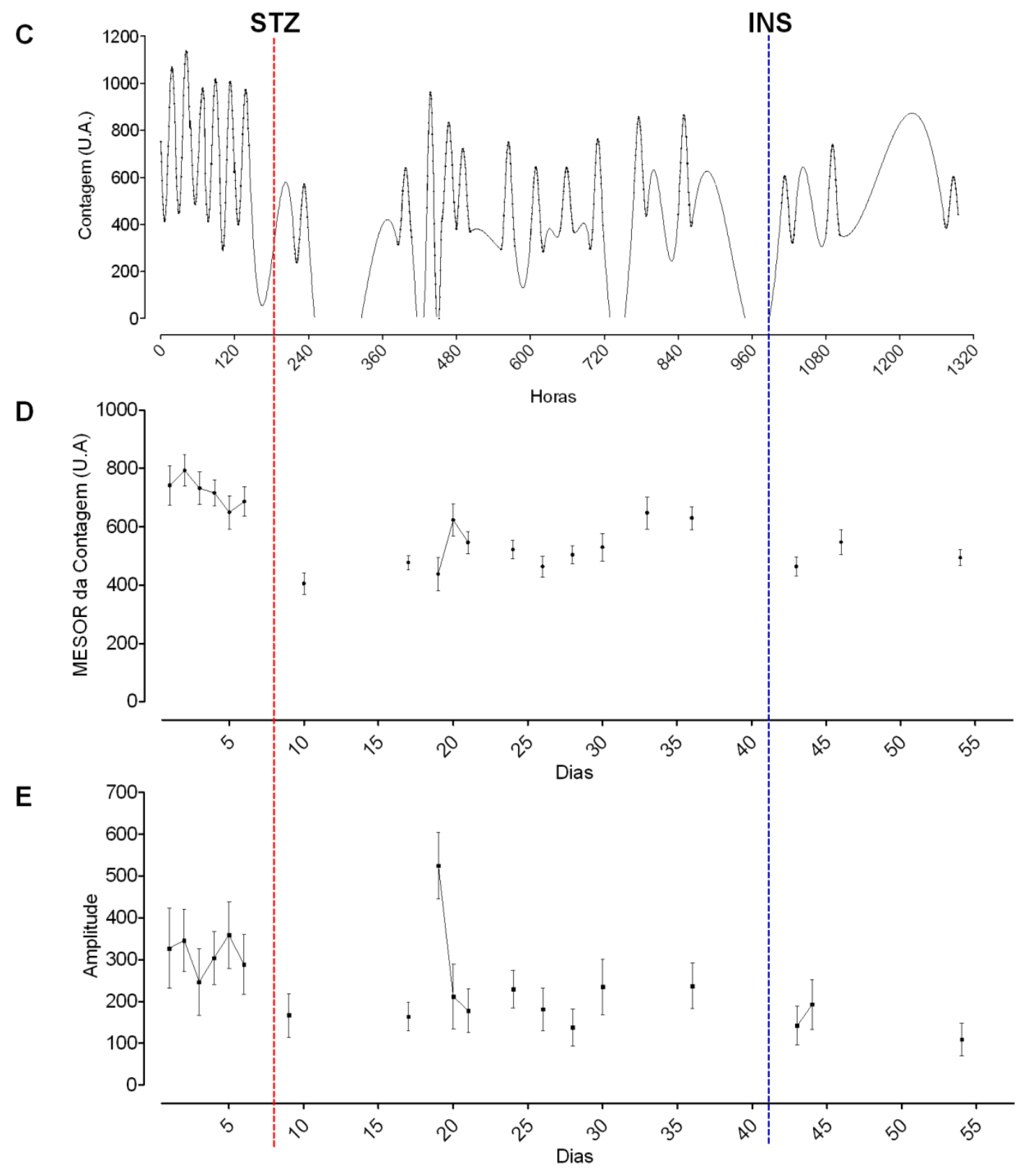

(A) Actograma representado por barras indicando diferentes níveis de atividade obtida por somatória a cada 1 hora. Cada linha representa um dia de registro. Retângulos brancos e pretos no inferior do actograma indicam o regime de luminosidade durante os experimentos. Barra lateral branca superior indica o período controle, barra preta indica período diabético e a barra branca inferior indica o período do tratamento. (B) Mapa de fases da atividade motora. Para gerar o mapa, as acrofases resultantes da análise pelo Cosinor (média de $1 \mathrm{dia}$ ) foram plotadas segundo o ZT correspondente para gerar o padrão diário (média \pm EPM). A fase escura (ZT12 a ZT24) esta representada pela área cinza do gráfico. As setas e barras laterais indicam o início dos períodos diabético (vermelha) e tratado (azul). Os painéis centrais mostram os periodogramas correspondentes a cada período (controle, painel superior; diabético, painel médio; tratado, painel inferior), indicando o período predominante, quando estiver por cima do limiar (1440 min = $24 \mathrm{~h}$ ). (C) Curva ajustada a cada $24 \mathrm{~h}$ pelo Cosinor e plotada dia a dia durante o experimento. (D) MESOR resultado das análises pelo Cosinor dia a dia da atividade. (E) Amplitude resultado das análises pelo Cosinor dia a dia da atividade. Para todos os parâmetros rítmicos (MESOR, amplitude, acrofase e curva ajustada) somente foram considerados os dias que apresentaram oscilações de $24 \mathrm{~h}$ na análise de ANOVA unifatorial. 
Figura 7 - Média da temperatura dos períodos controle (CT), diabético (D) e tratado com insulina (DI) do animal representado na figura 5

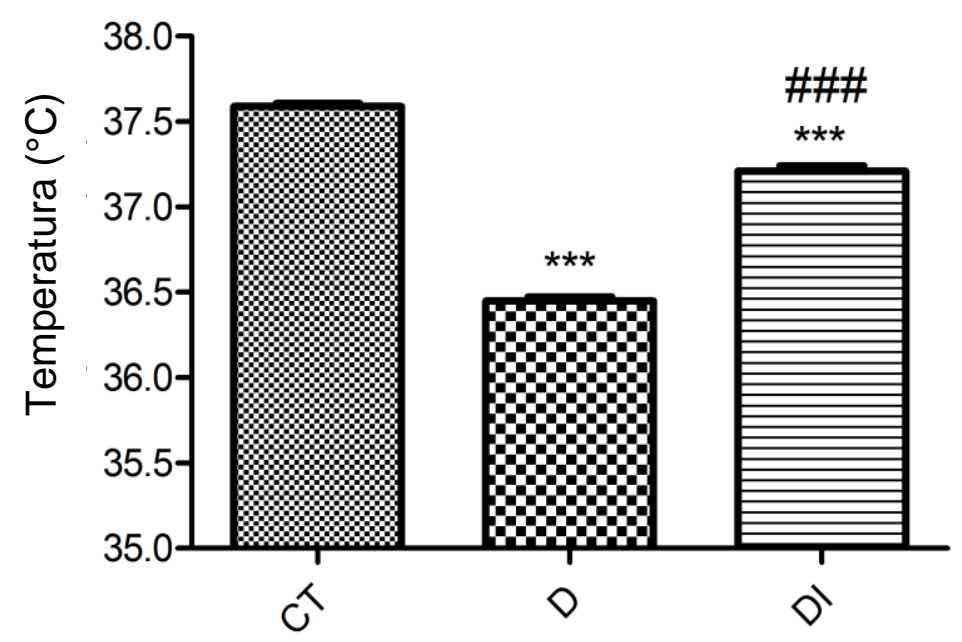

ANOVA unifatorial seguida de Bonferroni com $p<0,0001$ para o fator tratamento. ${ }^{* * *} p<0.001$ vs controle, ${ }^{\# \#} p<0,001$ vs diabético. Média \pm EPM.

Figura 8 - Média da atividade motora dos períodos controle (CT), diabético (D) e tratado com insulina (DI) do animal representado na figura 6

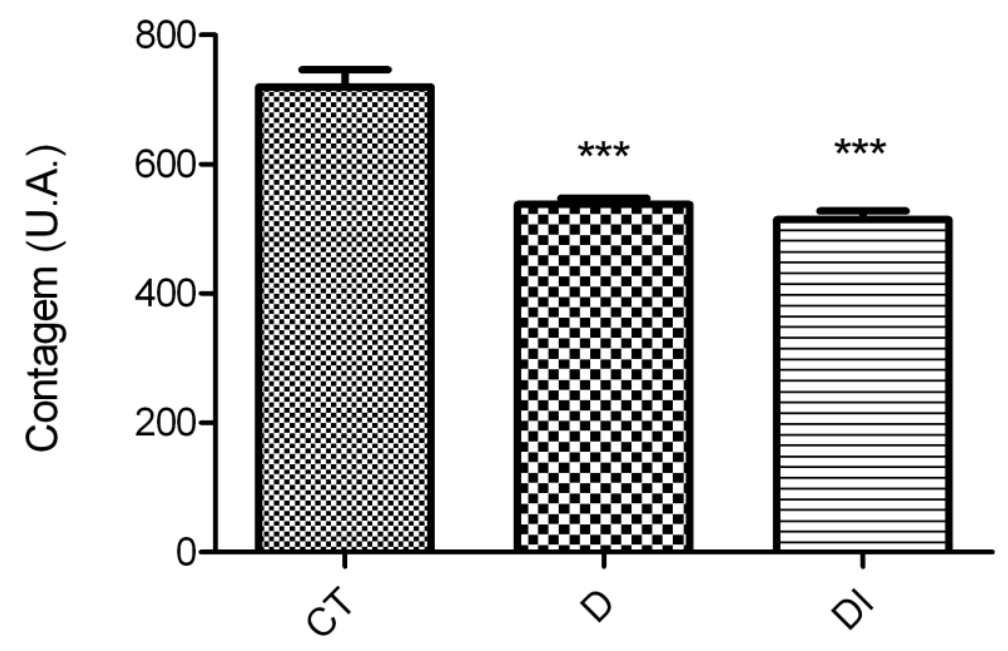

ANOVA unifatorial seguida de Bonferroni com $p<0,0001$ para o fator tratamento. ${ }^{* * *} p<0.001$ vs controle. Média \pm EPM. 


\subsection{Suplementação tardia com melatonina}

\subsubsection{Perfis diários dos ritmos de temperatura corporal e de atividade motora}

A suplementação tardia com melatonina restaurou o período de $24 \mathrm{~h}$ da temperatura corporal, perdido durante os 33 dias de diabetes (Figura 9, painel inferior). No entanto, durante a suplementação, a desorganização do ritmo de temperatura foi mantida, como é observado no termograma e na curva ajustada. Entre os dias 25-30 do experimento, no animal representado observamos dias específicos com temperaturas maiores ao período controle, devido à forte alteração do ritmo de temperatura (Figura $9 \mathrm{~A}$ e $\mathrm{C}$ ). $\mathrm{O}$ mapa de acrofases continuou desorganizado (apresentando dias com adiantamento de fase, dias com atraso de fase e dias sem ritmo de 24 h) durante a suplementação (Figura 9 B), e em média houve adiantamento de fase, porém não atingiu a significância estatística (Tabela 1). A melatonina não teve efeito no MESOR nem na amplitude, o MESOR permaneceu reduzido e a amplitude aumentada (Figura $9 \mathrm{D}$ e E, Tabela 1).

A suplementação com melatonina em doses fisiológicas 33 dias depois da indução do diabetes não foi suficiente para aumentar a média da temperatura corporal (Figura 11, terceira coluna).

No caso da atividade motora o período de $24 \mathrm{~h}$ também se manteve durante a suplementação (Figura 10, painel inferior). As alterações no ritmo de atividade causadas pelo diabetes não foram revertidas pela suplementação com melatonina, porém foi suficiente para atenuar esses efeitos deletérios, observando-se uma maior proporção de dias com ritmo de $24 \mathrm{~h}$, que não foi observado no tratamento com insulina (Figura $10 \mathrm{~A}, \mathrm{C}$ ). O mapa de acrofases apresentou maioria de dias com ritmo de $24 \mathrm{~h}$ e com suas acrofases na fase escura, revertendo o adiantamento de fase (Figura $10 \mathrm{~B}$ e Tabela 3). O MESOR e a amplitude diminuíram mais ainda durante a suplementação (Figura $10 \mathrm{D}$ e E, Tabela 3).

A suplementação tardia com melatonina não conseguiu frear a diminuição progressiva da média da atividade motora, a qual resultou significativamente menor que durante o período diabético sem tratamento (Figura 12, terceira coluna). 


\subsubsection{Características metabólicas}

Os animais suplementados com melatonina apresentaram um leve aumento de peso, porém não houve mudanças na hiperglicemia (Figura 30 B e D).

Figura 9 - Perfil diário da temperatura corporal de um animal representativo do grupo diabético suplementado tardiamente com melatonina

A

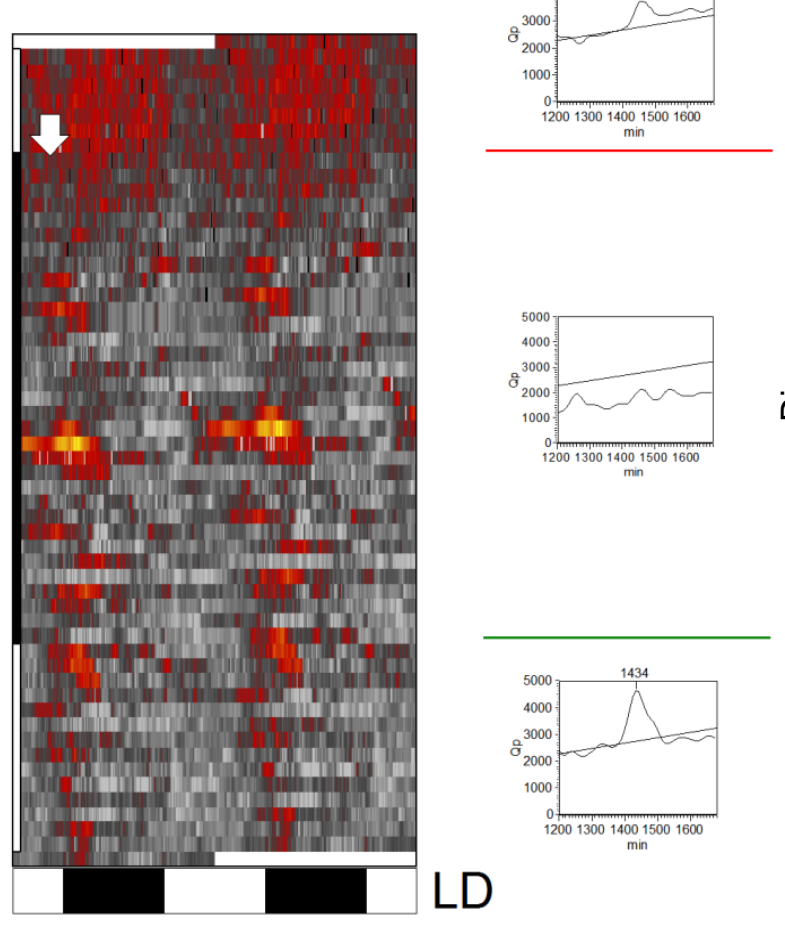

B $\quad$ ZT

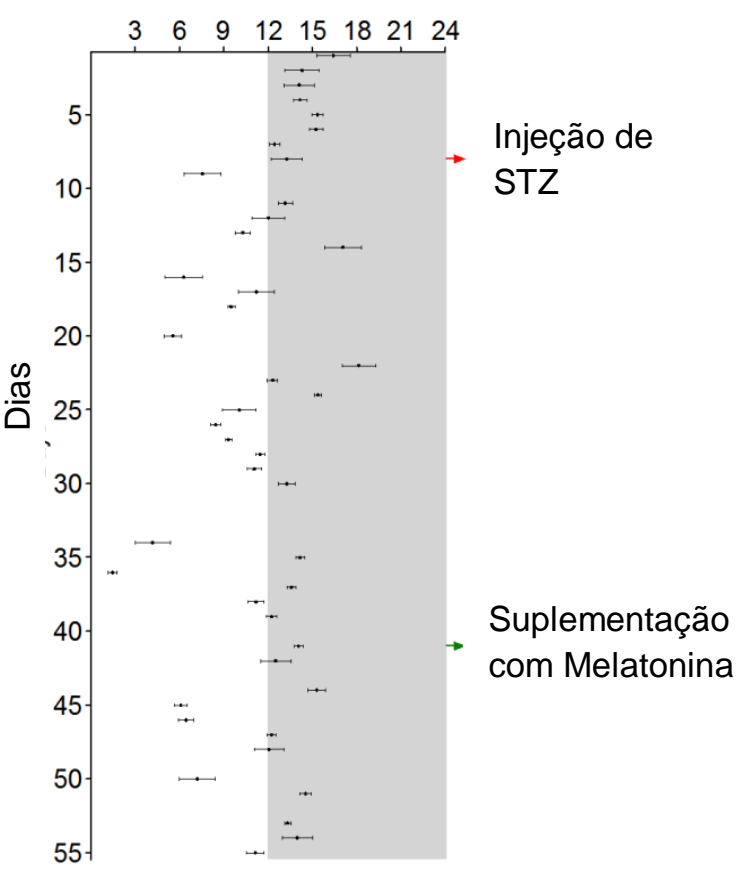




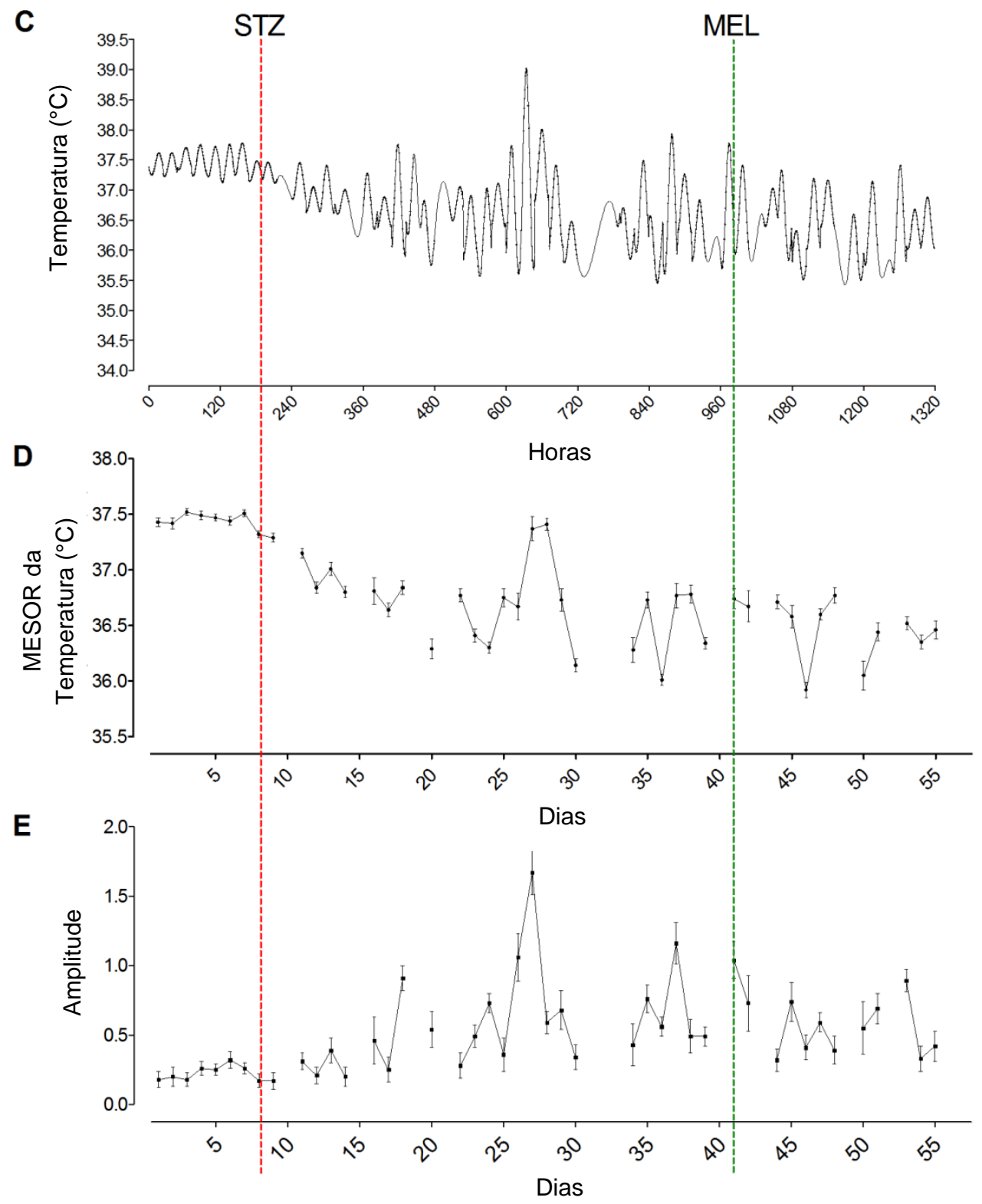

(A) Termograma representado por colorações vermelhas à amarelas indicando temperaturas maiores e gris a preto indicando temperaturas menores. Cada linha representa um dia de registro. Retângulos brancos e pretos no inferior do termograma indicam o regime de luminosidade durante os experimentos. Barra lateral branca superior indica o período controle, barra preta indica período diabético e a barra branca inferior indica o período da suplementação. (B) Mapa de fases da temperatura corporal. Para gerar o mapa, as acrofases resultantes da análise pelo Cosinor (média de 1 dia) foram plotadas segundo o ZT correspondente para gerar o padrão diário (média \pm EPM). A fase escura (ZT12 a ZT24) esta representada pela área cinza do gráfico. As setas e barras laterais indicam o início dos períodos diabético (vermelha) e suplementado (verde). Os painéis centrais mostram os periodogramas correspondentes a cada período (controle, painel superior; diabético, painel médio; suplementado, painel inferior), indicando o período predominante, quando estiver por cima do limiar (1440 $\min =24 \mathrm{~h}$ ). (C) Curva ajustada a cada $24 \mathrm{~h}$ pelo Cosinor e plotada dia a dia durante o experimento. (D) MESOR resultado das análises pelo Cosinor dia a dia da temperatura. (E) Amplitude resultado das análises pelo Cosinor dia a dia da temperatura. Para todos os parâmetros rítmicos (MESOR, amplitude, acrofase e curva ajustada) somente foram considerados os dias que apresentaram oscilações de 24h na análise de ANOVA unifatorial. 
Figura 10 - Perfil diário da atividade motora de um animal representativo do grupo diabético suplementado tardiamente com melatonina

A

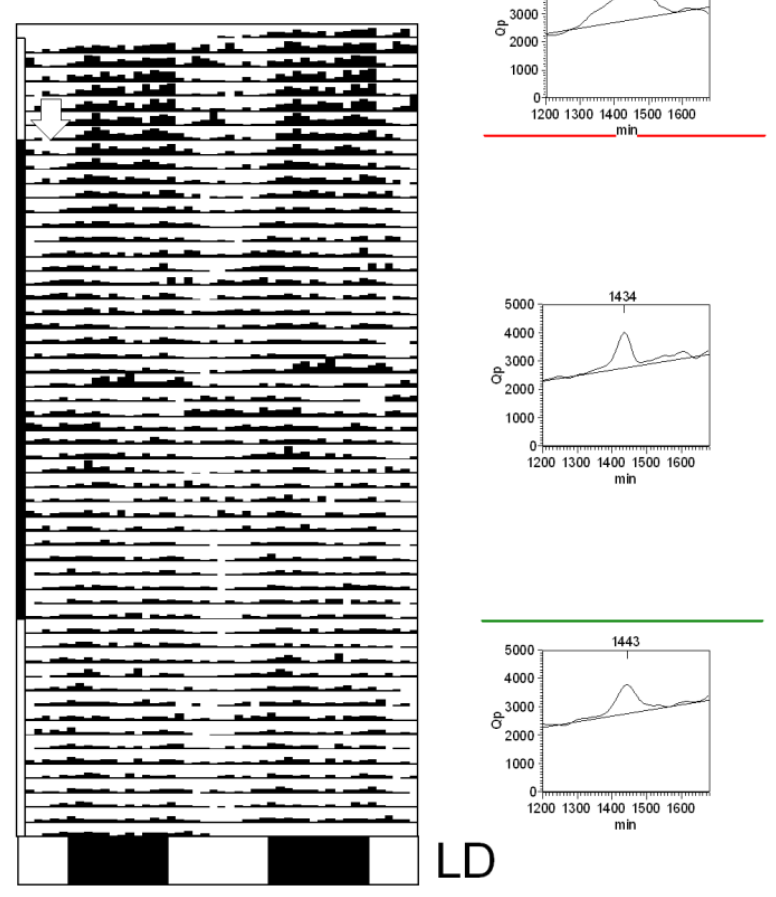

B $\quad Z T$

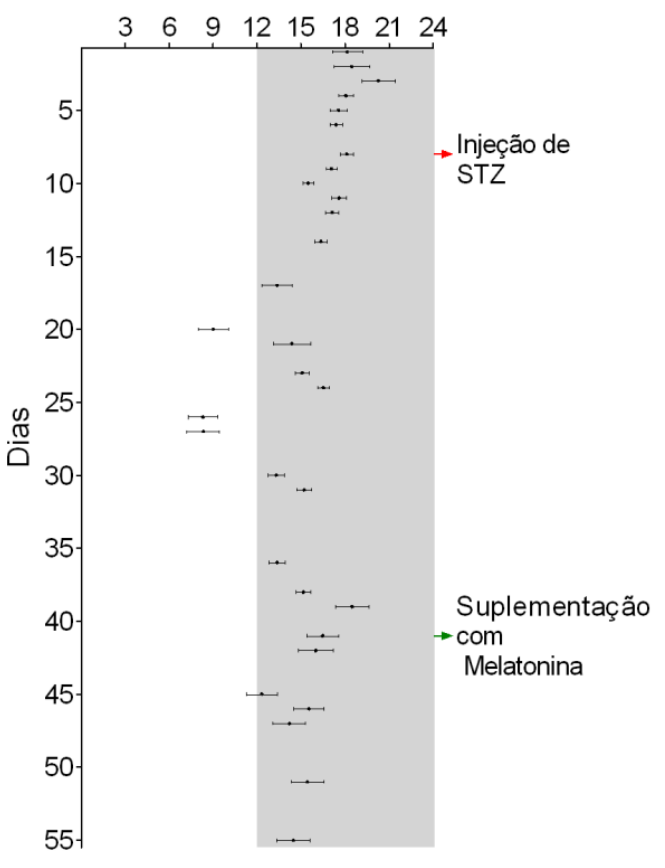




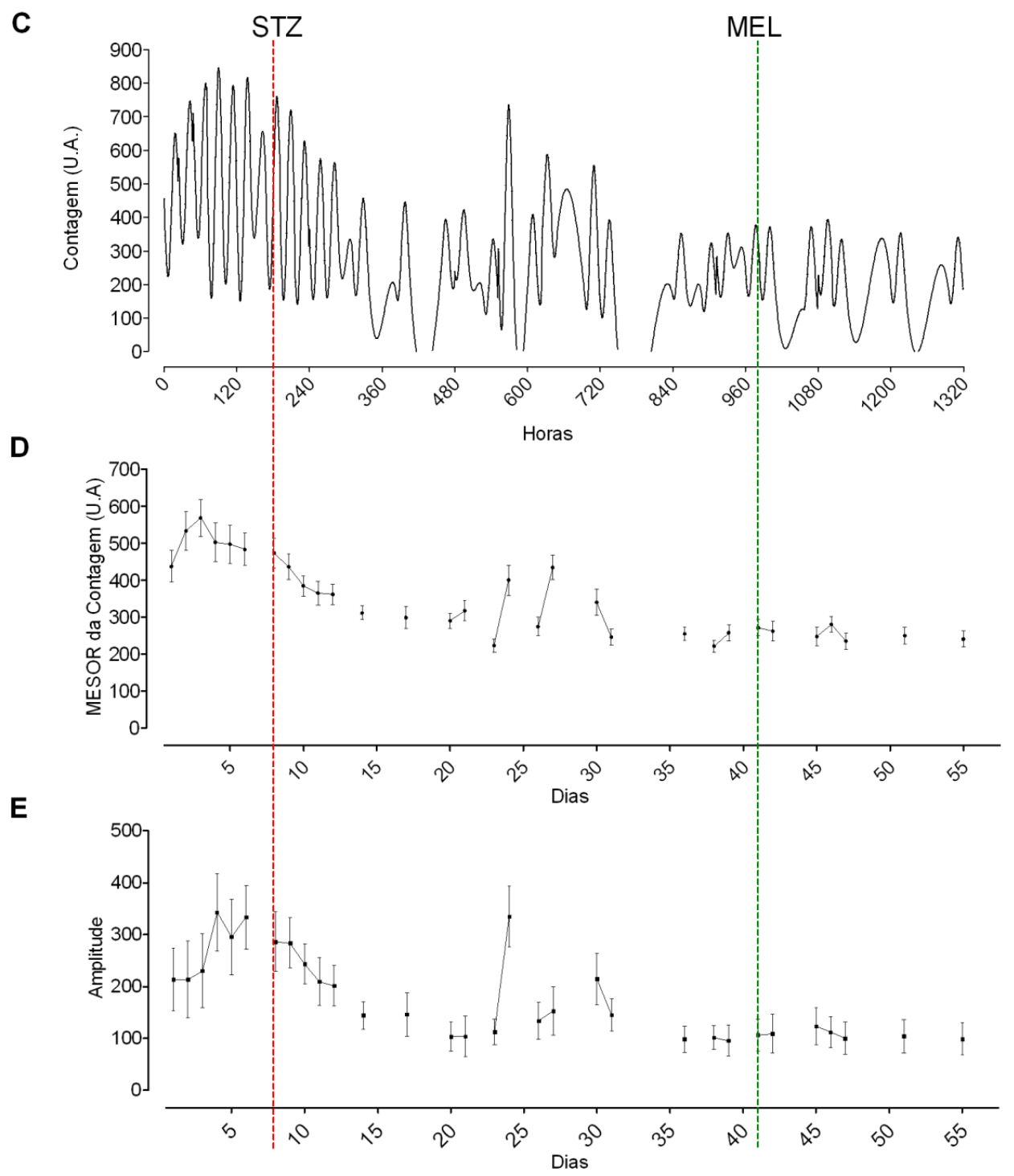

(A) Actograma representado por barras indicando diferentes níveis de atividade obtida por somatória a cada 1 hora. Cada linha representa um dia de registro. Retângulos brancos e pretos no inferior do actograma indicam o regime de luminosidade durante os experimentos. Barra lateral branca superior indica o período controle, barra preta indica período diabético e a barra branca inferior indica o período da suplementação. (B) Mapa de fases da atividade motora. Para gerar o mapa, as acrofases resultantes da análise pelo Cosinor (média de 1 dia) foram plotadas segundo o ZT correspondente para gerar o padrão diário (média \pm EPM). A fase escura (ZT12 a ZT24) esta representada pela área cinza do gráfico. As setas e barras laterais indicam o início dos períodos diabético (vermelha) e suplementado (verde). Os painéis centrais mostram os periodogramas correspondentes a cada período (controle, painel superior; diabético, painel médio; suplementado, painel inferior), indicando o período predominante, quando estiver por cima do limiar $(1440 \mathrm{~min}=24 \mathrm{~h})$. (C) Curva ajustada a cada $24 \mathrm{~h}$ pelo Cosinor e plotada dia a dia durante o experimento. (D) MESOR resultado das análises pelo Cosinor dia a dia da atividade. (E) Amplitude resultado das análises pelo Cosinor dia a dia da atividade. Para todos os parâmetros rítmicos (MESOR, amplitude, acrofase e curva ajustada) somente foram considerados os dias que apresentaram oscilações de $24 \mathrm{~h}$ na análise de ANOVA unifatorial. 
Figura 11 - Media da temperatura corporal dos períodos controle (CT), diabético (D) e suplementado com melatonina (DM) do animal representado na figura 9.

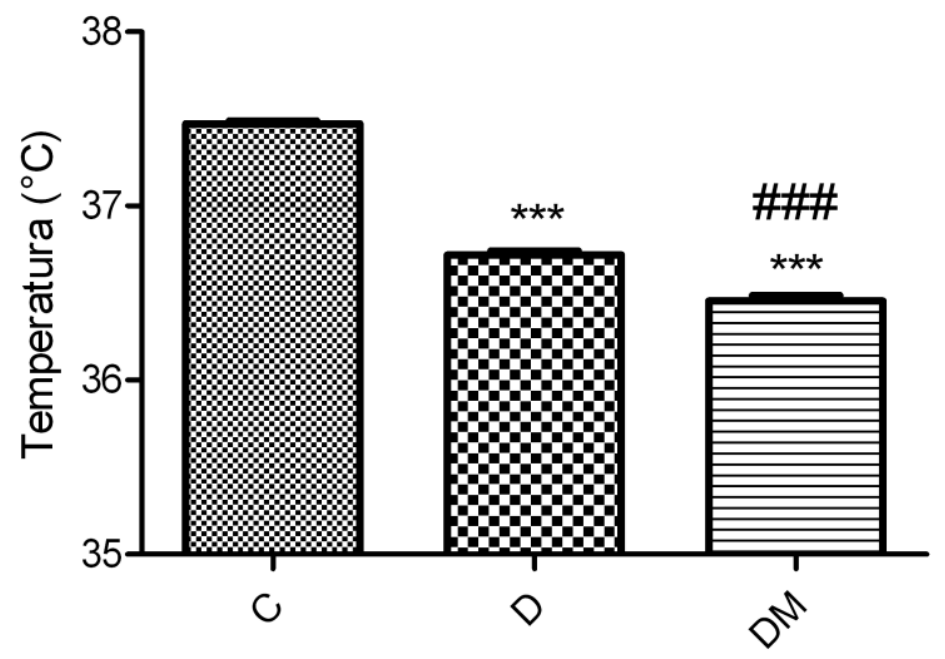

ANOVA unifatorial seguida de Bonferroni com $p<0,0001$ para o fator suplementação. ${ }^{* * *} p<0.001$ vs controle, ${ }^{\# \#} p<0,001$ vs diabético. Média \pm EPM.

Figura 12 - Média da atividade motora dos períodos controle (CT), diabético (D) e suplementado com melatonina (DM) do animal representado na figura 10.

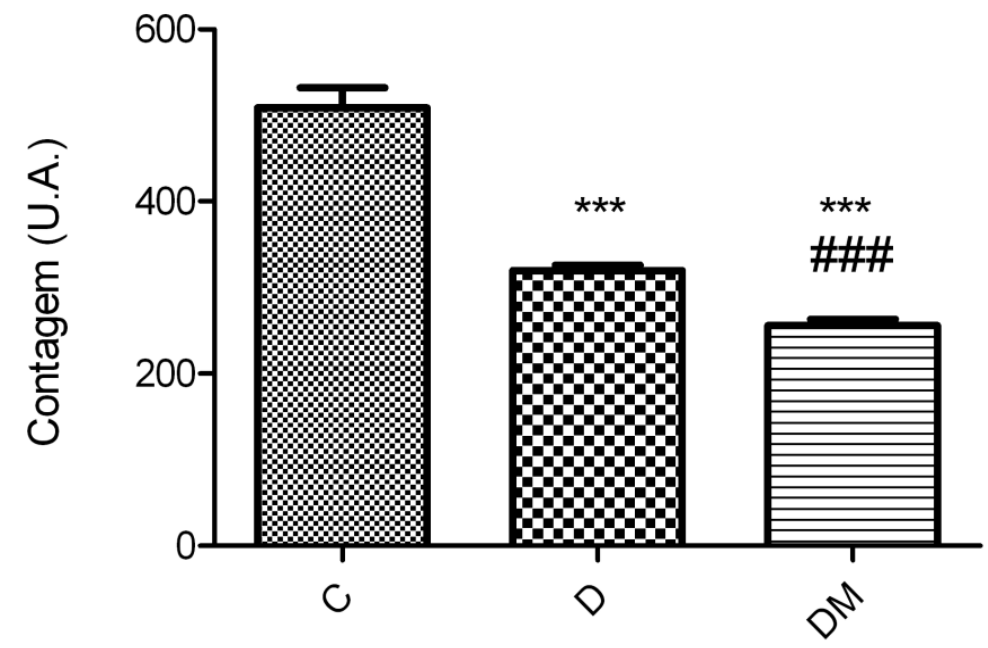

ANOVA unifatorial seguida de Bonferroni com $p<0,0001$ para o fator tratamento. ${ }^{* \star *} p<0.001$ vs controle, ${ }^{\# \#} p<0,001$ vs diabético. Média \pm EPM. 


\subsection{Tratamento tardio com insulina e melatonina}

\subsubsection{Perfis diários dos ritmos de temperatura corporal e de atividade motora}

Para avaliar o efeito dos dois hormônios combinados, os animais diabéticos foram tratados com insulina e melatonina 33 dias depois do início da doença.

$\mathrm{O}$ tratamento tardio com insulina e melatonina restaurou o período de $24 \mathrm{~h}$ do ritmo de temperatura, perdido durante os 33 dias de diabetes (Figura 13, painel inferior). O tratamento também foi suficiente para restaurar o ritmo diário da temperatura, como se observa no termograma e na curva ajustada (Figura $13 \mathrm{~A} \mathrm{e}$ C). O mapa de acrofases foi restaurado, já que as acrofases durante o tratamento retornaram à fase escura, como observado no período controle, e todos os dias resultaram rítmicos (Figura $13 \mathrm{~B}$ ). Diferentemente dos outros animais observados anteriormente, nesse animal não observamos adiantamento na média da acrofase. Dado o alto número de dias arrítmicos a média das acrofases não resultou diferente estatisticamente do controle (Tabela 1). Tanto o MESOR quanto a amplitude foram restaurados a valores iguais ao período controle (Figura $13 \mathrm{D}$ e E, Tabela 1).

$O$ tratamento tardio com insulina e melatonina aumentou a média da temperatura, revertendo a hipotermia e levando a temperatura a valores próximos daqueles observados no período controle, porém não atingiu a significância estatística (Figura 15, terceira coluna).

$\mathrm{O}$ período de $24 \mathrm{~h}$ do ritmo de atividade motora se manteve durante o tratamento (Figura 14, terceiro painel). O ritmo alterado durante o diabetes foi parcialmente restaurado pelo tratamento conjunto de insulina e melatonina, como se observa no actograma e na curva ajustada (Figura $14 \mathrm{~A}$ e $\mathrm{C}$ ). $\mathrm{O}$ tratamento devolveu a maioria de dias rítmicos e reverteu o adiantamento de fase causado pelo diabetes (Figura $14 \mathrm{~B}$ e Tabela 3). O MESOR aumentou com o tratamento, mas não conseguiu ser revertido completamente (Figura $14 \mathrm{D}$ e Tabela 3), e a amplitude continuou diminuída como no período diabético (Figura 14 E e Tabela 3).

$\mathrm{O}$ tratamento tardio com insulina e melatonina aumentou significativamente a atividade média dos animais, porém não conseguiu restaurar a atividade controle (Figura 16, terceira coluna). 


\subsubsection{Características metabólicas}

Com o tratamento combinado de insulina e melatonina, os animais ganharam peso, e a glicemia voltou aos valores observados no período controle (Figura $31 \mathrm{~B} \mathrm{e}$ D).

Figura 13 - Perfil diário de temperatura corporal de um animal representativo do grupo diabético tratado tardiamente com insulina e melatonina

A

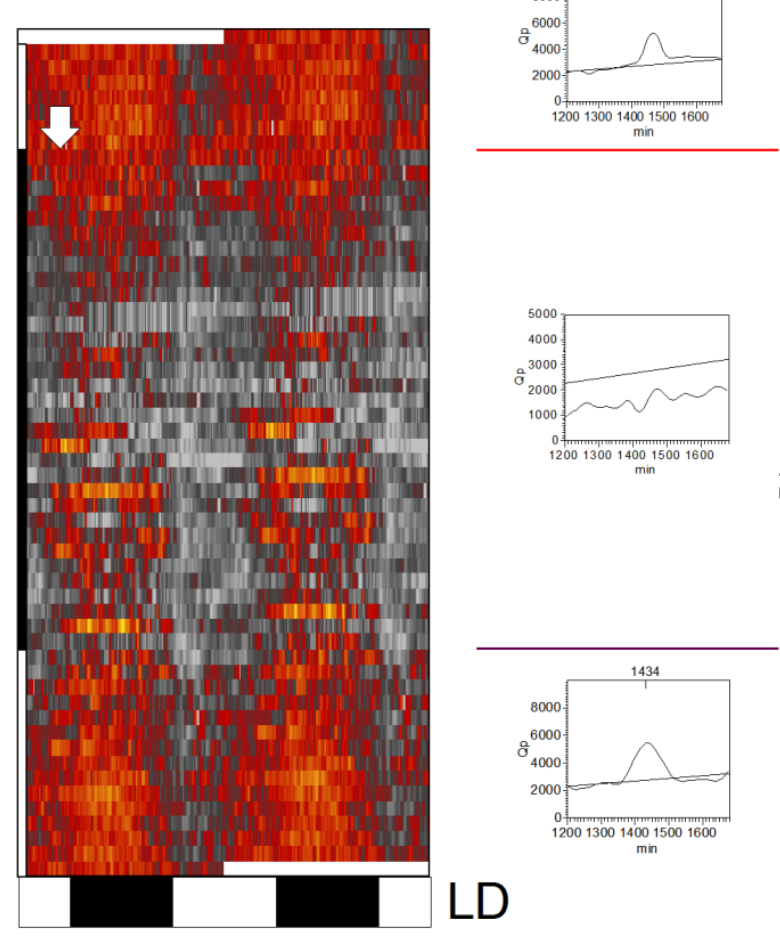

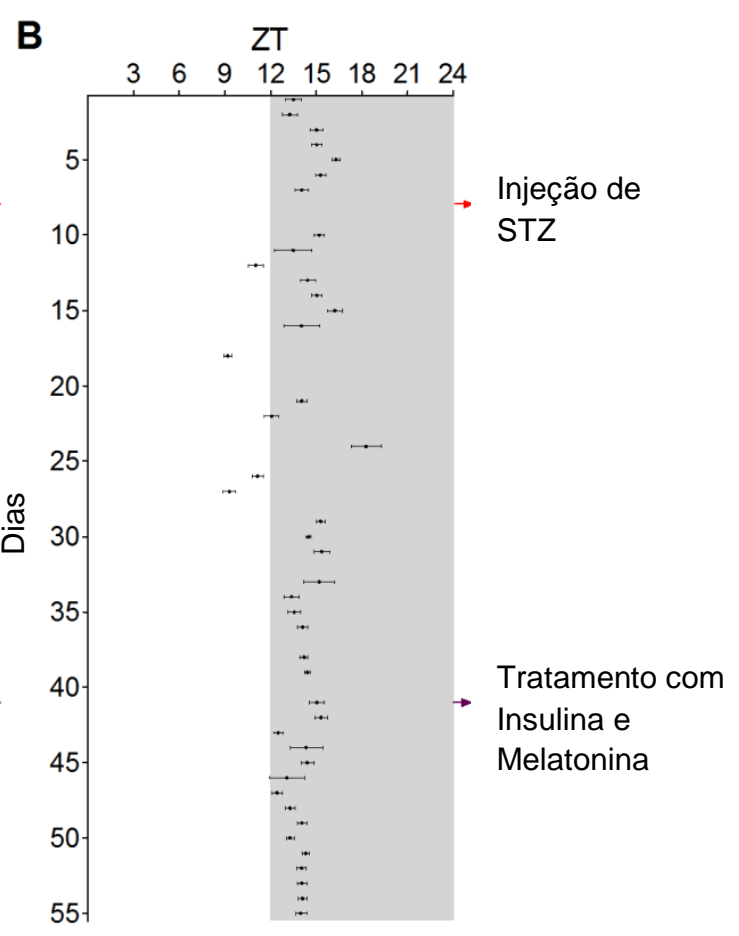




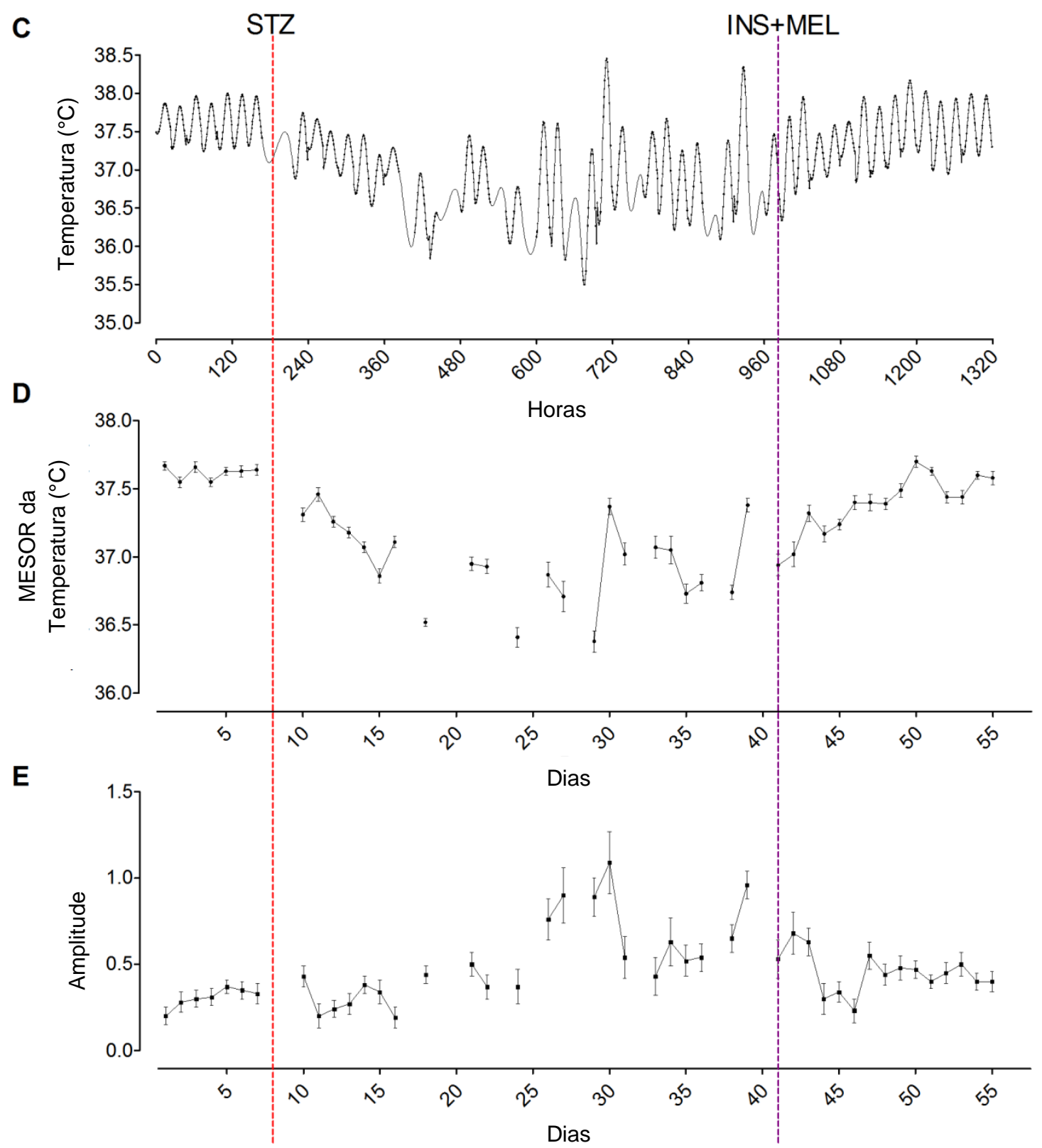

(A) Termograma representado por colorações vermelhas à amarelas indicando temperaturas maiores e gris a preto indicando temperaturas menores. Cada linha representa um dia de registro. Retângulos brancos e pretos no inferior do termograma indicam o regime de luminosidade durante os experimentos. Barra lateral branca superior indica o período controle, barra preta indica período diabético e a barra branca inferior indica o período do tratamento. (B) Mapa de fases da temperatura corporal. Para gerar o mapa, as acrofases resultantes da análise pelo Cosinor (média de $1 \mathrm{dia}$ ) foram plotadas segundo o ZT correspondente para gerar o padrão diário (média \pm EPM). A fase escura (ZT12 a ZT24) esta representada pela área cinza do gráfico. As setas e barras laterais indicam o início dos períodos diabético (vermelha) e tratado (roxa). Os painéis centrais mostram os periodogramas correspondentes a cada período (controle, painel superior; diabético, painel médio; tratado, painel inferior), indicando o período predominante, quando estiver por cima do limiar (1440 $\min =24 \mathrm{~h}$ ). (C) Curva ajustada a cada $24 \mathrm{~h}$ pelo Cosinor e plotada dia a dia durante o experimento. (D) MESOR resultado das análises pelo Cosinor dia a dia da temperatura. (E) Amplitude resultado das análises pelo Cosinor dia a dia da temperatura. Para todos os parâmetros rítmicos (MESOR, amplitude, acrofase e curva ajustada) somente foram considerados os dias que apresentaram oscilações de $24 \mathrm{~h}$ na análise de ANOVA unifatorial. 
Figura 14 - Perfil diário do ritmo de atividade motora de um animal representativo do grupo diabético tratado tardiamente com insulina e melatonina

A

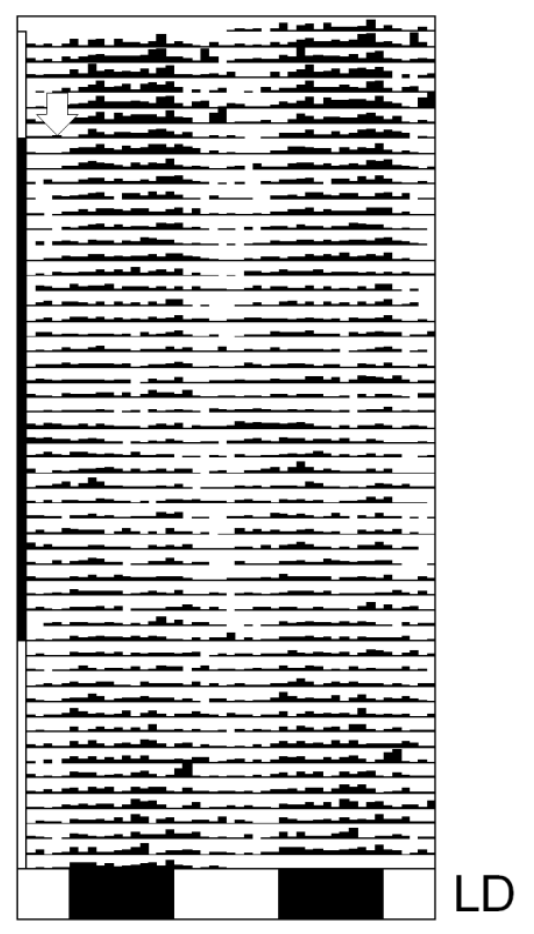

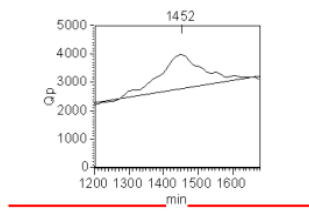
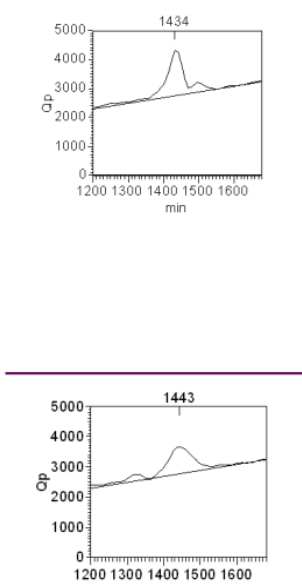

$\min 140016$
B ZT

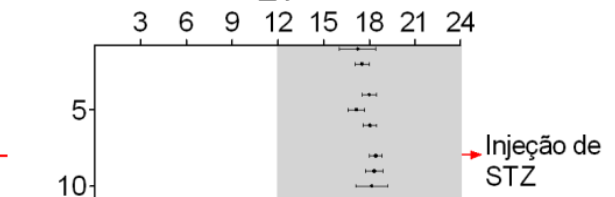

STZ

Tratamento

$\rightarrow$ com

Insulina +

Melatonina 


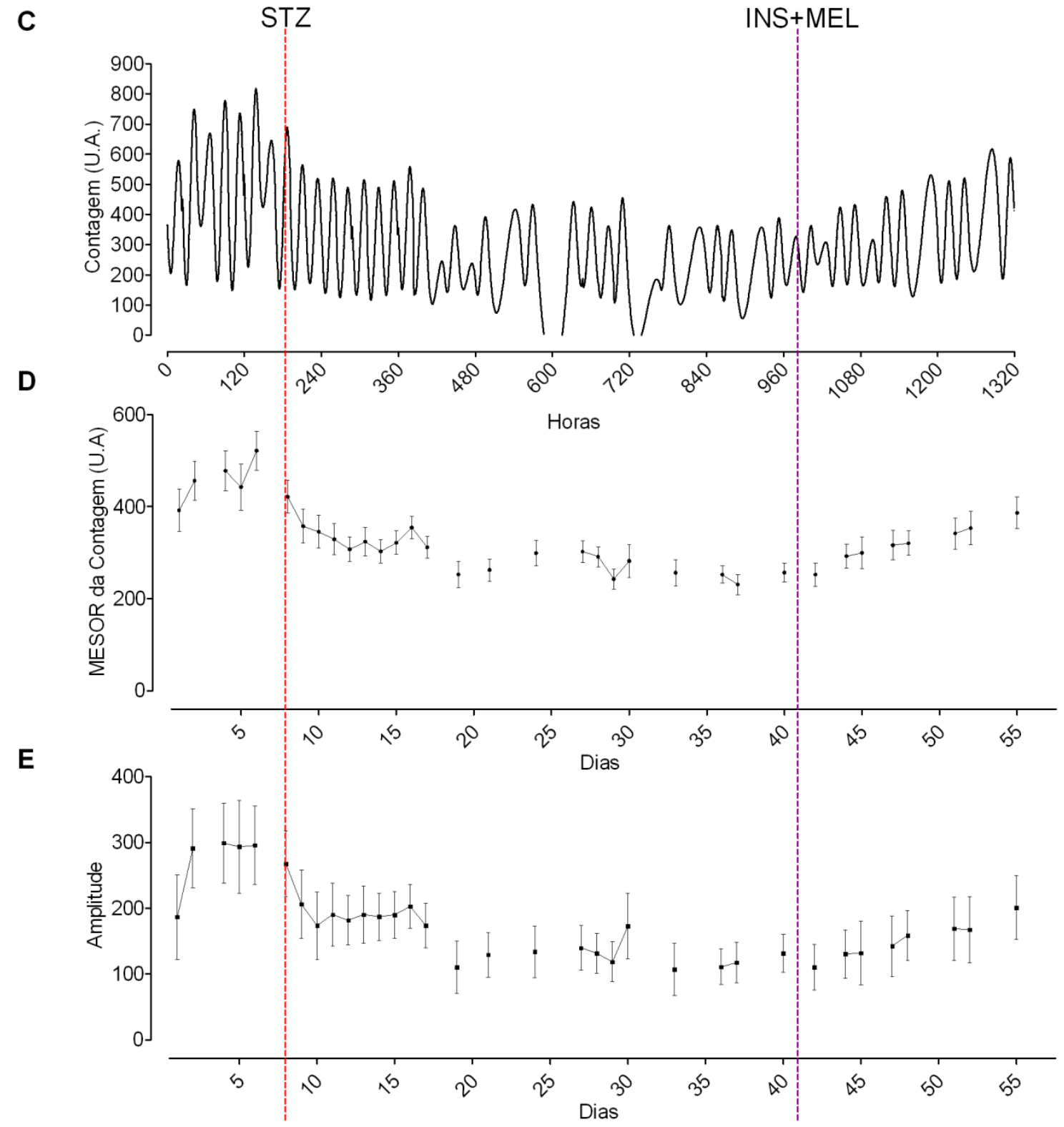

(A) Actograma representado por barras indicando diferentes níveis de atividade obtida por somatória a cada 1 hora. Cada linha representa um dia de registro. Retângulos brancos e pretos no inferior do actograma indicam o regime de luminosidade durante os experimentos. Barra lateral branca superior indica o período controle, barra preta indica período diabético e a barra branca inferior indica o período do tratamento. (B) Mapa de fases da atividade motora. Para gerar o mapa, as acrofases resultantes da análise pelo Cosinor (média de $1 \mathrm{dia}$ ) foram plotadas segundo o ZT correspondente para gerar o padrão diário (média \pm EPM). A fase escura (ZT12 a ZT24) esta representada pela área cinza do gráfico. As setas e barras laterais indicam o início dos períodos diabético (vermelha) e tratado (roxa). Os painéis centrais mostram os periodogramas correspondentes a cada período (controle, painel superior; diabético, painel médio; tratado, painel inferior), indicando o período predominante, quando estiver por cima do limiar $(1440 \mathrm{~min}=24 \mathrm{~h})$. (C) Curva ajustada a cada $24 \mathrm{~h}$ pelo Cosinor e plotada dia a dia durante o experimento. (D) MESOR resultado das análises pelo Cosinor dia a dia da atividade. (E) Amplitude resultado das análises pelo Cosinor dia a dia da atividade. Para todos os parâmetros rítmicos (MESOR, amplitude, acrofase e curva ajustada) somente foram considerados os dias que apresentaram oscilações de $24 \mathrm{~h}$ na análise de ANOVA unifatorial. 
Figura 15 - Média da temperatura corporal dos períodos controle (CT), diabético (D) e tratado com insulina e melatonina (DIM) do animal representado na figura 13

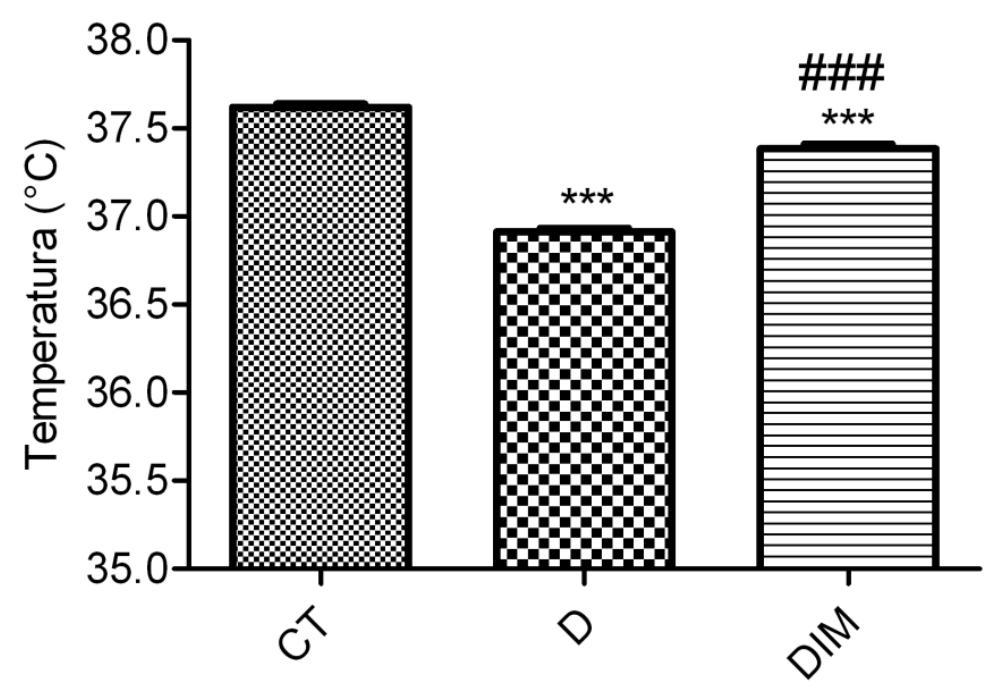

ANOVA unifatorial seguida de Bonferroni com $p<0,0001$ para o fator tratamento. ${ }^{* * *} p<0.001$ vs controle, ${ }^{\# \#} p<0,001$ vs diabético. Média \pm EPM.

Figura 16 - Média da atividade motora dos períodos controle (CT), diabético (D) e tratado com insulina e melatonina (DIM) do animal representado na figura 14

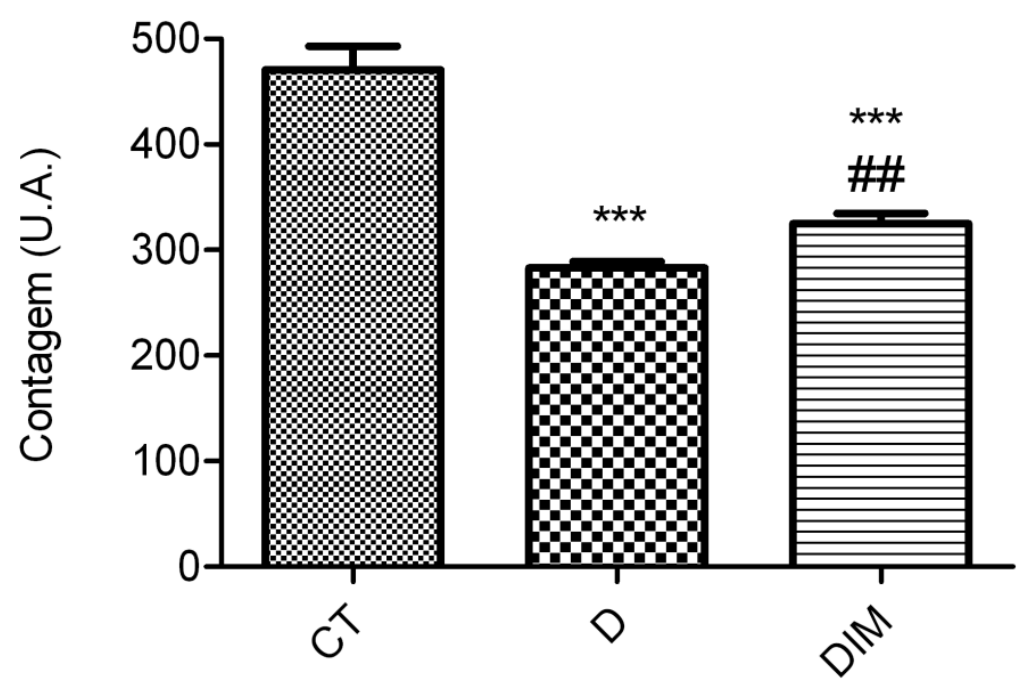

ANOVA unifatorial seguida de Bonferroni com $p<0,0001$ para o fator tratamento. ${ }^{* * *} p<0.001$ vs controle, ${ }^{\# \#} p<0,01$ vs diabético. Média \pm EPM. 
Tabela 1 - Parâmetros rítmicos da temperatura corporal nos diferentes tratamentos tardios

\begin{tabular}{|c|c|c|c|}
\hline & \multicolumn{3}{|c|}{ Tratamentos tardios } \\
\hline & \multicolumn{3}{|c|}{ Grupo tratado com insulina } \\
\hline & Controle & Diabético & Insulina \\
\hline MESOR & $37,59 \pm 0,01487$ & $36,48 \pm 0,07885^{\star \star x}$ & $37,22 \pm 0,07453^{\text {aaa }}$ \\
\hline Amplitude & $0,2300 \pm 0,02289$ & $0,5556 \pm 0,03913^{* * *}$ & $0,5521 \pm 0,05900^{* *}$ \\
\hline \multirow[t]{3}{*}{ Acrofase } & $13,45 \pm 0,9341$ & $10,58 \pm 0,4889^{*}$ & $9,762 \pm 0,6649^{* *}$ \\
\hline & \multicolumn{3}{|c|}{ Grupo suplementado com melatonina } \\
\hline & Controle & Diabético & Melatonina \\
\hline MESOR & $37,47 \pm 0,01503$ & $36,75 \pm 0,07445^{\star * *}$ & $36,48 \pm 0,07706^{\star \star \star}$ \\
\hline Amplitude & $0,2357 \pm 0,01950$ & $0,555 \pm 0,06827^{*}$ & $0,5917 \pm 0,06674^{*}$ \\
\hline \multirow[t]{3}{*}{ Acrofase } & $14,59 \pm 0,4758$ & $11,04 \pm 0,7539$ & $11,59 \pm 0,9328$ \\
\hline & \multicolumn{3}{|c|}{ Grupo tratado com insulina + melatonina } \\
\hline & Controle & Diabético & Insulina + Melatonina \\
\hline MESOR & $37,62 \pm 0,01857$ & $36,96 \pm 0,06499^{* * *}$ & $37,38 \pm 0,05622^{\text {aaa }}$ \\
\hline Amplitude & $0,3057 \pm 0,02103$ & $0,5291 \pm 0,05421^{*}$ & $0,4533 \pm 0,03055$ \\
\hline Acrofase & $14,65 \pm 0,4103$ & $13,65 \pm 0,4664$ & $13,90 \pm 0,2138$ \\
\hline
\end{tabular}

ANOVA unifatorial seguido de Bonferroni para cada tratamento (Insulina, Melatonina e Insulina + Melatonina). $p<0,05$ para o fator tratamento. ${ }^{\star * \star} p<0,001,{ }^{\star \star} p<0,01,{ }^{\star} p<0,05$ vs controle, ${ }^{\text {aaa }} p<$ 0,001 vs diabético. Média \pm EPM. 
Tabela 2 - Parâmetros rítmicos da atividade motora nos diferentes tratamentos tardios

\begin{tabular}{|c|c|c|c|}
\hline & \multicolumn{3}{|c|}{ Tratamentos tardios } \\
\hline & \multicolumn{3}{|c|}{ Grupo tratado com insulina } \\
\hline & Controle & Diabético & Insulina \\
\hline MESOR & $719,3 \pm 20,11$ & $525,7 \pm 24,18^{\star \star \star}$ & $501,3 \pm 24,32^{\star \star \star}$ \\
\hline Amplitude & $312,2 \pm 16,8$ & $226,7 \pm 34,84$ & $148,4 \pm 24,43^{a}$ \\
\hline \multirow[t]{3}{*}{ Acrofase } & $17,49 \pm 0,4648$ & $10,85 \pm 0,9047^{* \star}$ & $10,26 \pm 2,869^{\star \star}$ \\
\hline & \multicolumn{3}{|c|}{ Grupo suplementado com melatonina } \\
\hline & Controle & Diabético & Melatonina \\
\hline MESOR & $503,6 \pm 18,18$ & $327,2 \pm 18,11^{* * *}$ & $255,2 \pm 6,26^{* * *}$ aa \\
\hline Amplitude & $271,5 \pm 24,47$ & $172,8 \pm 17,55^{\star x}$ & $107,7 \pm 3,17^{*}$ \\
\hline \multirow[t]{3}{*}{ Acrofase } & $18,33 \pm 0,4229$ & $14,58 \pm 0,7496^{*}$ & $14,93 \pm 0,5294$ \\
\hline & \multicolumn{3}{|c|}{ Grupo tratado com insulina + melatonina } \\
\hline & Controle & Diabético & Insulina + Melatonina \\
\hline MESOR & $458,3 \pm 21,25$ & $300,4 \pm 10,17^{* * x}$ & $320,6 \pm 14,53^{* \star}$ \\
\hline Amplitude & $273,1 \pm 21,68$ & $160,3 \pm 9,109^{* * *}$ & $151,4 \pm 10,05^{* * *}$ \\
\hline Acrofase & $17,61 \pm 0,1883$ & $15,91 \pm 0,5557$ & $16,72 \pm 0.4171$ \\
\hline
\end{tabular}

ANOVA unifatorial seguido de Bonferroni para cada tratamento (Insulina, Melatonina e Insulina + Melatonina). $p<0,05$ para o fator tratamento. ${ }^{* *} p<0,001, \quad p<0,01, \quad p<0,05$ vs controle, ${ }^{\text {aa }} p<$ $0,01,{ }^{a} p<0,05$ vs diabético. Média \pm EPM. 


\subsection{Tratamentos precoces}

Para estudar se o tratamento com insulina tem uma ação precoce sobre os efeitos deletérios no ritmo de temperatura, os animais foram tratados com insulina três dias após a indução com STZ, momento em que os efeitos metabólicos e sobre a síntese de melatonina tanto pineal quanto retiniana já se expressam plenamente (Amaral et al., submetido; do Carmo Buonfiglio et al., 2011). No presente trabalho se observou que três dias de diabetes foi suficiente para levar à perda do ritmo de $24 \mathrm{~h}$, observado pelas alterações nos parâmetros rítmicos e na curva ajustada pelo Cosinor (Figuras 17, 21, e 25 A e C).

A analise utilizando o método do periodograma no conjunto temporal de 3 dias, mostrou que os períodos de $24 \mathrm{~h}$ tanto do ritmo de temperatura quanto de atividade motora não sofreram alterações (dados não mostrados).

As alterações no ritmo de atividade motora foram menos drásticas que no caso da temperatura, já que o ritmo se manteve e não houve alterações significativas nos parâmetros rítmicos (Figuras 18, 22, e 26, A e C).

Três dias não foram suficientes para induzir hipotermia (Figuras 19, 23, e 27, segunda coluna) nem diminuir a média da atividade motora (Figura 20, 24, e 28 , segunda coluna). O peso não resultou alterado (Figuras 29, 30 e 31, A), porem a hiperglicemia já foi evidente (Figuras 29, 30 e 31 C).

\subsection{Tratamento precoce com insulina}

\subsubsection{Perfis diários dos ritmos de temperatura corporal e de atividade motora}

Após três dias da indução do diabetes, o tratamento com insulina manteve o período de $24 \mathrm{~h}$ da temperatura, observado no periodograma (Figura 17, segundo painel), recuperando a ritmicidade da temperatura, como observado no termograma e na curva ajustada (Figura 17 A e C). O mapa de acrofases e os parâmetros rítmicos (MESOR, amplitude e acrofase) foram preservados como no período controle (Figura 17 B, D e E, Tabela 3). O tratamento precoce também preveniu a hipotermia (Figura 19, terceira coluna). 
O período de $24 \mathrm{~h}$ do ritmo de atividade motora também se manteve inalterado (Figura 18, segundo painel). A ritmicidade da atividade motora foi mantida também, com os dias rítmicos como observado no actograma e na curva ajustada (Figura $18 \mathrm{~A}$ e $\mathrm{C}$ ). Por sua vez, o tratamento também manteve o mapa de fases inalterado, assim como a media das acrofases constantes e na fase escura, como no período controle (Figura $18 \mathrm{~B}$ e Tabela 4). Também foram mantidos o MESOR e a amplitude, sem modificações significativas (Figura $18 \mathrm{D}$ e E, Tabela 4). O tratamento precoce com insulina manteve a atividade média dos animais após três dias de diabetes (Figura 20, terceira coluna).

\subsubsection{Características metabólicas}

O tratamento precoce com insulina preveniu a perda de peso e reverteu a hiperglicemia (Figura 29 A e C).

Figura 17 - Perfil diário do ritmo de temperatura corporal de um animal representativo do grupo diabético tratado precocemente com insulina

A

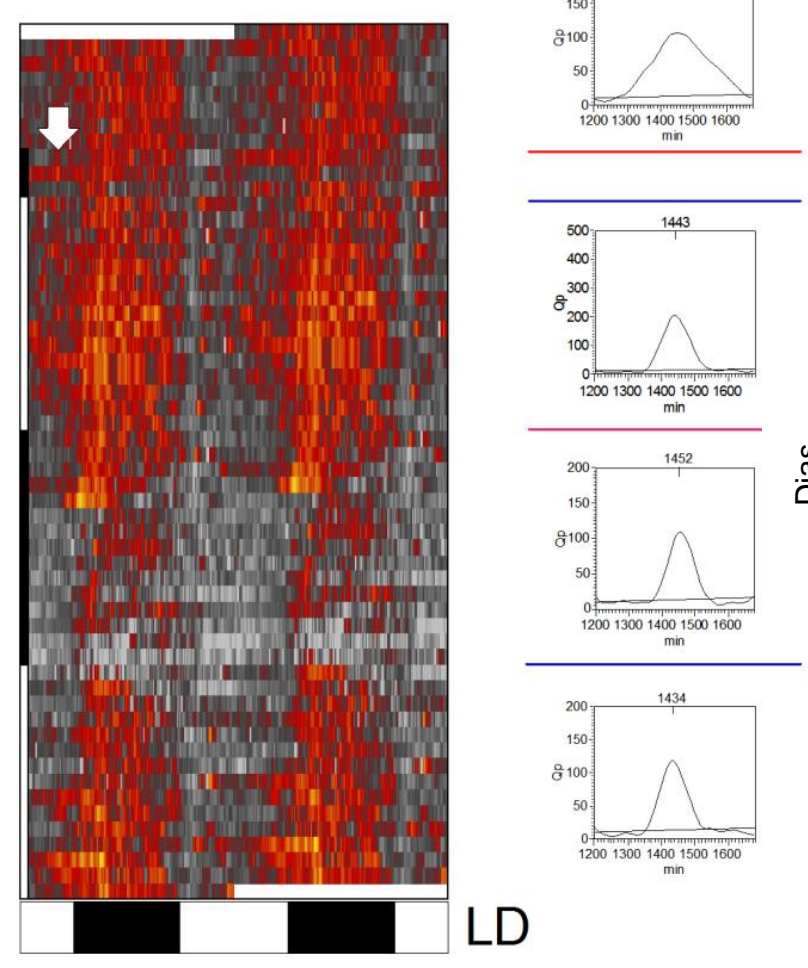

B

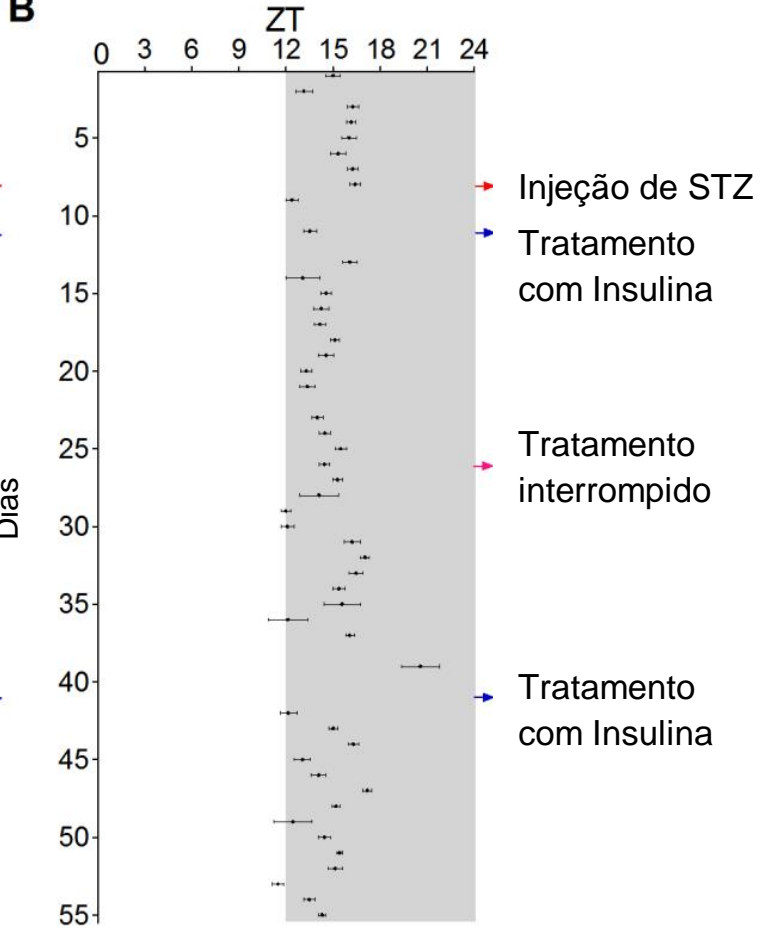




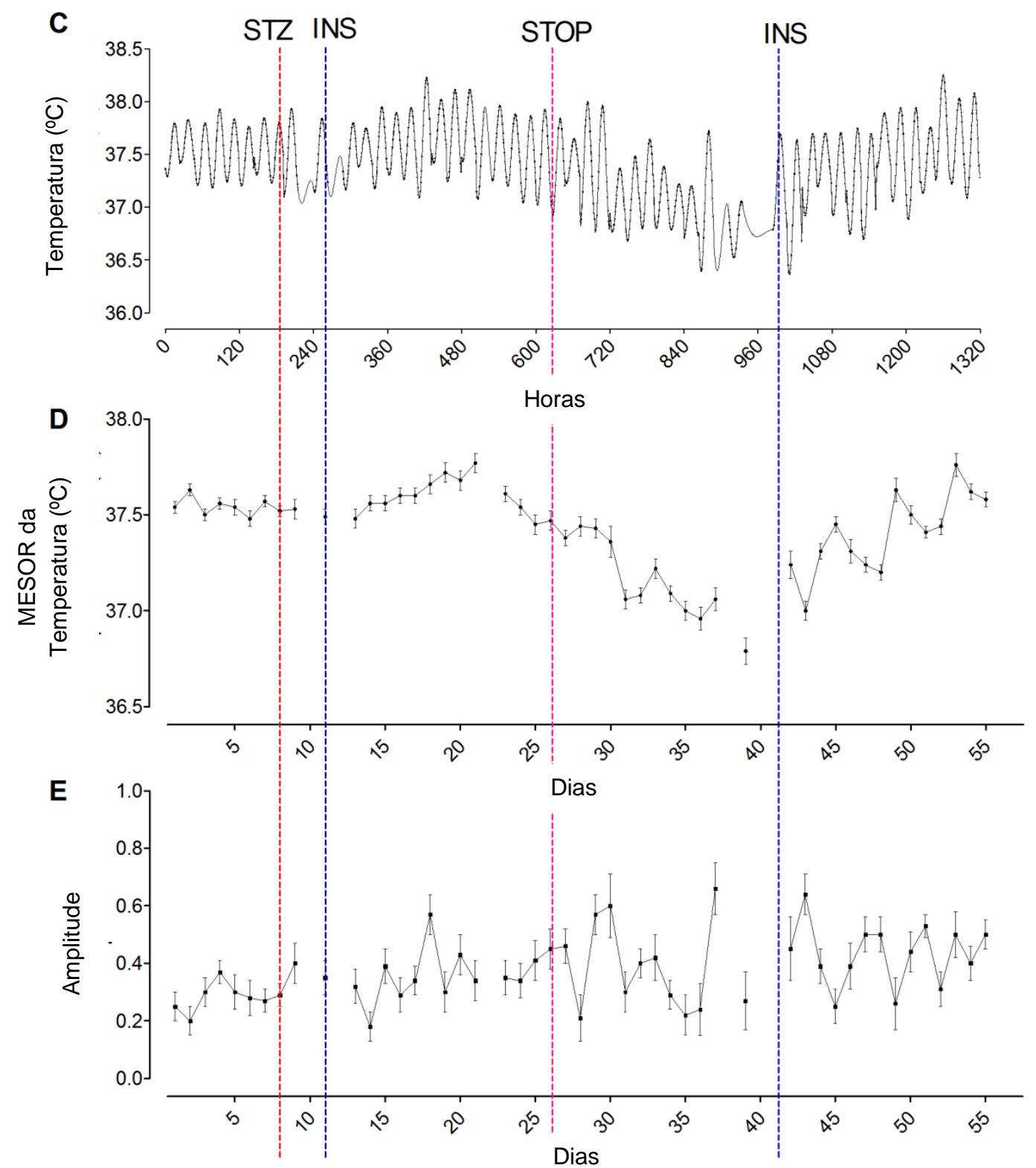

(A) Termograma representado por colorações vermelhas à amarelas indicando temperaturas maiores e gris a preto indicando temperaturas menores. Cada linha representa um dia de registro. Retângulos brancos e pretos no inferior do termograma indicam o regime de luminosidade durante os experimentos. Barra lateral branca superior indica o tratamento precoce e a inferior indica o segundo tratamento, a barra preta superior indica período diabético e a barra preta inferior indica o período em que o tratamento foi interrompido. (B) Mapa de fases da temperatura corporal. Para gerar o mapa, as acrofases resultantes da análise pelo Cosinor (média de 1 dia) foram plotadas segundo 0 ZT correspondente para gerar o padrão diário (média \pm EPM). A fase escura (ZT12 a ZT24) esta representada pela área cinza do gráfico. As setas e barras laterais indicam o início dos períodos diabético (vermelha), tratados (azul) e sem tratamento (rosa). Os painéis centrais mostram os periodogramas correspondentes a cada período (controle, painel superior; tratamento precoce, segundo painel, tratamento interrompido, terceiro painel; segundo tratamento, painel inferior), indicando o período predominante, quando estiver por cima do limiar (1440 $\min =24 \mathrm{~h}$ ). (C) Curva ajustada a cada $24 \mathrm{~h}$ pelo Cosinor e plotada dia a dia durante o experimento. (D) MESOR resultado das análises pelo Cosinor dia a dia da temperatura. (E) Amplitude resultado das análises pelo Cosinor dia a dia da temperatura. Para todos os parâmetros rítmicos (MESOR, amplitude, acrofase e curva ajustada) somente foram considerados os dias que apresentaram oscilações de $24 \mathrm{~h}$ na análise de ANOVA unifatorial. 
Figura 18 - Perfil diário do ritmo de atividade motora de um animal representativo do grupo diabético tratado precocemente com insulina

A

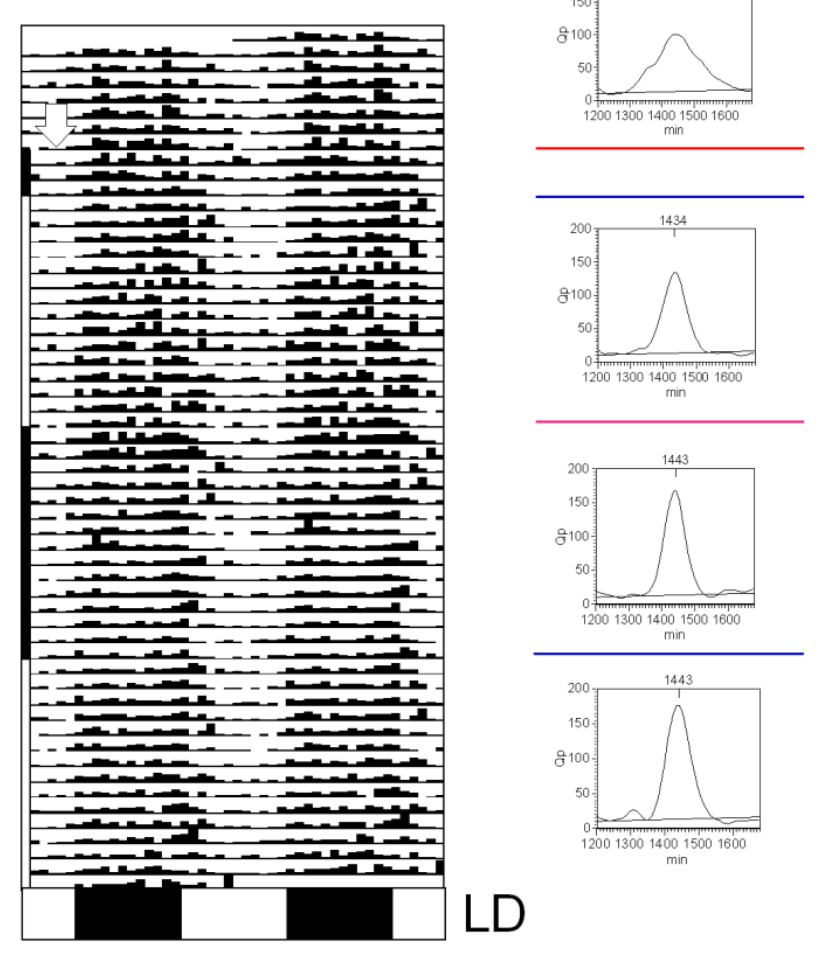

B

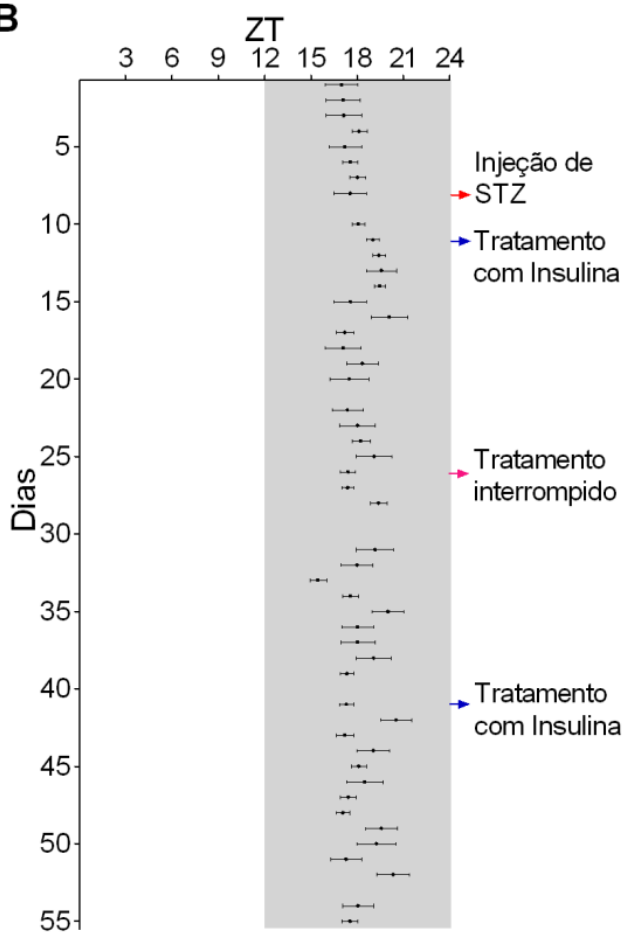




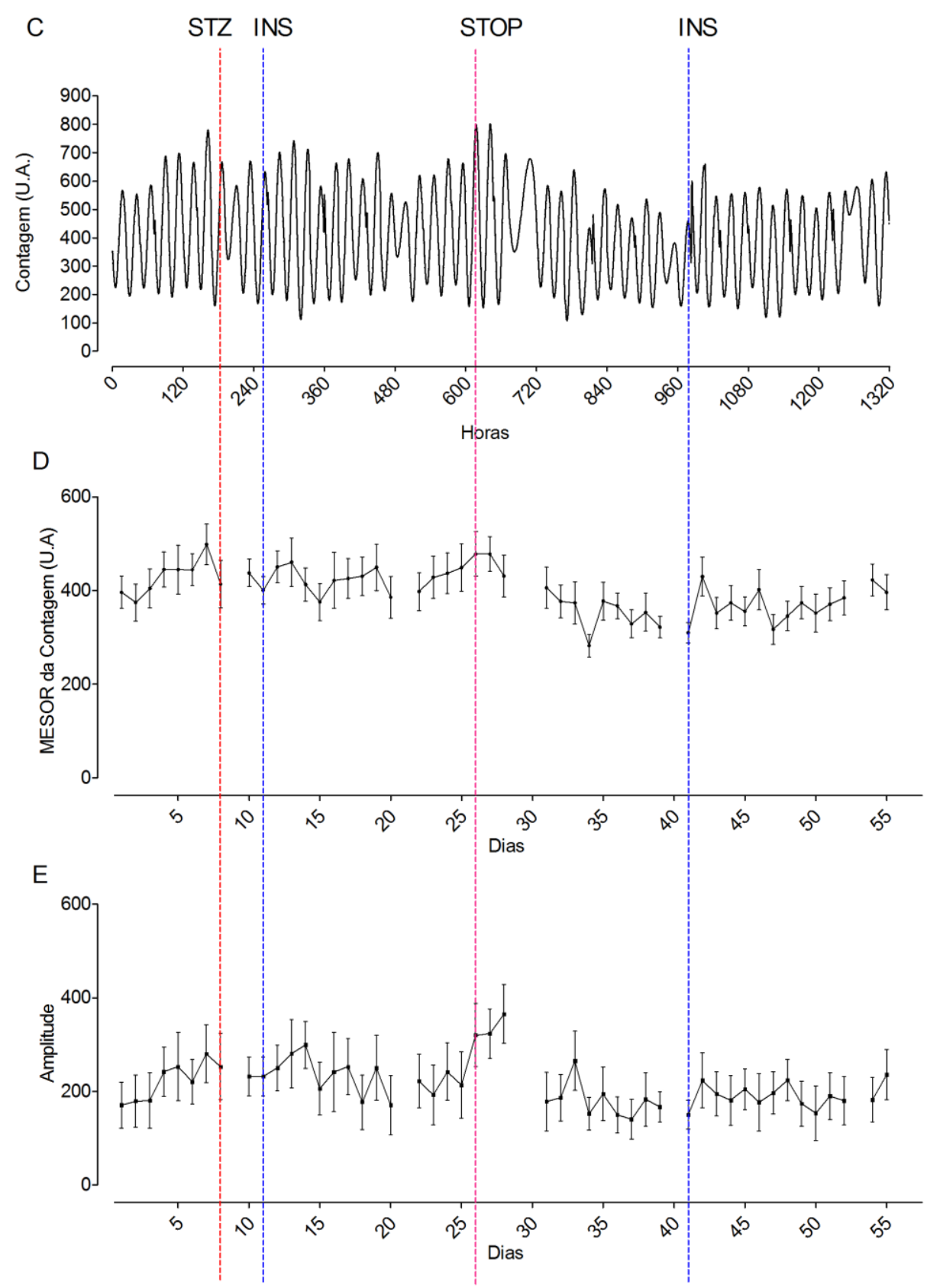

(A) Actograma representado por barras indicando diferentes níveis de atividade obtida por somatória a cada 1 hora. Cada linha representa um dia de registro. Retângulos brancos e pretos no inferior do termograma indicam o regime de luminosidade durante os experimentos. Barra lateral branca superior indica o tratamento precoce e a inferior indica o segundo tratamento, a barra preta superior indica período diabético e a barra preta inferior indica o período sem tratamento (B) Mapa de fases da atividade motora. Para gerar o mapa, as acrofases resultantes da análise pelo Cosinor (média de 1 dia) foram plotadas segundo o ZT correspondente para gerar o padrão diário (média \pm EPM). A fase escura (ZT12 a ZT24) esta representada pela área cinza do gráfico. As setas e barras laterais indicam o início dos períodos diabético (vermelha), tratados (azul) e sem tratamento (rosa). Os painéis centrais mostram os periodogramas correspondentes a cada período (controle, painel superior; tratamento precoce, segundo painel, diabético sem tratamento, terceiro painel; segundo tratamento, painel inferior), indicando o período predominante, quando estiver por cima do limiar (1440 $\mathrm{min}=24$ h). (C) Curva ajustada a cada $24 \mathrm{~h}$ pelo Cosinor e plotada dia a dia durante o experimento. (D) MESOR resultado das análises pelo Cosinor dia a dia da atividade. (E) Amplitude resultado das análises pelo Cosinor dia a dia da atividade. Para todos os parâmetros rítmicos (MESOR, amplitude, acrofase e curva ajustada) somente foram considerados os dias que apresentaram oscilações de $24 \mathrm{~h}$ na análise de ANOVA unifatorial. 
Figura 19 - Media da temperatura corporal dos períodos controle (CT), diabético (D1), tratamento precoce (DI1), tratamento interrompido (D2) e a restituição do tratamento com insulina (DI2) do animal representado na figura 17

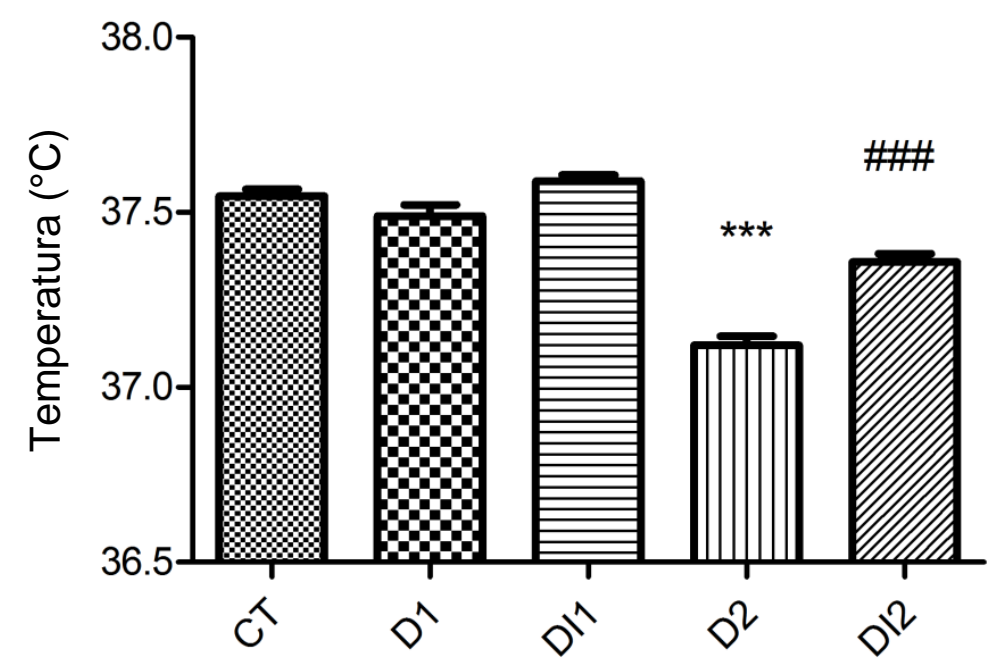

ANOVA unifatorial seguida de Bonferroni com $p<0,0001$ para o fator tratamento. ${ }^{* \star \star} p<0.001$ vs todos os grupos, ${ }^{\# \#} p<0,001$ vs todos os grupos. Média \pm EPM.

Figura 20 - Média da atividade motora dos períodos controle (CT), diabético (D1), primeiro tratamento (DI1), tratamento interrompido (D2) e a restituição do tratamento com insulina (DI2) do animal representado na figura 18

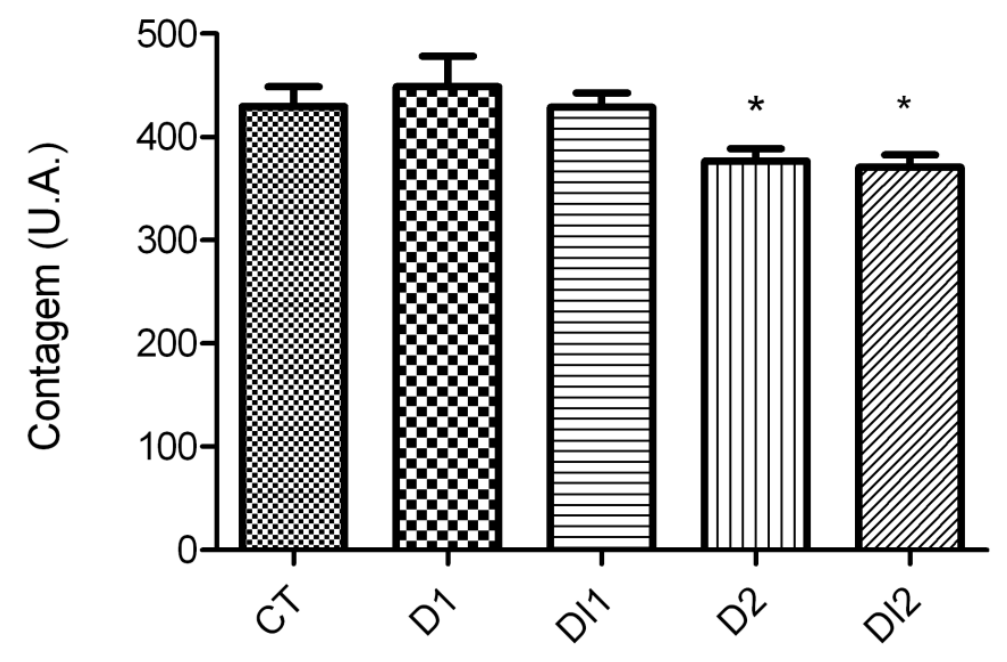

ANOVA unifatorial seguida de Bonferroni com $p<0,0001$ para o fator tratamento. * $p<0.05$ vs controle, diabético e primeiro tratamento. Média \pm EPM. 


\subsection{Suplementação precoce com melatonina}

4.7.1 Perfis diários dos ritmos de temperatura corporal e de atividade motora

Outro grupo de animais diabéticos foi suplementado com melatonina depois de três dias de diabetes. A análise de periodograma mostrou que no conjunto temporal de 15 dias o período de $24 \mathrm{~h}$ do ritmo de temperatura se manteve (Figura 21, segundo painel). A ritmicidade foi mantida pela suplementação com melatonina, como observado no termograma e na curva ajustada (Figura $21 \mathrm{~A}$ e C). O mapa de acrofases apresentou poucos dias sem ritmo de $24 \mathrm{~h}$ ou com adiantamento de fase, porém a média das acrofases não resultou alterada (Figura $21 \mathrm{~B}$ e Tabela 3). $\mathrm{O}$ mesmo foi observado para a amplitude (Figure $21 \mathrm{E}$ e Tabela 3). O MESOR permaneceu significativamente reduzido (Figura $21 \mathrm{D}$ e Tabela 3).

A suplementação precoce não preveniu a hipotermia (Figura 23, terceira coluna).

As análises de periodograma mostraram que o período de $24 \mathrm{~h}$ da atividade motora permaneceu normal (Figura 22, segundo painel). $O$ ritmo da atividade foi mantido pela suplementação precoce, como observado no actograma e na curva ajustada (Figura $22 \mathrm{~A} \mathrm{e} \mathrm{C}$ ). O mapa de acrofases apresentou um leve atraso de fase, porém não foi significativo (Figura $22 \mathrm{~B}$ e Tabela 4). O MESOR diminuiu e a amplitude aumentou durante a suplementação, mas não resultaram estatisticamente diferentes do período controle (Figura 22 D e E, Tabela 4).

A suplementação precoce com melatonina preveniu a diminuição na média da atividade motora após três dias de diabetes (Figura 24, terceira coluna), já que não se observou uma diferença estatística contrastando com o período controle.

\subsubsection{Características metabólicas}

A suplementação precoce não preveniu a perda de peso nem a hiperglicemia (Figura $30 \mathrm{~A}$ e C) causada pelo diabetes. 
Figura 21 - Perfil diário do ritmo de temperatura corporal de um animal representativo do grupo diabético suplementado precocemente com melatonina

A

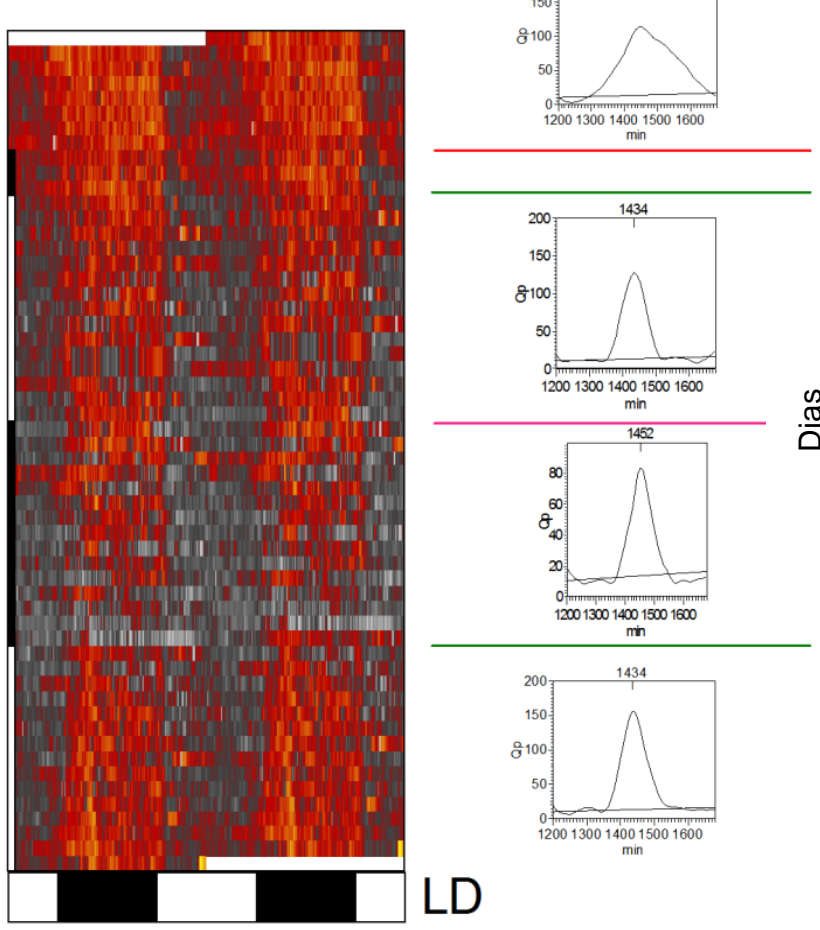

B

ZT

$\begin{array}{lllllllll}0 & 3 & 6 & 9 & 12 & 15 & 18 & 21 & 24\end{array}$

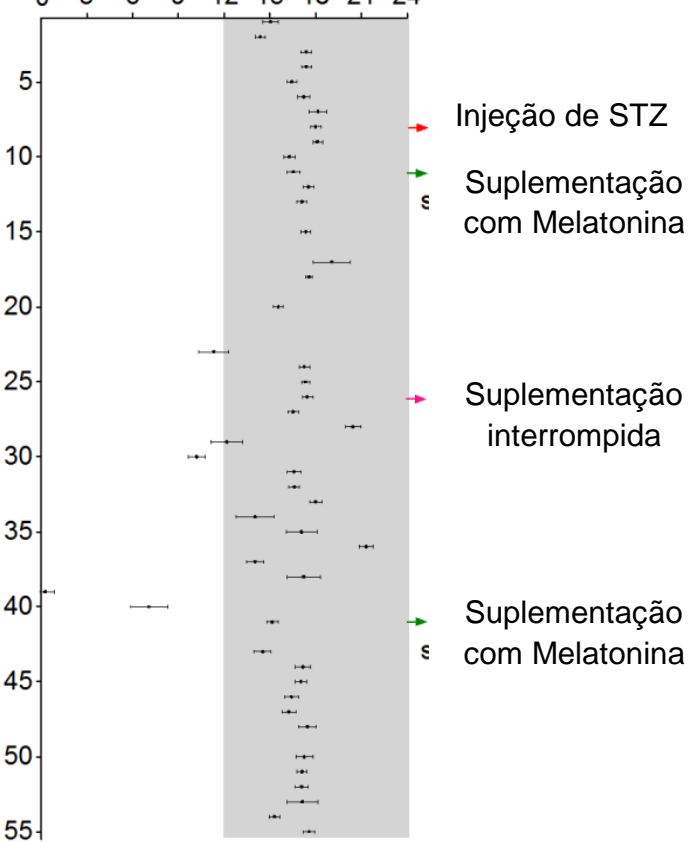




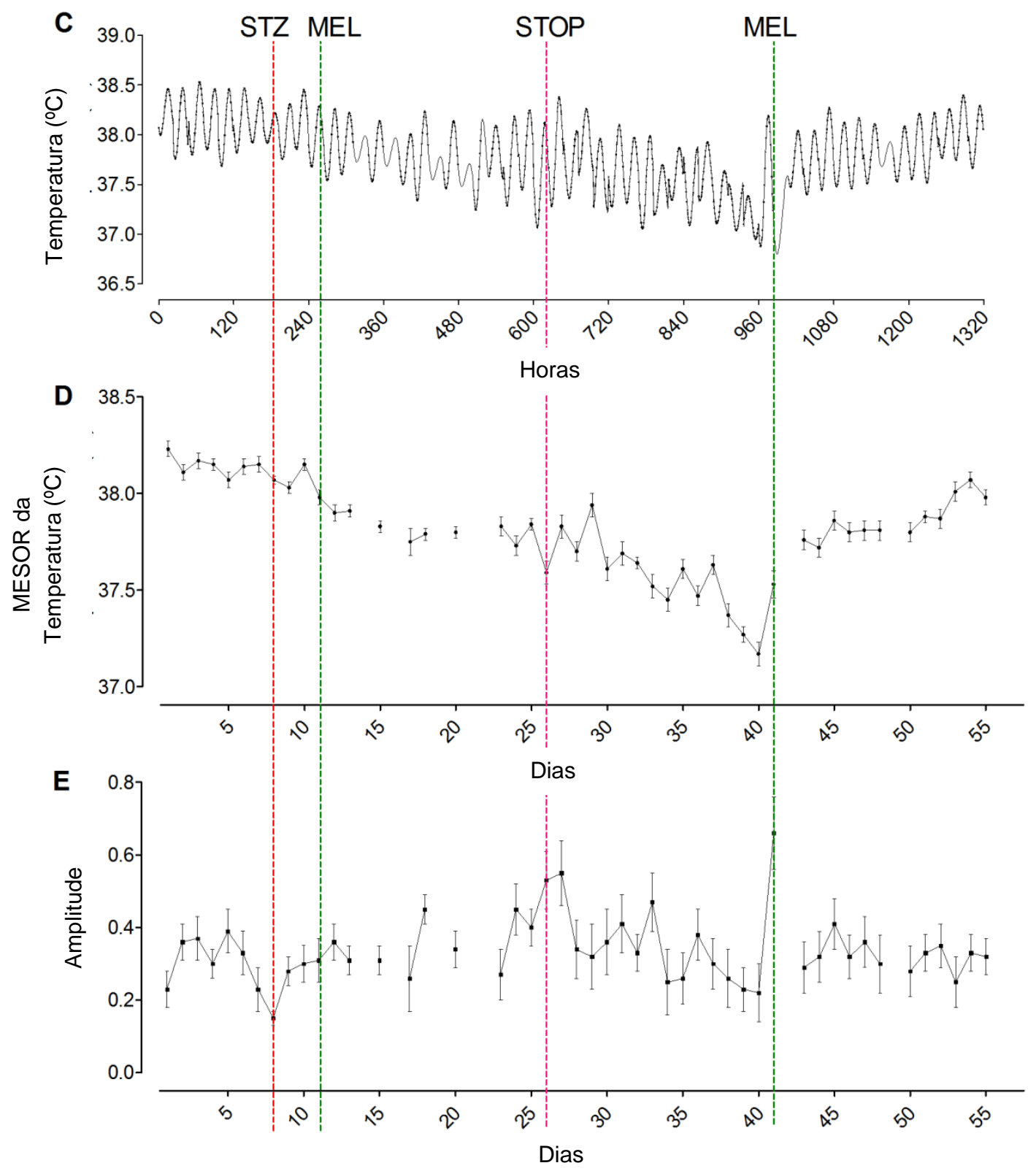

(A) Termograma representado por colorações vermelhas à amarelas indicando temperaturas maiores e gris a preto indicando temperaturas menores. Cada linha representa um dia de registro. Retângulos brancos e pretos no inferior do termograma indicam o regime de luminosidade durante os experimentos. Barra lateral branca superior indica a suplementação precoce e a inferior indica a segunda suplementação, a barra preta superior indica período diabético e a barra preta inferior indica o período sem suplementação. (B) Mapa de fases da temperatura corporal. Para gerar o mapa, as acrofases resultantes da análise pelo Cosinor (média de 1 dia) foram plotadas segundo o ZT correspondente para gerar o padrão diário (média \pm EPM). A fase escura (ZT12 a ZT24) esta representada pela área cinza do gráfico. As setas e barras laterais indicam o início dos períodos diabético (vermelha), suplementados (verde) e sem tratamento (rosa). Os painéis centrais mostram os periodogramas correspondentes a cada período (controle, painel superior; suplementação precoce, segundo painel, diabético sem suplementação, terceiro painel; segunda suplementação, painel inferior), indicando o período predominante, quando estiver por cima do limiar (1440 $\min =24 \mathrm{~h}$ ). (C) Curva ajustada a cada $24 \mathrm{~h}$ pelo Cosinor e plotada dia a dia durante o experimento. (D) MESOR resultado das análises pelo Cosinor dia a dia da temperatura. (E) Amplitude resultado das análises pelo Cosinor dia a dia da temperatura. Para todos os parâmetros rítmicos (MESOR, amplitude, acrofase e curva ajustada) somente foram considerados os dias que apresentaram oscilações de $24 \mathrm{~h}$ na análise de ANOVA unifatorial. 
Figura 22 - Perfil diário do ritmo de atividade motora de um animal representativo do grupo diabético suplementado precocemente com melatonina

A

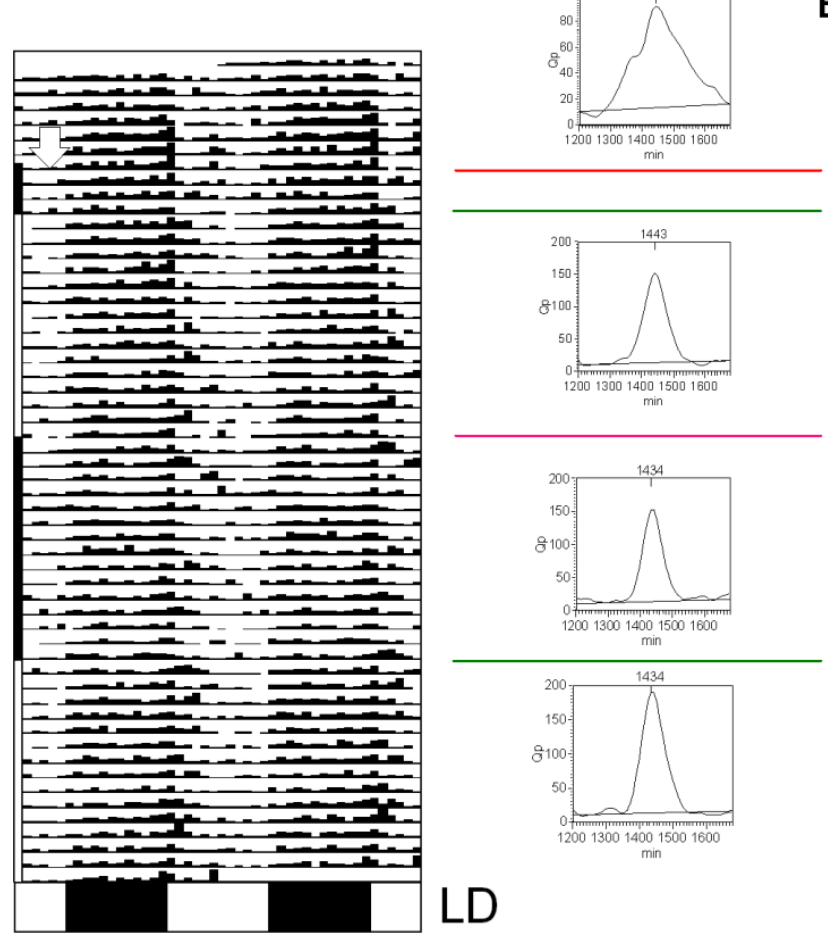

B

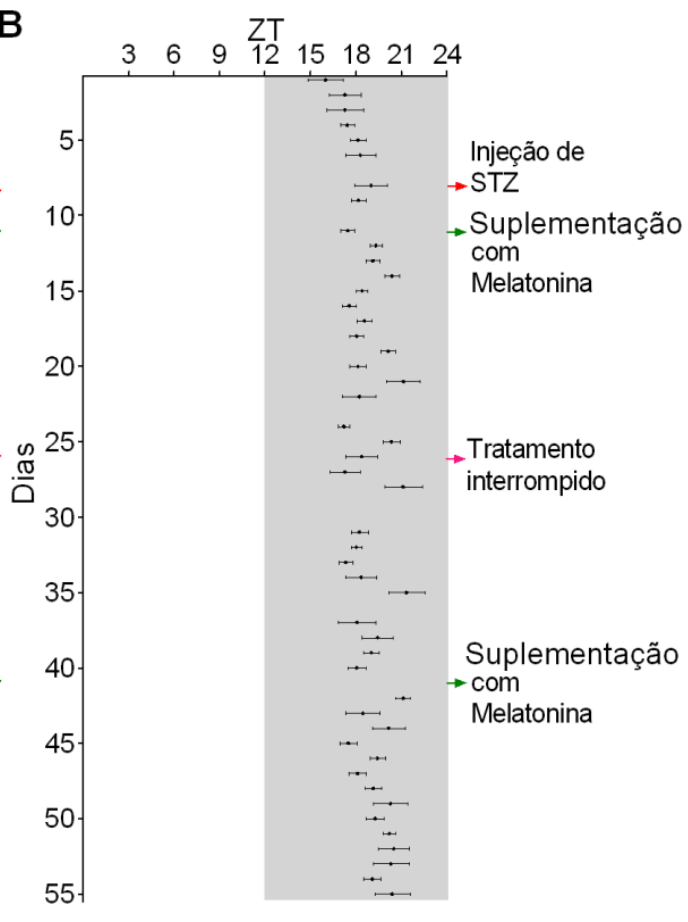




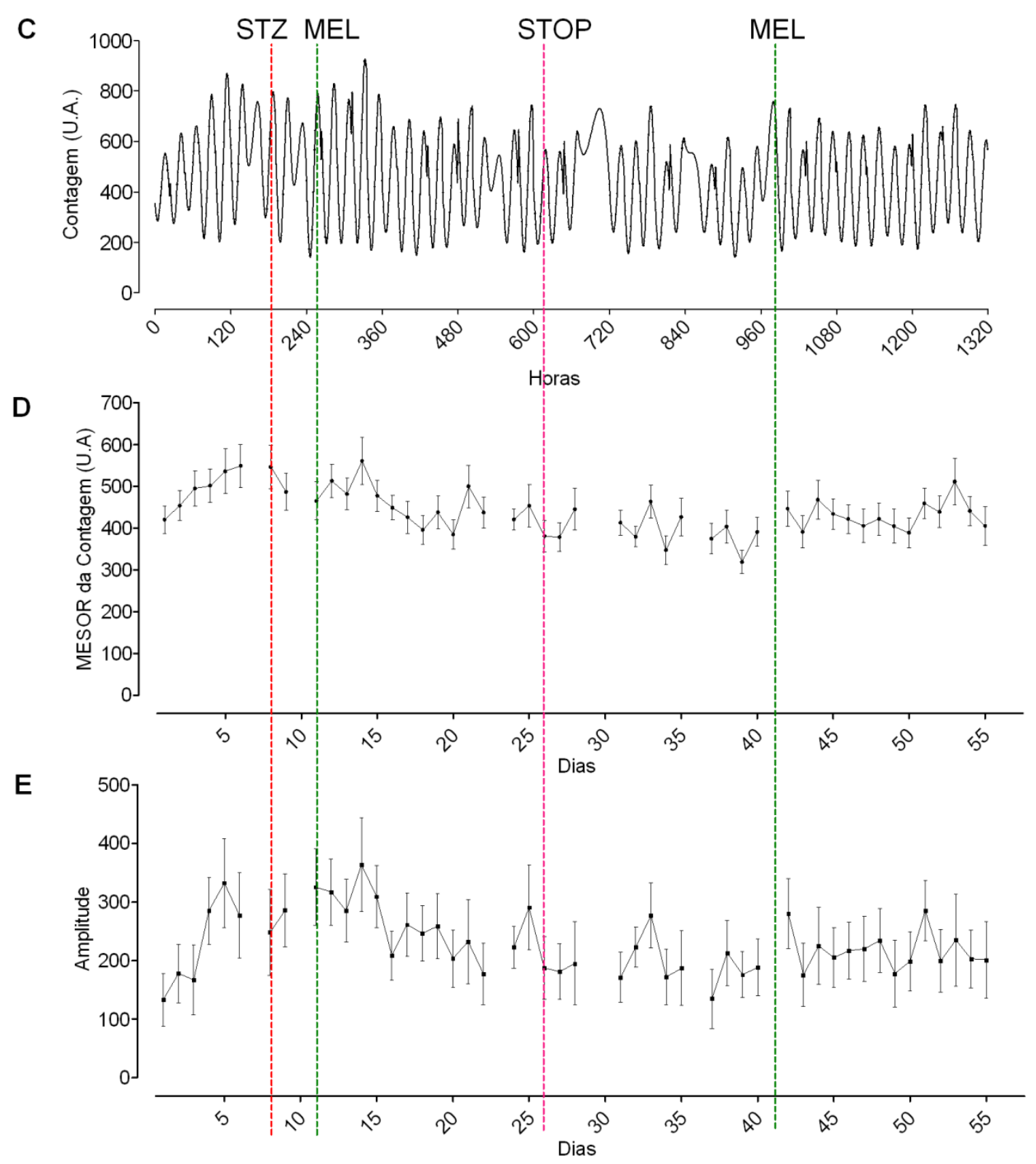

(A) Actograma representado por barras indicando diferentes níveis de atividade obtida por somatória a cada 1 hora. Cada linha representa um dia de registro. Retângulos brancos e pretos no inferior do termograma indicam o regime de luminosidade durante os experimentos. Barra lateral branca superior indica o tratamento precoce e a inferior indica a restituição da suplementação, a barra preta superior indica período diabético e a barra preta inferior indica o período sem suplementação. (B) Mapa de fases da atividade motora. Para gerar o mapa, as acrofases resultantes da análise pelo Cosinor (média de $1 \mathrm{dia}$ ) foram plotadas segundo o ZT correspondente para gerar o padrão diário (média \pm EPM). A fase escura (ZT12 a ZT24) esta representada pela área cinza do gráfico. As setas laterais indicam o início dos períodos diabético (vermelha), suplementados (verde) e sem suplementação (rosa). Os painéis centrais mostram os periodogramas correspondentes a cada período (controle, painel superior; suplementação precoce, segundo painel, diabético sem suplementação, terceiro painel; restituição da suplementação, painel inferior), indicando o período predominante, quando estiver por cima do limiar (1440 $\mathrm{min}=24 \mathrm{~h}$ ). (C) Curva ajustada a cada $24 \mathrm{~h}$ pelo Cosinor e plotada dia a dia durante o experimento. (D) MESOR resultado das análises pelo Cosinor dia a dia da atividade. (E) Amplitude resultado das análises pelo Cosinor dia a dia da atividade. Para todos os parâmetros rítmicos (MESOR, amplitude, acrofase e curva ajustada) somente foram considerados os dias que apresentaram oscilações de $24 \mathrm{~h}$ na análise de ANOVA unifatorial. 
Figura 23 - Média da temperatura dos períodos controle (CT), diabético (D1), primeira suplementação (DM1), suplementação interrompida (D2) e a restituição da suplementação com melatonina (DM2) do animal representado na figura 21

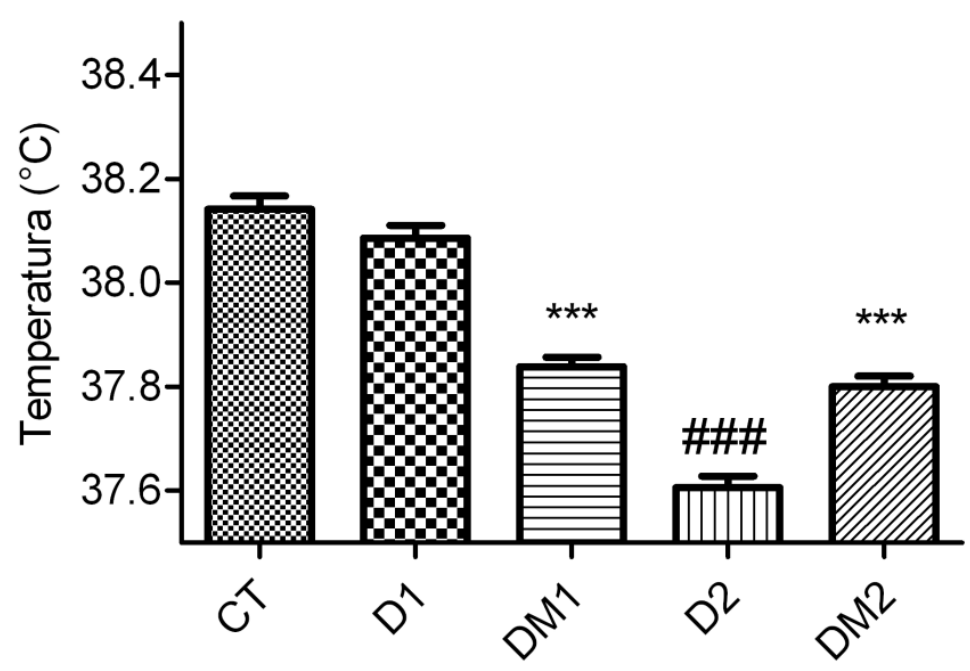

ANOVA unifatorial seguida de Bonferroni com $p<0,0001$ para o fator suplementação. ${ }^{* \star *} p<0.001$ vs controle, diabético e suplementação interrompida, ${ }^{\#} p<0,001$ vs todos os grupos. Média \pm EPM.

Figura 24 - Média da atividade dos períodos controle (CT), diabético (D1), primeira suplementação (DM1), suplementação interrompida (D2) e restituição da suplementação com melatonina (DM2) do animal representado na figura 22

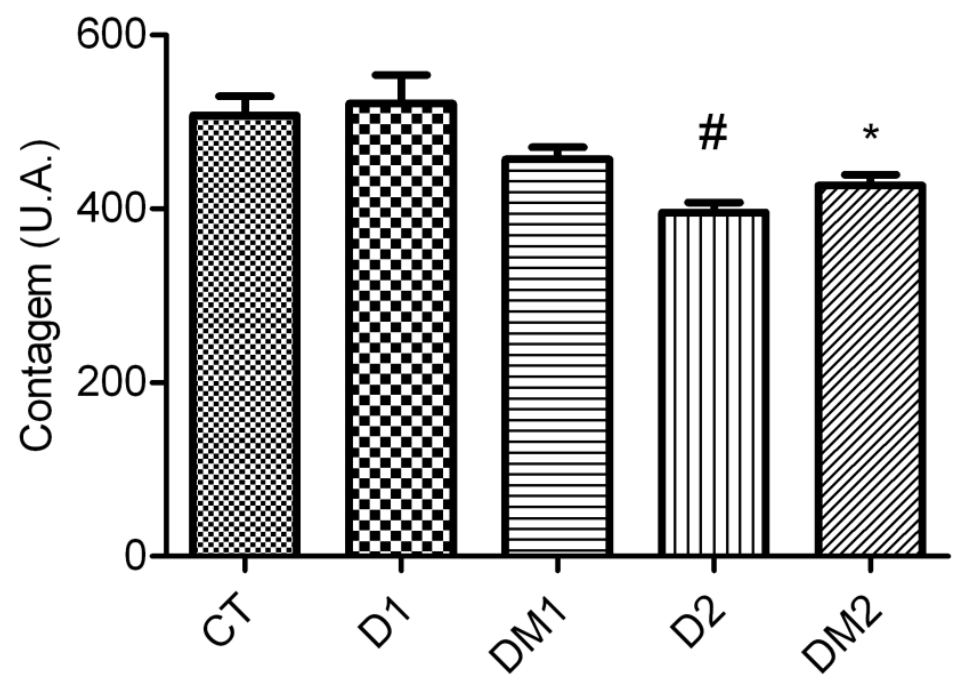

ANOVA unifatorial seguida de Bonferroni com $p<0,0001$ para o fator suplementação. ${ }^{\#} p<0.05$ vs todos os grupos, ${ }^{*} \mathrm{p}<0,05$ vs controle e diabético. Média \pm EPM. 


\subsection{Tratamento precoce com insulina e melatonina}

4.8.1 Perfis diários dos ritmos de temperatura corporal e de atividade motora

Finalmente, foi estudado o efeito do tratamento conjunto de insulina e melatonina quando administrado precocemente. O periodograma mostrou que o período de $24 \mathrm{~h}$ da temperatura foi mantido durante os 15 dias de tratamento precoce (Figura 25, segundo painel). A análise da ritmicidade pelo Cosinor mostrou que o ritmo da temperatura foi mantido com o tratamento precoce, como observado no termograma e na curva ajustada (Figura 25 A e C), o mapa de acrofases também foi mantido, porém houve um adiantamento de fase significativo (Figura $25 \mathrm{~B}$ e Tabela 3). O MESOR aumentou e a amplitude permaneceu inalterada (Figura $25 \mathrm{D}$ e E, Tabela 3).

Este tratamento precoce preveniu a hipotermia, inclusive aumentando a temperatura sobre os valores controle (Figura 27, terceira coluna).

O periodograma do ritmo de atividade motora se manteve inalterado durante 0 tratamento precoce (Figura 26, segundo painel). O tratamento preveniu os efeitos deletérios do diabetes, mantendo a ritmicidade da atividade, como observado no actograma e na curva ajustada (Figura 26 A e C). O mapa de acrofases se manteve inalterado durante o tratamento, assim como os parâmetros rítmicos, que não apresentaram diferenças significativas respeito ao período controle (Figura 26 B, D e E, Tabela 4).

O tratamento precoce impediu a queda da atividade média, e causou um aumento da mesma, porém não significativamente diferente do controle (Figura 28, terceira coluna).

\subsubsection{Características metabólicas}

Durante o tratamento precoce os animais continuaram ganhando peso e a glicemia voltou aos valores normais (Figura $31 \mathrm{~A} \mathrm{e} \mathrm{C)}$. 
Figura 25 - Perfil diário do ritmo de temperatura corporal de um animal representativo do grupo diabético tratado precocemente com insulina e melatonina

A

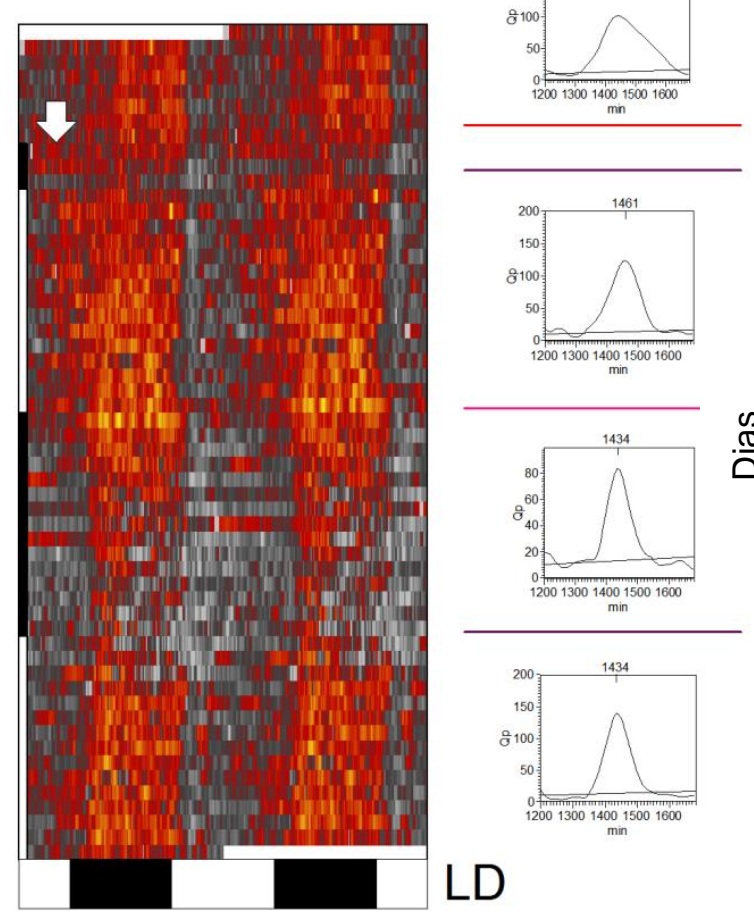

B

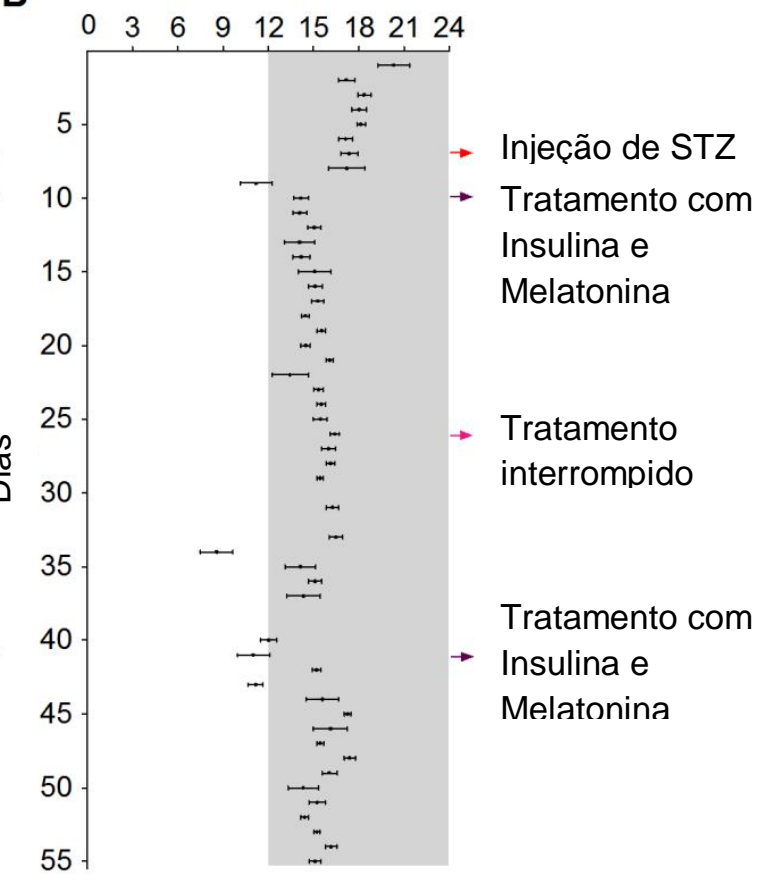




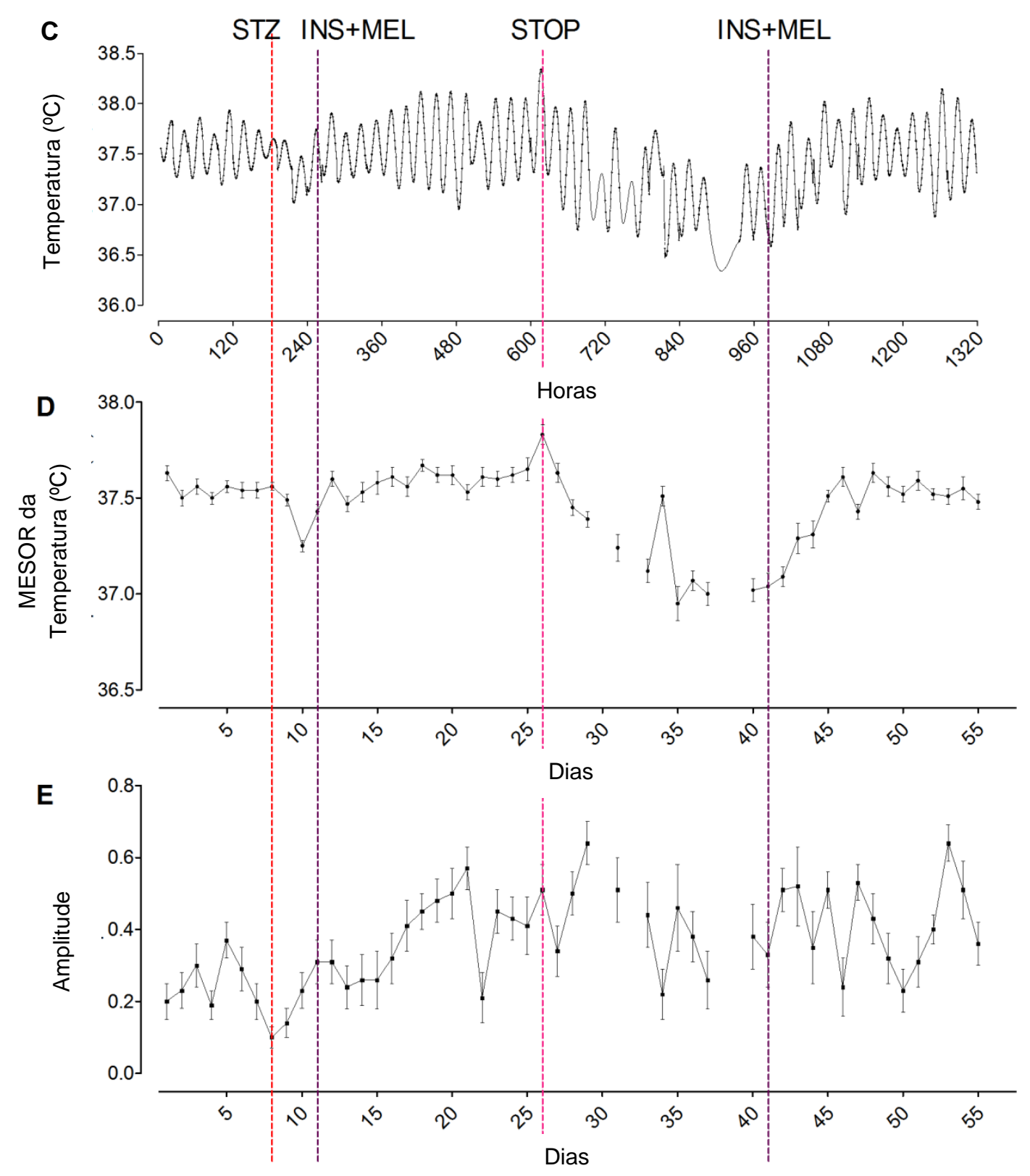

(A) Termograma representado por colorações vermelhas à amarelas indicando temperaturas maiores e gris a preto indicando temperaturas menores. Cada linha representa um dia de registro. Retângulos brancos e pretos no inferior do termograma indicam o regime de luminosidade durante os experimentos. Barra lateral branca superior indica o tratamento precoce e a inferior indica o segundo tratamento, a barra preta superior indica período diabético e a barra preta inferior indica o período sem tratamento. (B) Mapa de fases da temperatura corporal. Para gerar o mapa, as acrofases resultantes da análise pelo Cosinor (média de 1 dia) foram plotadas segundo o ZT correspondente para gerar o padrão diário (média \pm EPM). A fase escura (ZT12 a ZT24) esta representada pela área cinza do gráfico. As setas laterais indicam o início dos períodos diabético (vermelha), tratados (roxa) e sem tratamento (rosa). Os painéis centrais mostram os periodogramas correspondentes a cada período (controle, painel superior; tratamento precoce, segundo painel, diabético sem tratamento, terceiro painel; segundo tratamento, painel inferior), indicando o período predominante, quando estiver por cima do limiar (1440 $\mathrm{min}=24 \mathrm{~h}$ ). (C) Curva ajustada a cada $24 \mathrm{~h}$ pelo Cosinor e plotada dia a dia durante o experimento. (D) MESOR resultado das análises pelo Cosinor dia a dia da temperatura. (E) Amplitude resultado das análises pelo Cosinor dia a dia da temperatura. Para todos os parâmetros rítmicos (MESOR, amplitude, acrofase e curva ajustada) somente foram considerados os dias que apresentaram oscilações de 24h na análise de ANOVA unifatorial. 
Figura 26 - Perfil diário do ritmo de atividade motora de um animal representativo do grupo diabético tratado precocemente com insulina e melatonina

A

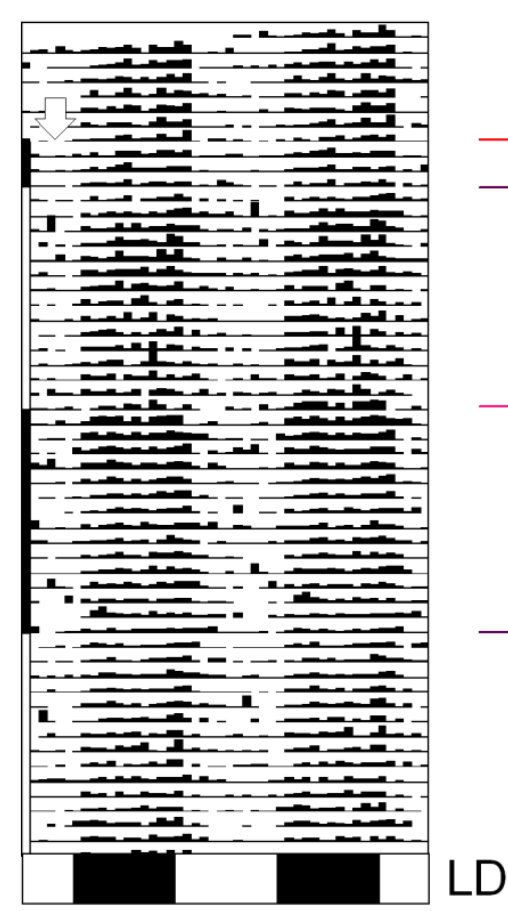

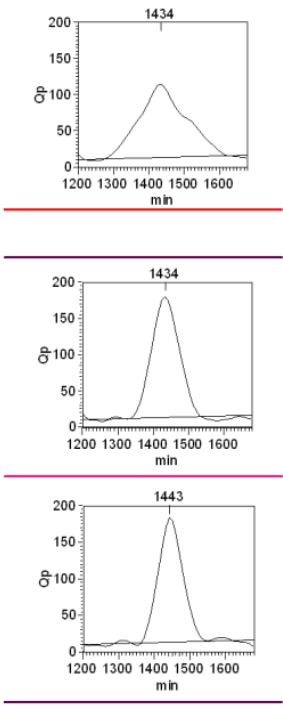

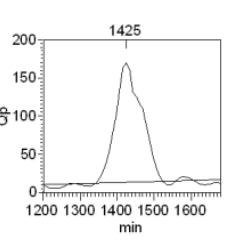

B

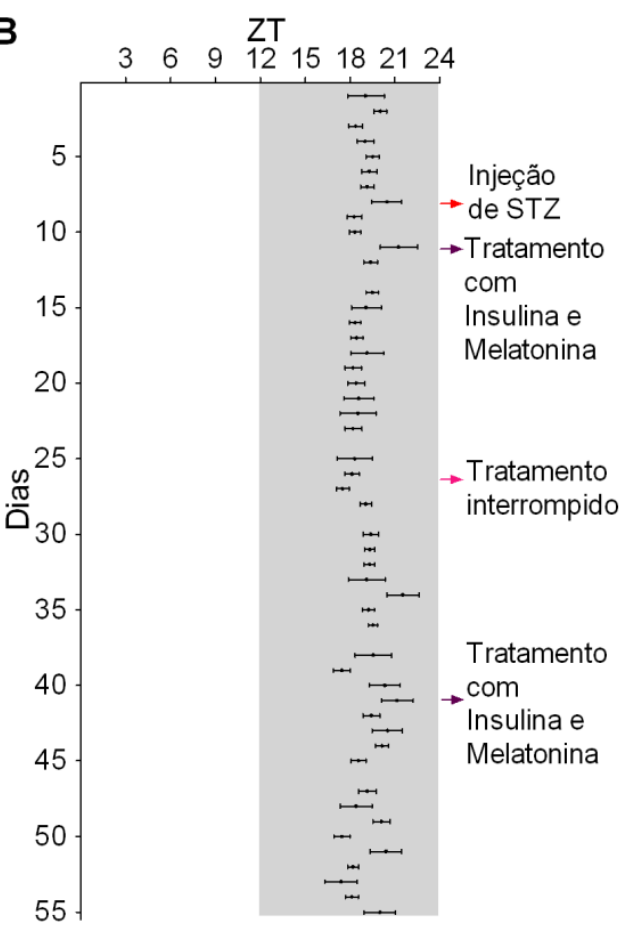


C

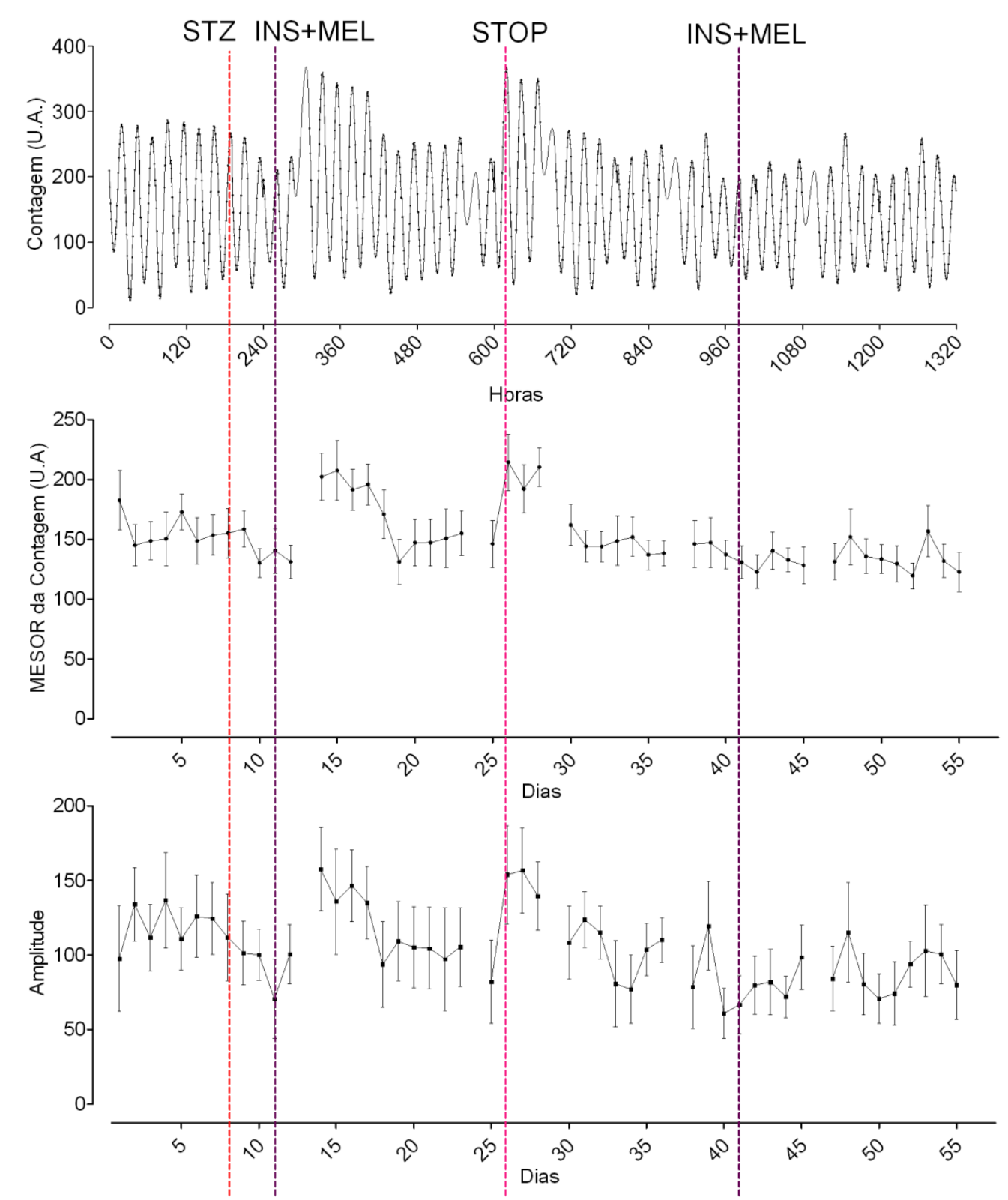

(A) Actograma representado por barras indicando diferentes níveis de atividade obtida por somatória a cada 1 hora. Cada linha representa um dia de registro. Retângulos brancos e pretos no inferior do termograma indicam o regime de luminosidade durante os experimentos. Barra lateral branca superior indica o tratamento precoce e a inferior indica o segundo tratamento, a barra preta superior indica período diabético e a barra preta inferior indica o período sem tratamento. (B) Mapa de fases da atividade motora. Para gerar o mapa, as acrofases resultantes da análise pelo Cosinor (média de 1 dia) foram plotadas segundo o ZT correspondente para gerar o padrão diário (média \pm EPM). A fase escura (ZT12 a ZT24) esta representada pela área cinza do gráfico. As setas laterais indicam o início dos períodos diabético (vermelha), tratados (roxa) e sem tratamento (rosa). Os painéis centrais mostram os periodogramas correspondentes a cada período (controle, painel superior; tratamento precoce, segundo painel, diabético sem tratamento, terceiro painel; segundo tratamento, painel inferior), indicando o período predominante, quando estiver por cima do limiar (1440 $\min =24 \mathrm{~h}$ ). (C) Curva ajustada a cada $24 \mathrm{~h}$ pelo Cosinor e plotada dia a dia durante o experimento. (D) MESOR resultado das análises pelo Cosinor dia a dia da atividade. (E) Amplitude resultado das análises pelo Cosinor dia a dia da atividade. Para todos os parâmetros rítmicos (MESOR, amplitude, acrofase e curva ajustada) somente foram considerados os dias que apresentaram oscilações de $24 \mathrm{~h}$ na análise de ANOVA unifatorial. 
Figura 27 - Média da temperatura dos períodos controle (CT), diabético (D1), primeiro tratamento (DIM1), tratamento interrompido (D2) e restituição do tratamento com insulina e melatonina (DIM2) do animal representado na figura 25

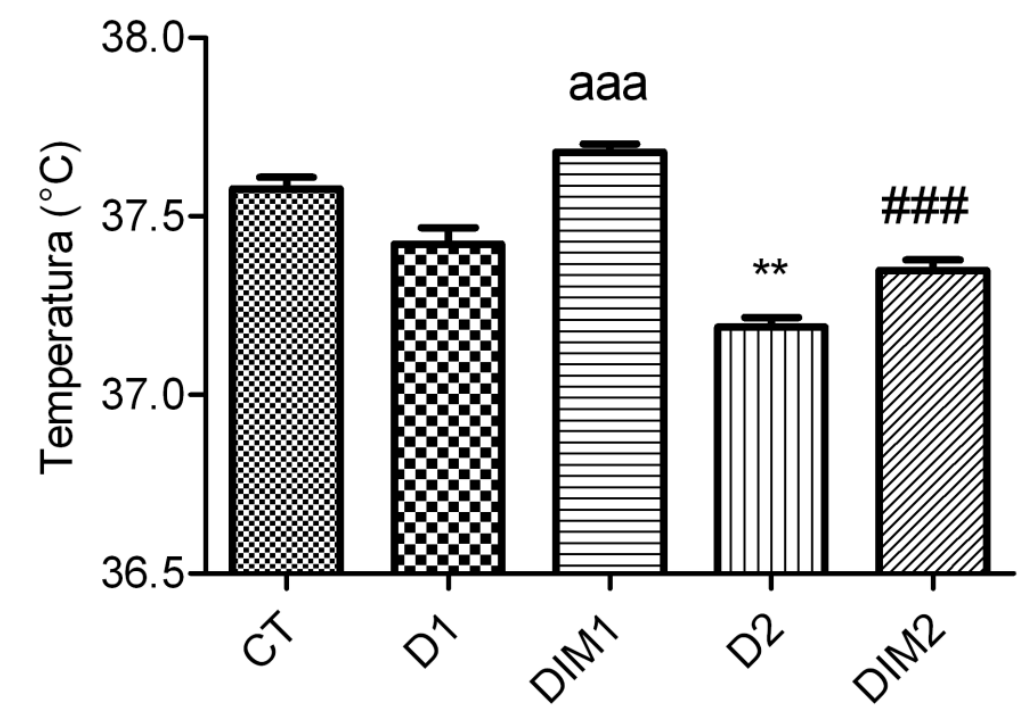

ANOVA unifatorial seguida de Bonferroni com $p<0,0001$ para o fator tratamento. ${ }^{* *} p<0.01$ vs todos os grupos, ${ }^{\# \#} p<0,001$ vs controle, primeiro tratamento e tratamento interrompido, ${ }^{\text {aaa }} p<0,001$ vs diabético. Média \pm EPM.

Figura 28 - Média da atividade dos períodos controle (CT), diabético (D1), primeiro tratamento (DIM1), tratamento interrompido (D2) e restituição do tratamento com insulina e melatonina (DIM2) do animal representado na figura 26

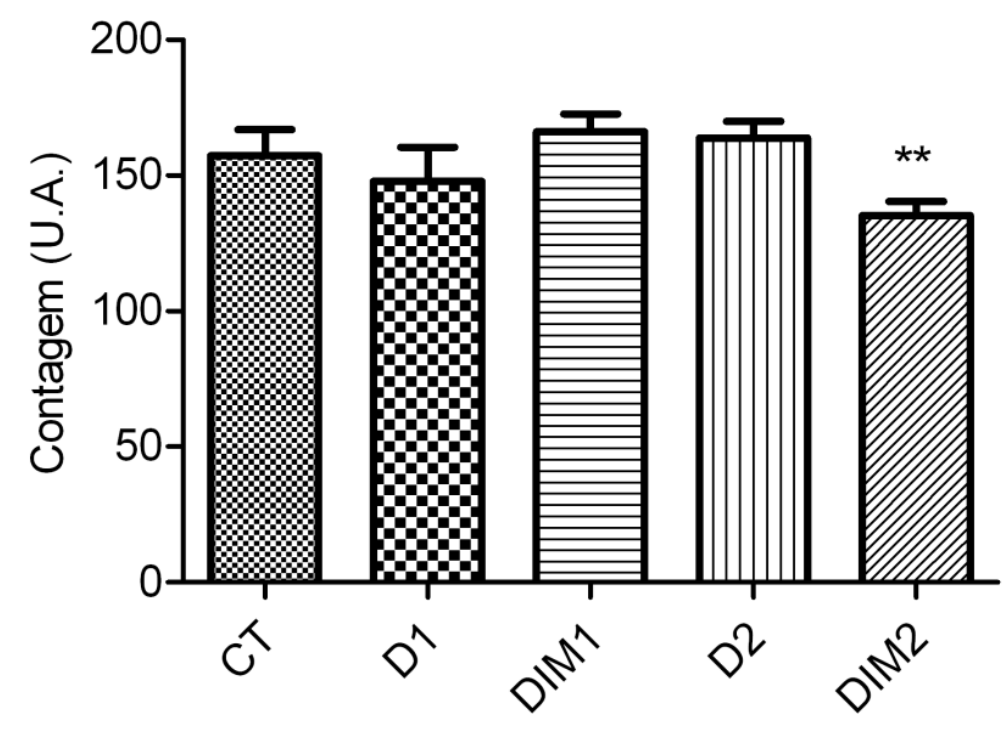

ANOVA unifatorial seguida de Bonferroni com $p<0,0001$ para o fator tratamento. ${ }^{* *} p<0,01$ vs primeiro tratamento e tratamento interrompido. Média \pm EPM. 


\subsection{Interrupção dos tratamentos precoces}

Também, estudamos se os efeitos dos diferentes tratamentos precoces eram dependentes da continuidade dos mesmos. Para avaliar isto, os tratamentos foram suspensos por 15 dias e logo restituídos por mais 15 dias (Figura 4).

As análises de periodograma mostraram que durante os 15 dias que os tratamentos foram interrompidos o período de $24 \mathrm{~h}$ da temperatura foi mantido (Figura 17, 21, 25, terceiro painel). As análises pelo método do Cosinor mostraram que durante esses 15 dias a ritmicidade da temperatura corporal não foi totalmente perdida, como se observou nos animais com 33 dias de diabetes porém, tanto o termograma quanto a curva ajustada apresentaram alterações significativas (Figura 17, 21, 25 A e C), o MESOR resultou significativamente reduzido (Figura 17, 21, 25 D e Tabela 3), mas as médias das acrofases e da amplitude não resultaram alteradas (Figura 17, 21, 25 E e Tabela 3). O mapa de acrofases apresentou alterações, mas a maioria dos dias resultou rítmica (Figura 17, 21, 25 B).

No caso da atividade, o período de $24 \mathrm{~h}$ também foi mantido durante os 15 dias sem tratamentos (Figura 18, 22, 26, terceiro painel). Houve alteração parcial dos parâmetros rítmicos, porém o diabetes não causou uma ruptura total, como foi observado no ritmo de temperatura (Figuras 18, 22 e 26 A e C). Houve uma tendência à diminuição do MESOR e da amplitude, mas não atingiu significância estatística (Tabela 4).

As médias da temperatura (Figuras 19, 23 e 27, quarta coluna) e da atividade (Figura 20, 24, e 28, quarta coluna) resultaram diminuídas significativamente. A hiperglicemia reapareceu e os animais cessaram o ganho de peso (Figura 29, 30, 31 $\mathrm{A}$ e C).

\subsection{Restituição do tratamento com insulina}

4.10.1 Perfis diários dos ritmos de temperatura corporal e de atividade motora

O período de $24 \mathrm{~h}$ da temperatura corporal foi mantido depois da restituição do tratamento com insulina, na análise da série temporal de 15 dias (Figura 17, painel inferior). A ritmicidade perdida durante a interrupção do tratamento foi 
restaurada (Figura $17 \mathrm{~A}$ e $\mathrm{C}$ ) quando o tratamento com insulina foi restituído, assim como o MESOR e as acrofases, mas a amplitude continuou aumentada (Figura 17 $B, D$ e E, Tabela 3).

A restituição do tratamento com insulina, 15 dias depois da interrupção do tratamento precoce, aumentou a média da temperatura, porém não atingiu a significância estatística (Figura 19, última coluna).

Para a atividade, assim como observado para a temperatura, a restituição do tratamento manteve o periodograma inalterado, com o período predominante de $24 \mathrm{~h}$ (Figura 18, último painel). A restituição do tratamento não conseguiu reverter a diminuição do MESOR observada no período em que os animais não receberam tratamento, que continuou significativamente reduzido, e a amplitude também permaneceu reduzida, mas sem atingir a diferença estatística (Figura 18 D e E, Tabela 4).

A média da atividade não foi revertida após a restituição do tratamento com insulina e permaneceu reduzida (Figura 20, última coluna).

\subsubsection{Características metabólicas}

Durante o tratamento com insulina, o peso continuou aumentando e a glicemia novamente retornou aos valores normais (Figura 29 A e C).

\subsection{Restituição da suplementação com melatonina}

\subsubsection{Perfis diários dos ritmos de temperatura corporal e de atividade motora}

A análise de periodograma mostrou que o período de $24 \mathrm{~h}$ da temperatura se manteve sem modificações (Figura 21, painel inferior). A ritmicidade perdida da temperatura durante a interrupção dos tratamentos foi restaurada quando a suplementação foi retomada (Figura 21 A e C). O MESOR não foi normalizado, mas voltou ao mesmo valor que tinha durante a primeira suplementação, a média da amplitude e das acrofases permaneceram inalteradas, e o mapa de acrofases foi restaurado completamente (Figura $21 \mathrm{~B}, \mathrm{D}$ e E, Tabela 3).

A restituição da suplementação, após 15 dias de ter sido interrompida, aumentou a temperatura média até o nível atingido durante a primeira 
suplementação, porém ainda menor que durante o período controle (Figura 23, última coluna).

No caso da atividade motora, o periodograma também mostrou que o período de $24 \mathrm{~h}$ foi mantido (Figura 22, painel interior). O ritmo se manteve como no período controle, como se observa no actograma e na curva ajustada (Figura $22 \mathrm{~A} \mathrm{e} \mathrm{C).} \mathrm{O}$ mapa de acrofases mostrou um atraso de fase significativo (Figura $22 \mathrm{~B}$ e Tabela 4). O MESOR e a amplitude aumentaram, mas o MESOR continuou diferente ao controle (Figura 22 D e E, Tabela 4).

A restituição da suplementação não conseguiu reverter à queda da atividade média (Figura 24, última coluna).

\subsubsection{Características metabólicas}

A segunda suplementação com melatonina não teve efeito sobre a hiperglicemia nem sobre o peso corporal, que continuou diminuído (Figura $30 \mathrm{~A}$ e C).

\subsection{Restituição do tratamento com insulina e melatonina}

\subsubsection{Perfis diários dos ritmos de temperatura corporal e de atividade motora}

A ritmicidade perdida durante a interrupção do tratamento foi restaurada (Figura $25 \mathrm{~A} \mathrm{e} \mathrm{C}$ ), e com a restituição do tratamento o MESOR aumentou, porém a amplitude e as acrofases permaneceram inalteradas, mas o mapa de acrofases foi restabelecido (Figura $25 \mathrm{~B}, \mathrm{D}$ e E, Tabela 3). O período de $24 \mathrm{~h}$ se manteve com o tratamento restituído (Figura 25, último painel).

A média da temperatura corporal aumentou significativamente em relação ao período sem tratamento, porem não atingiu os valores do período controle (Figura 27 ultima coluna).

A ritmicidade da atividade motora se manteve pode se observar no actograma e na curva ajustada (Figura 26 A e C), porém houve uma queda significativa do MESOR e da amplitude, mas o mapa de acrofases assim como a média das acrofases não resultou alterado (Figura 26 B, D, E, Tabela 4). O período de $24 \mathrm{~h}$ da atividade motora se manteve após a restituição do tratamento (Figura 26, painel inferior). 
A média da atividade motora diminuiu significativamente durante o segundo tratamento (Figura 28 ultima coluna).

\subsubsection{Características metabólicas}

Com a restituição do tratamento com insulina e melatonina os animais continuaram ganhando peso e se restabeleceu a normoglicemia (Figura $31 \mathrm{~A} \mathrm{e} \mathrm{C}$ ).

Figura 29 - Variação de peso corporal e glicemia de animais diabéticos tratados precoce ou tardiamente com insulina

A
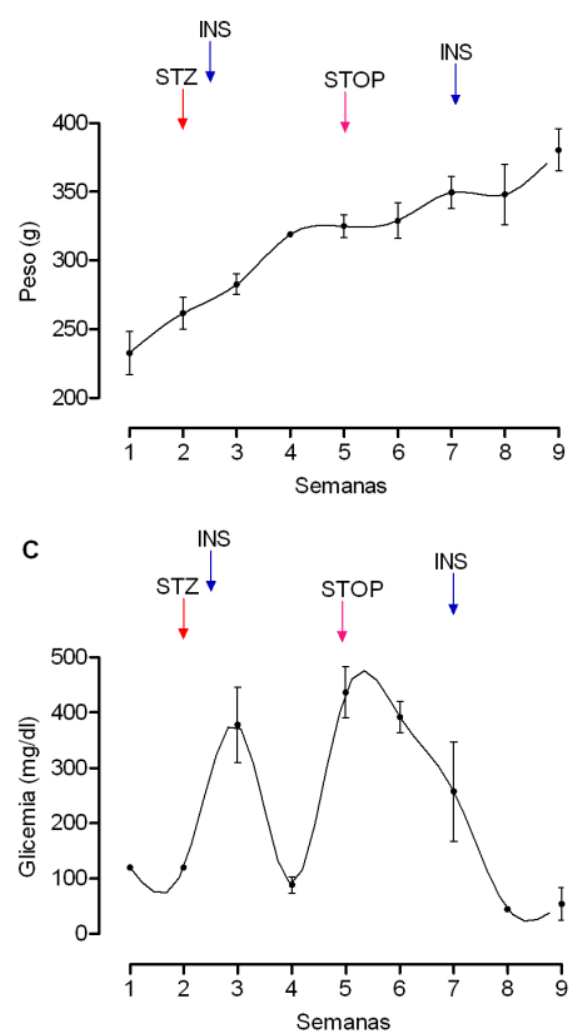

B

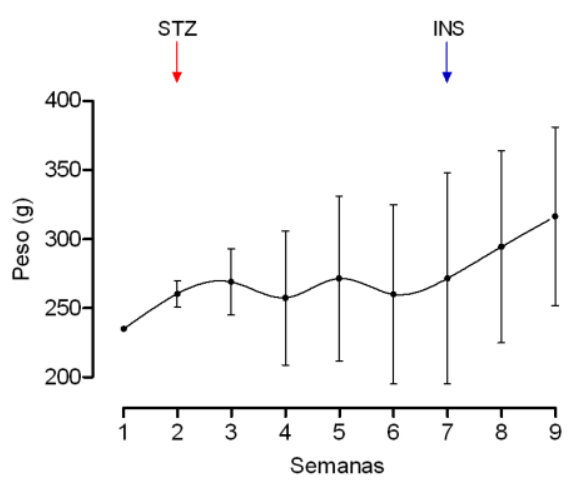

D

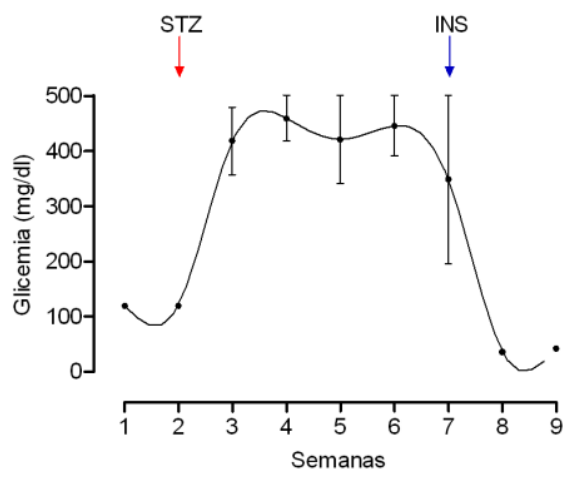

Média do peso dos animais diabéticos (STZ) tratados precoce (A) ou tardiamente (B) com insulina (INS) ao longo das 9 semanas de registro. Variação da glicemia de animais diabéticos tratados precoce (C), ou tardiamente (D) com insulina. Os animais com tratamento precoce tiveram seus tratamentos interrompidos (STOP). ( $n=3 /$ grupo). Média \pm EPM. 
Figura 30 - Variação de peso corporal e glicemia de animais diabéticos suplementados precoce ou tardiamente com melatonina

A

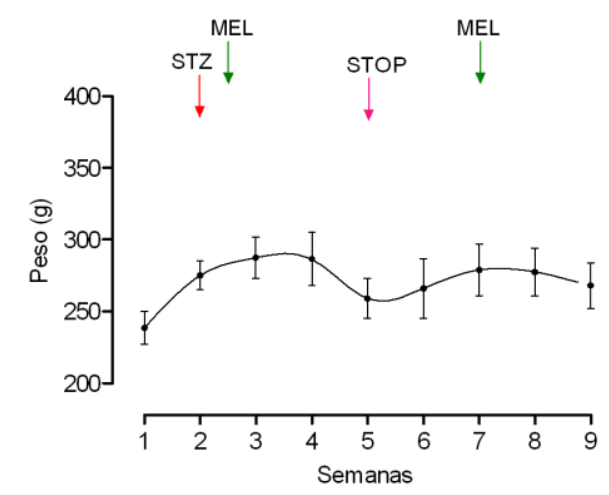

C

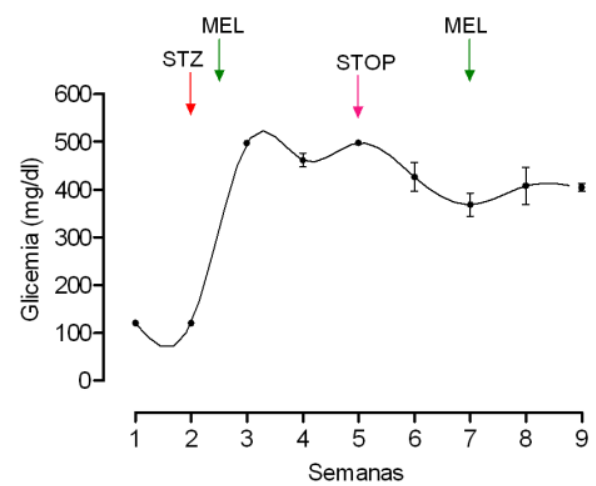

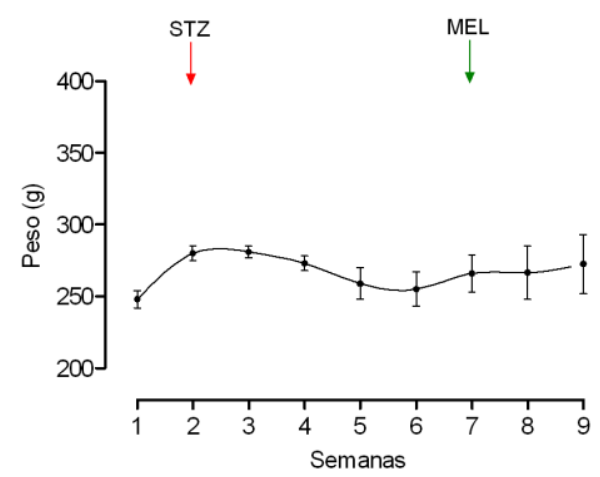

D

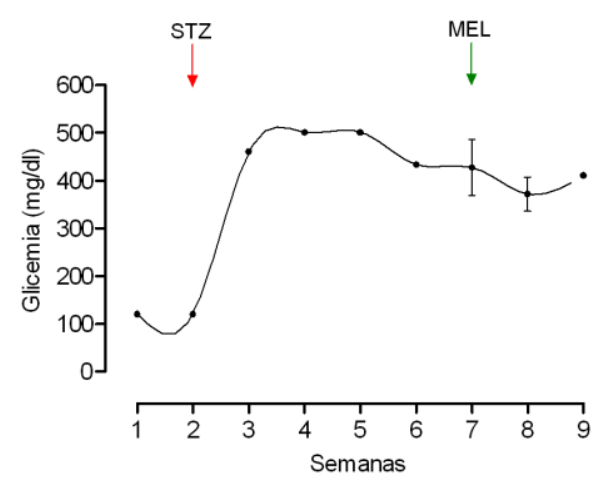

Média do peso dos animais diabéticos (STZ) suplementados precoce (A) ou tardiamente (B) com melatonina (MEL) ao longo das 9 semanas de registro. Variação da glicemia de animais diabéticos suplementados precoce (C), ou tardiamente (D) com melatonina. Os animais com tratamento precoce tiveram seus tratamentos interrompidos (STOP). ( $n=3 /$ grupo). Média \pm EPM. 
Figura 31 - Variação de peso corporal e glicemia de animais diabéticos tratados precoce ou tardiamente com insulina e melatonina

A

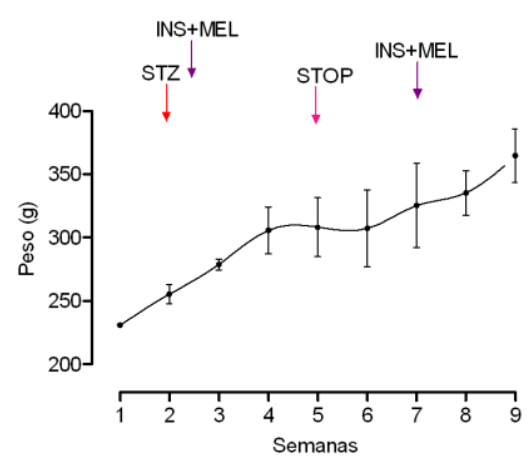

c

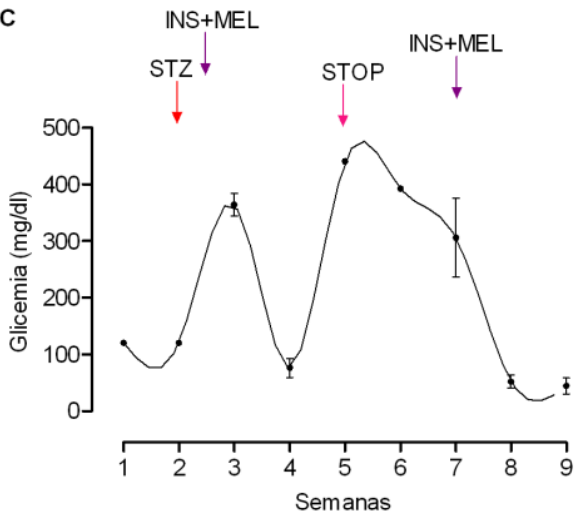

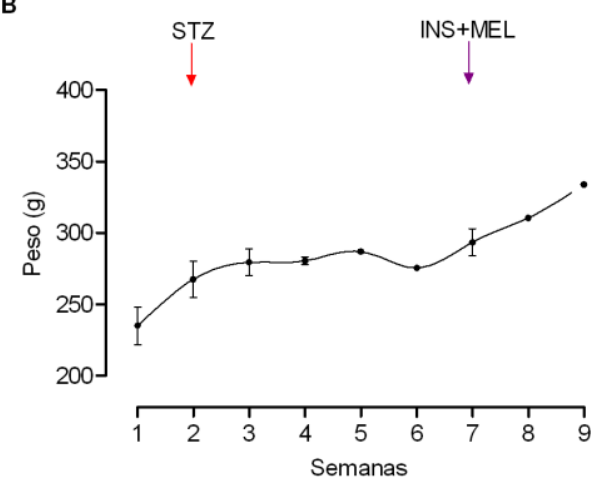

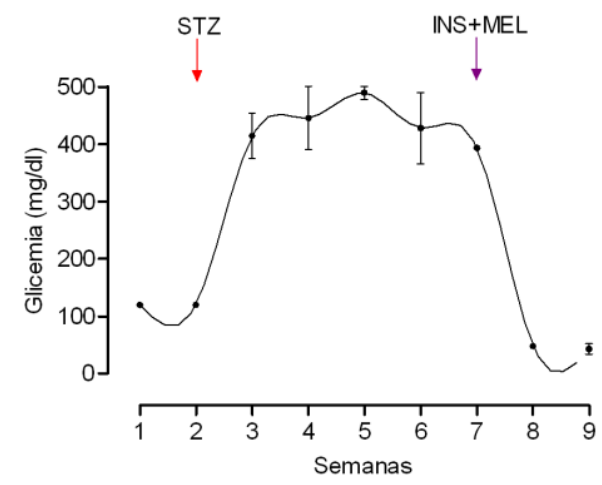

Média do peso dos animais diabéticos (STZ) tratados precoce (A) ou tardiamente (B) com insulina e melatonina (INS+MEL) ao longo das 9 semanas de registro. Variação da glicemia de animais diabéticos tratados precoce $(C)$, ou tardiamente $(D)$ com insulina e melatonina. Os animais com tratamento precoce tiveram seus tratamentos interrompidos (STOP). ( $n=3 /$ grupo). Média \pm EPM. 
Tabela 3 - Parâmetros rítmicos da temperatura corporal nos diferentes tratamentos precoces

\begin{tabular}{|c|c|c|c|c|}
\hline & \multicolumn{4}{|c|}{ Tratamentos precoces } \\
\hline & \multicolumn{4}{|c|}{ Grupo tratado com insulina } \\
\hline & Controle & 1ro Insulina & Diabético & 2do Insulina \\
\hline MESOR & $37,55 \pm 0,01850$ & $37,59 \pm 0,02640$ & $\begin{array}{l}37,18 \pm^{* \star \star} \text { bbb } \\
0,06034^{-1}\end{array}$ & ${ }_{b}^{37,41 \pm 0,05469^{a a}}$ \\
\hline Amplitude & $0,2814 \pm 0,01969$ & $0,3546 \pm 0,0248$ & $0,3915 \pm 0,042$ & $0,4329 \pm 0,0908^{*}$ \\
\hline \multirow[t]{3}{*}{ Acrofase } & $15,46 \pm 0,4256$ & $14,31 \pm 0,2471$ & $15,18 \pm 0,6522$ & $14,27 \pm 0,4303$ \\
\hline & \multicolumn{4}{|c|}{ Grupo suplementado com melatonina } \\
\hline & Controle & 1ra Melatonina & Diabético & 2da Melatonina \\
\hline MESOR & $38,15 \pm 0,01875$ & $37,84 \pm 0,02414^{\star \star \star}$ & $\begin{array}{l}37,57 \pm \\
0,05185^{\text {** bbb }}\end{array}$ & ${ }_{\text {aaa }}^{37,84 \pm 0,03808^{* * *}}$ \\
\hline Amplitude & $0,3157 \pm 0,02467$ & $0,3460 \pm 0,02156$ & $\begin{array}{l}0,3473 \pm \\
0,02697\end{array}$ & $0,3477 \pm 0,02822$ \\
\hline \multirow[t]{3}{*}{ Acrofase } & $16,57 \pm 0,5227$ & $16,66 \pm 0,6569$ & $14,60 \pm 1,400$ & $16,57 \pm 0,2733$ \\
\hline & \multicolumn{4}{|c|}{ Grupo tratado com insulina + melatonina } \\
\hline & Controle & $\begin{array}{l}\text { 1ro Insulina + } \\
\text { Melatonina }\end{array}$ & Diabético & $\begin{array}{l}\text { 2do Insulina + } \\
\text { Melatonina }\end{array}$ \\
\hline MESOR & $37,55 \pm 0,01672$ & $37,58 \pm 0,01696$ & $\begin{array}{l}37,29 \pm \\
0,08757^{\mathrm{bb}}\end{array}$ & $37,44 \pm 0,04681$ \\
\hline Amplitude & $0,2543 \pm 0,02553$ & $0,3740 \pm 0,02801$ & $\begin{array}{l}0,4218 \pm \\
0,03670^{*}\end{array}$ & $0,4127 \pm 0,03099^{*}$ \\
\hline Acrofase & $18,08 \pm 0,4162$ & $14,89 \pm 0,1850^{*}$ & $14,63 \pm 0,7259^{* x x}$ & $15,06 \pm 0,4708^{\star *}$ \\
\hline
\end{tabular}

ANOVA unifatorial seguido de Bonferroni para cada tratamento (insulina, melatonina e insulina + melatonina). $p<0,05$ para o fator tratamento. ${ }^{* * *} p<0,001,{ }^{* *} p<0,01,{ }^{*} p<0,05$ vs controle, ${ }^{\text {aaa }} p<$ $0,001,{ }^{\text {aa }} p<0,01$ vs diabético, ${ }^{\mathrm{bb}} p<0,01,{ }^{\mathrm{b}} p<0,05$ vs 1 ro tratamento. Média $\pm \mathrm{EPM}$. 
Tabela 4 - Parâmetros rítmicos da atividade motora nos diferentes tratamentos precoces

\begin{tabular}{|c|c|c|c|c|}
\hline & \multicolumn{4}{|c|}{ Tratamentos Precoces } \\
\hline & \multicolumn{4}{|c|}{ Grupo tratado com insulina } \\
\hline & Controle & 1ra Insulina & Diabético & 2da Insulina \\
\hline MESOR & $429,8 \pm 15,63$ & $423,3 \pm 6,920$ & $381,3 \pm 17,20$ & $370,5 \pm 9,423^{\times b}$ \\
\hline Amplitude & $218,2 \pm 16,08$ & $230,8 \pm 9.846$ & $218,9 \pm 22,63$ & $190,6 \pm 6,747$ \\
\hline \multirow[t]{3}{*}{ Acrofase } & $17,46 \pm 0,1777$ & $18,44 \pm 0,2694$ & $18,08 \pm 0,3496$ & $18,38 \pm 0,3168$ \\
\hline & \multicolumn{4}{|c|}{ Grupo suplementado com melatonina } \\
\hline & Controle & 1ra Mel & Diabético & 2da Melatonina \\
\hline MESOR & $492,8 \pm 19,95$ & $457,6 \pm 12,59$ & $393,7 \pm 11,62^{\times \times x} b b$ & $431,4 \pm 9,013^{*}$ \\
\hline Amplitude & $228,7 \pm 32,55$ & $264,3 \pm 14,23$ & $192,1 \pm 9,983^{b b}$ & $218,4 \pm 8,724$ \\
\hline \multirow[t]{3}{*}{ Acrofase } & $17,42 \pm 0,3367$ & $18,87 \pm 0,3315$ & $18,73 \pm 0,3789$ & $19,58 \pm 0,2764^{* *}$ \\
\hline & \multicolumn{4}{|c|}{ Grupo tratado com insulina + melatonina } \\
\hline & Controle & $\begin{array}{l}\text { 1ra Insulina + } \\
\text { Melatonina }\end{array}$ & Diabético & $\begin{array}{l}\text { 2da Insulina + } \\
\text { Melatonina }\end{array}$ \\
\hline MESOR & $157,3 \pm 5,452$ & $162,8 \pm 7,599$ & $159,4 \pm 7,630$ & $\begin{array}{l}133,3 \pm 2,799^{b b} \\
a\end{array}$ \\
\hline Amplitude & $120,2 \pm 5,297$ & $111,1 \pm 7,069$ & $109,9 \pm 8,270$ & $85,83 \pm 3,804^{* b}$ \\
\hline Acrofase & $19,21 \pm 0,1896$ & $18,88 \pm 0,2337$ & $19,19 \pm 0,3015$ & $19,22 \pm 0,3223$ \\
\hline
\end{tabular}

ANOVA unifatorial seguido de Bonferroni para cada tratamento (insulina, melatonina e insulina + melatonina). $p<0,05$ para o fator tratamento. ${ }^{* \star} p<0,001,{ }^{* \star} p<0,01,{ }^{\star} p<0,05$ vs controle, ${ }^{\text {aaa }} p<$ $0,001,{ }^{\mathrm{a}} p<0,05$ vs diabético, ${ }^{\mathrm{bb}} p<0,01,{ }^{\mathrm{b}} p<0,05$ vs 1 ro tratamento. Média $\pm \mathrm{EPM}$. 


\section{DISCUSSÃO}

A relação entre os ritmos de atividade locomotora e de temperatura foram discutidos em vários estudos e em diversas espécies. Em humanos, foi observado que o ritmo de temperatura possui um adiantamento de fase em relação ao ritmo de atividade (Wever, 1980) e ocasionalmente esses dois ritmos podem sofrer desacoplamento, como por exemplo, em indivíduos com tendências neuróticas mantidos em livre curso (sem "pistas" ambientais) onde foi demonstrada uma dessincronização interna desses pacientes em relação aos indivíduos controles, já que a instabilidade emocional estaria relacionada com distúrbios temporais e comportamentais; ou por existir uma multiplicidade de osciladores no organismo (Aschoff et al., 1967; Lund, 1974). Por outro lado, estudos em outras espécies de mamíferos não observaram esse fenômeno, tanto em espécies diurnas quanto noturnas, (Refinetti et al., 1997, 1999), sugerindo que nesses animais os ritmos de atividade locomotora e de temperatura estão fortemente acoplados e provavelmente sejam controlados por um único marca-passo circadiano (Refinetti et al., 1992, 1999).

No presente trabalho foi estudado o perfil diário dos ritmos de temperatura e atividade motora de ratos Wistar tanto de seus períodos controle, diabético induzido por STZ como das possíveis modificações resultantes do tratamento tardio com insulina e/ou suplementação com melatonina, assim como os parâmetros rítmicos (MESOR, amplitude e acrofase). Também foi estudado o papel precoce que esses tratamentos poderiam ter nos ritmos de temperatura e atividade e se esses efeitos seriam dependentes da continuidade dos tratamentos.

Os animais apresentaram ritmos diários de temperatura e atividade motora, definidos e estruturados, com valores mais altos durante a fase escura. Esses resultados já eram esperados, pois estes animais são de hábitos noturnos e conseqüentemente todos seus parâmetros metabólicos e fisiológicos estão adaptados à fase de maior atividade.

O diabetes induzido por STZ causou ruptura do ritmo de temperatura e alteração do ritmo de atividade motora já que neste último caso não houve perda do período de $24 \mathrm{~h}$ nem dos seus parâmetros rítmicos (MESOR, amplitude e acrofase). Devido à sua robustez, o ritmo de temperatura corporal é considerado amplamente 
um "ritmo marcador" do relógio biológico (Hanneman et al., 2001). Sua complexa regulação envolve vários elementos como o hormônio tireoidiano, o tecido adiposo marrom (TAM), assim como estruturas neurais como o núcleo paraventricular (NPV) e os núcleos supraquiasmáticos (NSQ), através de mecanismos cronobiológicos, neurais, endócrinos, metabólicos e moleculares.

Existem várias evidências na literatura mostrando que o diabetes induzido por STZ causa uma diminuição significativa na temperatura corporal levando à hipotermia (Howarth et al., 2005a,b, 2006), e que o tratamento exógeno com insulina é capaz de reverter esse quadro restabelecendo a temperatura normal, mas não a atividade média, a qual permanece inalterada com respeito ao estado diabético (Howarth et al., 2006, 2011). No presente trabalho descrevemos pela primeira vez 0 perfil diário da temperatura corporal e de atividade motora de animais diabéticos, e demonstramos que o diabetes não somente causa hipotermia, como também causa a alteração dos ritmos diários de temperatura e atividade motora, de forma progressiva observada através das alterações em todos os parâmetros rítmicos (MESOR, amplitude e acrofase).

Como esperado, os animais diabéticos perderam peso e mantiveram a hiperglicemia. No presente modelo é fundamental o uso do próprio animal como controle dele mesmo, devido a cada indivíduo possuir um perfil de temperatura e atividade motora particular, com intervalos de valores diferentes entre os indivíduos. Essas variações de temperaturas e atividade seriam perdidas se os animais fossem agrupados para as análises rítmicas.

O diabetes é uma doença metabólica diretamente relacionada ao metabolismo energético e à regulação da temperatura. Por outra parte, o hipotireoidismo é uma doença associada à maioria dos modelos experimentais de diabetes (STZ e Alloxana), e também tem um papel importante na termorregulação (Katovitch et al., 1993; Rodgers et al., 1991; Rondeel et al., 1992; Schroder-Van Der Elst, Van Der Heide, 1992; Sochor et al., 1987; Sundaresan et al., 1984). Dados mais recentes na literatura mostram que a STZ causa hipotireoidismo (diminuição do conteúdo de T3 e T4, assim como aparecimento de sinais clínicos do hipotireoidismo, aumento do intervalo Q-T e diminuição da temperatura retal). Dados na literatura mostraram diminuição significativa na temperatura corporal após oito semanas de diabetes por STZ, porém duas semanas não é tempo suficiente para 
observar esse fenômeno (Zhang et al., 2002). Esses dados diferem dos obtidos no presente trabalho assim como com outros trabalhos na literatura (Howarth et al 2005a, 2006), onde duas semanas de diabetes é tempo suficiente para observar a diminuição da temperatura corporal. Essa discrepância nos resultados provavelmente se deve a diferenças metodológicas, dado que Zhang et al., (2002) mediram a temperatura retal somente duas vezes (duas e oito semanas após a injeção de STZ), ao invés de monitorá-la continuamente, como mostrado no presente trabalho. O diabetes diminui a temperatura média e causa ruptura do seu ritmo diário, porém, observamos que durante esse período os animais apresentaram dias onde a temperatura atingiu valores normais. Devido a este fenômeno, a temperatura retal poderia mascarar a hipotermia causada pelo diabetes, que já é observada no início da doença e, portanto o monitoramento da temperatura por telemetria resulta num método mais adequado, além de ser menos invasivo por requerer manipulações menos repetitivas no momento de registrar a temperatura do animal (Clement et al., 1980; Harkin et al., 2002).

Trabalhos anteriores mostraram uma correlação negativa entre a glicemia e 0 conteúdo de T3 e T4 livres. O tratamento com insulina preveniu todos os sinais do hipotireoidismo e restaurou o conteúdo normal de T3 e T4 livres; o tratamento com T3 normalizou a temperatura corporal, a frequência cardíaca e o intervalo Q-T, mas não teve ação sobre a hiperglicemia. Portanto esses efeitos são resultado de um hipotireoidismo secundário ao diabetes induzido por STZ (Matsen et al., 2013; Zhang et al., 2002).

Outros trabalhos demonstraram a importância do TAM na regulação da temperatura. A termogênese pelo TAM contribui com o aumento da temperatura central durante a fase escura, indicando que mudanças circadianas na termogênese pelo TAM possuem um papel importante na manutenção geral do ritmo circadiano de temperatura (Yang et al., 2011).

A melatonina também está envolvida na regulação da temperatura mediante a indução de perda de calor por vasodilatação (Krauchi et al., 1997), possuindo assim um efeito hipotérmico, provavelmente agindo a través de mecanismos serotoninérgicos (Lin et al., 2002). Outro trabalho mostrou variações no ritmo de secreção de melatonina não têm efeito no MESOR nem na amplitude da temperatura (Aguzzi et al., 2006). Dados na literatura mostram resultados 
controversos a respeito da síntese pineal de melatonina em animais diabéticos por STZ. Herichová et al. (2005) mostraram que não existem alterações no ritmo de síntese de melatonina nesses animais. Peschke et al. (2008) mostraram um aumento no conteúdo plasmático de melatonina após a injeção de STZ. Finalmente, dados do grupo (Amaral et al., submetido) mostraram, usando técnicas variadas, inclusive microdiálise pineal, uma diminuição significativa na síntese de melatonina pela glândula pineal em animais diabéticos.

Nossos dados demonstram que, o diabetes causou uma diminuição significativa na atividade média dos animais. Isso está em concordância com a literatura que mostra que quinze dias de diabetes é suficiente para diminuir significativamente a média da atividade motora (Howarth et al., 2006). Além disso, demonstramos que o diabetes provocou a desorganização do ritmo diário da atividade motora, sendo menos afetado que o ritmo da temperatura, já que a maioria dos dias permaneceu rítmica, e o período de $24 \mathrm{~h}$ não foi perdido ao final dos 33 dias de diabetes. O ritmo de atividade motora é um ritmo menos sensível aos danos provocados pelo diabetes, que também atua alterando outros mecanismos que controlam a temperatura. Os animais apresentam menos atividade, possivelmente associado ao seu estado metabólico, já que não ter a insulina reduzida pela ação da STZ, a captação de glicose muscular esta reduzida e, portanto a atividade motora dos animais se encontra diretamente afetada.

Devido a insulina e a melatonina serem hormônios importantes e ambos estarem envolvidos na regulação da temperatura, que foi o ritmo mais afetado pelo diabetes, tratamos animais diabéticos com insulina e/ou melatonina e estudamos os efeitos desses hormônios nos ritmos de temperatura e atividade motora. O tratamento tardio com insulina reverteu à hipotermia, como se esperava pelas evidências na literatura (Howarth et al., 2006, 2011) e de forma geral, a desorganização do ritmo de temperatura gerada pelo diabetes, já que o período de $24 \mathrm{~h}$ perdido durante a doença foi restaurado pelo tratamento. Porém, a amplitude e as acrofases não foram restauradas. A atividade média, por sua parte, não foi revertida pela insulina, nem os parâmetros rítmicos. Dados na literatura mostram que o tratamento com insulina reverte à diminuição da temperatura média, porém não da atividade motora média, causados pela indução do diabetes por STZ (Howarth et al., 2006). Isto demonstra que a insulina regula principalmente o ritmo de temperatura 
tendo um efeito menos significativo sobre o ritmo da atividade, porém a insulina consegue prevenir a diminuição ainda maior da atividade por melhorar a condição metabólica do animal.

A melatonina é o hormônio que sinaliza as variações das fases clara e escura do ambiente para o meio interno, e também é importante na manutenção da sincronização interna (Gubin et al., 2006). Após demonstrarmos a ruptura do ritmo de temperatura e sabendo que, a temperatura é um marcador da sincronização interna do organismo, que a melatonina é um regulador importante da temperatura em humanos (Cagnacci et al., 1992) e que o rato é um animal de hábito noturno, suplementamos com melatonina em doses fisiológicas. A melatonina não foi capaz de reverter a hipotermia nem restaurar o ritmo normal da temperatura; porém foi suficiente para restabelecer o período de $24 \mathrm{~h}$. Por outro lado, a melatonina teve um efeito mais forte sobre o ritmo de atividade. A melatonina não conseguiu atenuar a queda na atividade média, levando a uma queda ainda maior que no período diabético. Com a suplementação, aumentou o número de dias rítmicos e as acrofases resultaram na fase escura, o que poderia se explicar pelo fato de que a melatonina age como sincronizador do meio interno, fazendo com que o animal apresente sua atividade predominantemente na fase escura. Já o MESOR e a amplitude permaneceram diminuídos. O animal se movimenta menos por falta de energia, mas sua atividade ocorre na fase certa. Finalmente, o tratamento combinado com insulina e melatonina reverteu à hipotermia, a perda de peso e a hiperglicemia, assim como restaurou completamente o ritmo de temperatura. A média da atividade aumentou significativamente, porém não reverteu aos valores normais. O ritmo resultou parcialmente restaurado, com maioria de dias rítmicos com suas acrofases na fase escura. Esses resultados mostram uma ação conjunta dos dois hormônios, já que a insulina permite que o animal tenha melhor estado metabólico e reverte o hipotireoidismo que estaria causando a hipotermia, e a melatonina sincroniza a temperatura e a atividade para a fase certa. Ainda é preciso estudar os mecanismos por trás deste fenômeno, mas provavelmente a melatonina esteja potenciando a ação da insulina, agindo como agente sincronizador. Com esses resultados resulta importante considerar a inclusão da melatonina no tratamento com insulina em indivíduos diabéticos, dado que a ruptura do ritmo de temperatura e as alterações no ritmo de atividade motora, assim como 
provavelmente outros ritmos no organismo, que estejam sendo alterados pelo diabetes não estejam sendo restaurados unicamente pelo tratamento com insulina.

Observa-se que frente à desorganização circadiana decorrente do diabetes, houve uma resposta diferente dos dois ritmos estudados. Isso, junto com os efeitos observados da melatonina sobre os dois ritmos (ação predominante sobre o ritmo de atividade), nos leva a pensar na possibilidade de serem controlados por osciladores diferentes nos NSQ. Em roedores, é bem estabelecido que a temperatura corporal e a atividade motora estão acopladas no ciclo claro/escuro 12:12 e em condições constantes (claro constante; escuro constante). Ainda é desconhecido se esses dois ritmos são gerados por um mecanismo circadiano único ou controlados por mecanismos separados (Benstaali et al., 2001). Por outro lado, dados mais recentes na literatura discordam dessa teoria, fundamentando a existência de um único oscilador no NSQ responsável pelos dois ritmos já que em condições de luz tênue constante (livre-curso), os períodos e amplitudes dos ritmos de temperatura e atividade de roda resultaram acoplados, mesmo em ratos com dessincronização interna espontânea até a perda de ritmicidade (Aguzzi et al., 2006).

Alguns efeitos deletérios do diabetes sobre os parâmetros rítmicos da temperatura e da atividade motora foram melhorados, e a perda de peso, a hipotermia e a hiperglicemia foram prevenidos pelo tratamento precoce com insulina. Esses efeitos benéficos da insulina são dependentes da continuidade do tratamento, já que quando ele fora interrompido, alguns dos efeitos deletérios do diabetes reapareceram. A restituição do tratamento, 15 dias depois, teve um efeito similar ao da insulina quando administrada tardiamente. Portanto, a insulina possui um efeito precoce nos ritmos diários de temperatura e atividade quando administrada logo após o início da doença, já que a restituição do tratamento não resultou tão efetiva, pois não restaurou todos os parâmetros rítmicos nem conseguiu restaurar a temperatura nem a atividade média. Por outro lado, nem 3 nem 15 dias de diabetes foram suficientes para se observar a predominância de outro período diferente do de $24 \mathrm{~h}$ nos dois ritmos, enquanto que os animais que ficaram diabéticos durante 33 perderam o períodos de 20 a $28 \mathrm{~h}$ somente do ritmo de temperatura. Portanto é possível que o período seja um parâmetro mais estável e seja necessário um dano maior para que desapareça. 
No presente trabalho demonstramos que a melatonina é capaz de manter parcialmente o ritmo de temperatura em animais diabéticos quando administrada poucos dias após o início da doença, porém não resulta tão eficiente como a insulina, já que os parâmetros rítmicos resultaram alterados significativamente. Novamente, a melatonina foi mais efetiva sobre o ritmo de atividade, já que preveniu a queda da média e manteve seu ritmo. A restituição da suplementação com melatonina restabeleceu os valores obtidos na suplementação precoce, e no caso da atividade, não reverteu à diminuição na média, mas atenuou os efeitos dos quinze dias de diabetes. Portanto, no caso da melatonina ela tem um papel limitado na ritmicidade da temperatura, atenuando os efeitos deletérios do diabetes, e os quinze dias durante os quais foi interrompida sua administração não causaram dano significativo que não permitisse a ela cumprir sua função. A melatonina também aumentou a temperatura média, mas não teve efeito sobre a hiperglicemia, a qual se manteve durante a suplementação. Com vista nesses resultados, a melatonina tem um papel mais importante na ritmicidade (prevenindo a perda do período de $24 \mathrm{~h}$ nos ritmos de temperatura e atividade), e na atividade, no entanto a insulina age tanto sobre os efeitos no metabolismo e na ritmicidade, principalmente na temperatura. Mesmo assim, demonstramos no presente trabalho que a melatonina administrada precocemente é importante como prevenção da disrupção da ritmicidade da temperatura e a desorganização no ritmo de atividade motora. Esses resultados diferem dos encontrados na literatura, que apontam para um efeito hipotermiante da melatonina (Lin et al., 2002). A diferença pode dever-se a que Lin et al. (2002) injetaram melatonina em doses farmacológicas (30-120 mg/kg i.p.) em animais saudáveis, enquanto no presente trabalho suplementamos com doses fisiológicas $(0,5 \mathrm{mg} / \mathrm{kg}$ na água de bebida) animais diabéticos que possuiriam menor conteúdo plasmático de melatonina. Finalmente, devido a o tratamento combinado de insulina com melatonina apresentar melhores resultados que quando administradas separadamente na ritmicidade de animais com a doença estabelecida, o mesmo tratamento foi realizado precocemente. Durante o tratamento precoce a temperatura e a atividade média aumentaram acima dos valores do período controle, sendo isto talvez por que ambos os hormônios agem impedindo a hipotermia. Após quinze dias sem tratamento, a restituição do mesmo melhorou novamente o quadro, porém, desta vez não reverteu completamente o dano causado pelo diabetes. Portanto, o 
tratamento com insulina e melatonina após quinze dias de diabetes, mesmo sendo que os animais receberam tratamento preventivo, não resulta tão eficiente quanto tratar os animais logo no início da doença. Mais uma vez, o tratamento precoce com insulina e melatonina, igualmente observado quando administrados separadamente, manteve o período de $24 \mathrm{~h}$ de ambos os ritmos. Pareceria, pelos resultados obtidos, que o período é uma característica do sistema circadiano que persiste mesmo quando outras características desaparecem e, a diferença dos outros parâmetros rítmicos (MESOR, amplitude e acrofase) o período foi restituído com todos os tratamentos tardios.

O presente estudo demonstra pela primeira vez as alterações nos ritmos diários de temperatura corporal e atividade motora, dois dos ritmos mais importantes, causadas pelo diabetes induzido por STZ. Resulta importante levar em consideração que o diabetes não é somente responsável pelos danos metabólicos, mas também pelos danos severos ao sistema circadiano; a informação apresentada neste trabalho proporciona um novo ponto de vista do diabetes e permite pensar em estratégias mais amplas na hora de desenhar terapias para tratar esta doença, considerando um novo sistema que resulta significativamente alterado e que não é totalmente restaurado pelas terapias atualmente utilizadas. Serão necessários novos estudos para entender os mecanismos por trás dessas observações, como o papel do TAM e da glândula tireoide no ritmo diário da temperatura corporal, e aqueles que integram os sistemas metabólico, cronobiológico e molecular. 


\section{CONCLUSÃO}

Em conclusão, o diabetes do tipo I causa ruptura do ritmo diário de temperatura corporal e severas alterações no ritmo de atividade motora, junto com uma diminuição significativa da temperatura e da atividade média; quando a doença é tratada, a insulina é capaz de restaurar o ritmo e reverter a hipotermia, porém não tem efeito no ritmo da atividade; a melatonina não restaura o ritmo nem reverte a hipotermia, mas restaura parcialmente o ritmo de atividade; o tratamento conjunto de insulina e melatonina restaura completamente os ritmos e a temperatura e a atividade média normal. Os tratamentos logo após o início da doença agem precocemente prevenindo os efeitos deletérios do diabetes sobre os ritmos. A melatonina atenua os efeitos deletérios e aumenta parcialmente a temperatura, porém não é suficiente para manter o ritmo normal, tendo uma ação mais importante sobre a atividade. A insulina e a melatonina agem de forma complementar, resultando em um tratamento mais eficiente, quando administrados tanto de forma precoce quanto tardia. Todos os tratamentos atuam de forma dependente da continuidade dos mesmos, sendo os tratamentos precoces mais eficientes que aqueles administrados quinze dias após interrupção. 


\section{REFERÊNCIAS}

Abrams R, Hammel HT. Circadian variations in hypothalamic temperatures in unanesthetized rats. Am J Physiol. 1965;208:698-702.

Aguzzi J, Bullock NM, Tosini G. Spontaneous internal desynchronization of locomotor activity and body temperature rhythms from plasma melatonin rhythm in rats exposed to constant dim light. J Circadian Rhythms. 2006;4:6.

Alonso-Vale MI, Anhe GF, Borges-Silva C, Andreotti S, Peres SB, et al. Pinealectomy alters adipose tissue adaptability to fasting in rats. Metabolism. 2004a;53:500-6.

Alonso-Vale MI, Borges-Silva CN, Anhe GF, Andreotti S, Machado MA, et al. Light/dark cycle-dependent metabolic changes in adipose tissue of pinealectomized rats. Horm Metab Res. 2004b;36:474-9.

Alonso-Vale MI, Adreotti S, Peres SB, Anhê GF, Borges-Silva C, Cipolla-Neto J, Lima FB. Melatonin enhances leptin expression by rat adipocytes in the presence of insulin. Am J Phys End Met. 2005;288(4):805-12.

Alonso-Vale MI, Adreotti S, Borges-Silva C, Mukai PY, Cipolla-Neto J, Lima FB. Intermittent and rhythmic exposure to melatonin in primary cultured adipocytes enhances the insulin and dexamethasone effects on leptin expression. J Pin Res. 2006;41(1):28-34.

Alonso-Vale Ml, Andreotti S, Mukai PY, Borges-Silva CN, Peres SB, Cipolla-Neto J, Lima FB. Melatonin and the circadian entrainment of metabolic and hormonal activities in primary isolated adipocytes. J Pin Res. 2008;45(4):422-29.

American Diabetes Association. Diagnosis and classification of diabetes mellitus. Diabetes care. 2008;31(Suppl 1):S55-S60.

Amaral F, Turati A, Barone M, Scialfa J, Buonfilgio D, Peres R, et al. Naughty hyperglycemia: diabetes and melatonin synthesis disruption. J Clin Invest. In press.

Andersson AK, Sandler S. Melatonin protects against streptozotocin, but not interleukin-1 [beta]-induced damage of rodent pancreatic [beta]-cells. J Pin Res. 2001;30(3):157-65.

Anhê GF, Caperuto LC, Pereira-da-Silva M, Souza LC, Hirata AE, Velloso LA, et al. In vivo activation of insulin receptor tyrosine kinase by melatonin in the rat hypothalamus. J Neurochem. 2004;90 (3):559-66.

Arendt J. Melatonin. Clin Endocrin. 1988;29:205-29.

*De acordo com:

International Committee of Medical Journal Editors. [Internet]. Uniform requirements for manuscripts submitted to Biomedical Journal: sample references. [Cited 2011 Jul 15]. Available from: http://www.icmje.org 
Arendt J. Melatonin and the mammalian pineal gland. London, Chapman \& Hall. 1995.

Armstrong SM, Redman J. Melatonin administration: Effects on rodent rhythms. In: Photoperiodism, Melatonin and the Pineal. In: Everett D, Clarck S, organizers. Ciba Foundation Symposium, 117. London, Pitman; 1985. p. 188-207.

Aschoff J, Gerecke U, Weaver R. Desynchronization of human circadian rhythms. Jpn J Physiol. 1967;17:450-7.

Barone MT, Menna-Barreto L. Diabetes and sleep: a complex cause-and-effect relationship. Diabetes Res Clin Pract. 2011;91(2):129-37.

Benstaali C, Mailloux A, Bogdan A, Auzéby A, Touitou Y. Circadian rhythms of body temperature and motor activity in rodents their relationships with the light-dark cycle. Life Sci. 2001;68(24):2645-56.

Brown G, Grota L, Niles L. Melatonin origin, control of circadian rhythm and site of action. Adv Biosc. 1981;29:193-6.

Cagnacci A, Elliott JA, Yen SS. Melatonin: a major regulator of the circadian rhythm of core temperature in humans. J Clin Endocrinol Metab. 1992;75: 447-52.

Cardinali DP. Melatonin: A mammalian pineal hormone. Endocr Ver. 1981;2: 327-46.

Cardinali DP, Jordá Catalá JJ, Sánchez Barceló EJ. Introducción a la Cronobiología: fisiología de los ritmos biológicos. Ed. Universidad de Cantabria; 1994.

Cardinali DP, Vacas MI. Molecular endocrinology of melatonin receptor sites in brain and peripheral organs. Adv Biosci. 1981;29:237-46.

Cassone VM, Chesworth MJ, Armstrong SM. Entrainment of rat circadian rhythms by daily injection of melatonin depends upon the hypothalamic suprachiasmatic nuclei. Physiol \& Behav. 1986;36:1111-21.

Cassone VM, Roberts MH, Moore RY. Effects of melatonin on 2-deoxy(1-14C) glucose within the rat suprachiasmatic nucleus. Am J Physiol. 1988;255:R332-R37.

Castro Afeche S, Cipolla-Neto J. Fisiologia. In: Aires, MM. Ed. Guanabara Koogan Ltda. São Paulo, 2008. Capítulo 4.

Cipolla-Neto, J. Introdução ao Estudo da Cronobiologia. In: Cipolla-Neto J, Marques N, Menna-Barreto LS, editores. Ícone. São Paulo. 1988. Capítulo 2.

Cosana. Benedito Silva. Brasil. Software.

Clement JG, Mills P, Brockway B. Use of telemetry to record body temperature and activity in mice. J Pharm Met. 1989;21:129-40. 
De Castro JM. Diurnal rhythms of behavioral effects on core temperature. Physiol Behav. 1978;21:883-6.

Delaney CA, Dunger A, DiMatteo M, Cunningham JM, Green MH, Green IC. Comparison of inhibition of glucose-stimulated insulin secretion in rat islets of langerhans by streptozotocin and methyl and ethyl nitrosoureas and methanesulphonates. Lack of correlation with nitric oxide-releasing or O6-alkylating ability. Biochem Pharmacol. 1995;50(12):2015-20.

do Carmo Buonfiglio D, Peliciari-Garcia RA, do Amaral FG, Peres R, Nogueira TC, et al. Early-stage retinal melatonin synthesis impairment in streptozotocin-induced diabetic wistar rats. Invest Ophthalmol Vis Sci. 2011;52:7416-22.

El Temps. Diez-Noguera. Barcelona. España. Software.

Fu Z, Gilbert ER, Liu D. Regulation of insulin synthesis and secretion and pancreatic Beta-cell dysfunction in diabetes. Curr Diabetes Rev. 2013;9:25-53.

Garcia RAP, Afeche SC, Scialfa JH, Amaral FG, Santos SHJ, Lima FB, et al. Insulin modulates norepinephrine-mediates melatonin synthesis in cultured rat pineal gland. Life Sciences. 2008;82 (1-2):108-14.

Garcia RAP, Marçal AC, Silva JA, Carmo-Buonfiglio D, Amaral FG, Afeche SC, et al. Insulin temporal sensitivity and its signaling pathway in the rat pineal gland. Life Sciences. 2010;87:169-74.

Gillette MU, Mitchell JW. Signaling in the suprachiasmatic nucleus: selectively responsive and integrative. Cell and Tissue Research. 2002;309 (1):99-107.

Goldman BD. The physiology of melatonin in mammals. Pineal Res Rev. 1983;1: 145-82.

Goncharova ND, Vengerin AA, Khavinson V, Lapin BA. Pineal peptides restore the age-related disturbances in hormonal functions of the pineal gland and the pancreas. Exp Gerontol. 2005;40:51-7.

GraphPad Prism 5. GraphPad Software.

Gubin DG, Gubin GD, Waterhouse J, Weinert D. The circadian body temperature rhythm in the elderly: effect of single daily melatonin dosing. Chronobiol Int. 2006;23:639-58.

Gül M, Emre S, Eşrefoğlu M, Vard N. Protective effects of melatonin and aminoguanidine on the cornea in streptozotocin-induced diabetic rats. Cornea. 2008;27(7):795-801.

Hanneman SK. Measuring circadian temperature rhythm. Biol Res Nurs. 2001;2: 236-48. 
Hakim ZS, Patel BK, Goyal RK. Effects of chronic ramipril treatment in streptozotocin-induced diabetic rats. Indian J Pharmacol. 1997;41:353-60.

Harkin A, O'Donnell JM, Kelly JP. A study of VitalView for behavioural and physiological monitoring in laboratory rats. Physiol Behav. 2002;77:65-77.

Herichova I, Zeman M, Stebelova K, Ravingerova T. Effect of streptozotocin-induced diabetes on daily expression of per2 and $\mathrm{dbp}$ in the heart and liver and melatonin rhythm in the pineal gland of wistar rat. Mol Cell Biochem. 2005;270:223-9.

Honma S, Katsumno Y, Honma K. Light suppression of nocturnal pineal and plasma melatonin in rats depends on wavelength and time of day. Neurosci Lett. 1992;147:201-4.

Howarth FC, Jacobson M, Naseer O, Adeghate E. Short-term effects of streptozotocin-induced diabetes on the electrocardiogram, physical activity and body temperature in rats. Exp Physiol. 2005a;90:237-45.

Howarth FC, Jacobson M, Shafiullah M, Adeghate E. Long-term effects of streptozotocin-induced diabetes on the electrocardiogram, physical activity and body temperature in rats. Exp Physiol. 2005b);90:827-35.

Howarth FC, Jacobson M, Shafiullah M, Adeghate E. Effects of insulin treatment on heart rhythm, body temperature and physical activity in streptozotocin-induced diabetic rat. Clin Exp Pharmacol Physiol. 2006;33:327-31.

Howarth FC, Jacobson M, Shafiullah M, Ljubisavljevic M, Adeghate E. Heart rate, body temperature and physical activity are variously affected during insulin treatment in alloxan-induced type 1 diabetic rat. Physiol Res. 2011;60:65-73.

International Diabetes Federation. The Diabetes Atlas. Third Edition. Brussels: International Diabetes Federation. 2007.

Karunanayake EH, Baker JR, Christian RA, Hearse DJ, Mellows G. Autoradiographic study of the distribution and cellular uptake of (14C)-streptozotocin in the rat. Diabetologia. 1976;12:123-8.

Katovich MJ, Marks KS, Sninsky CA. Effect of insulin on the altered thyroid function and adrenergic responsiveness in the diabetic rat. Can $\mathrm{J}$ Physiol Pharmacol. 1993;71:568-75.

Korkmaz A, Topal T, Tan DX, Reiter RJ. Role of melatonin in metabolic regulation. Rev Endocr Metab Disord. 2009;10:261-70.

Krauchi K, Cajochen C, Wirz-Justice A. A relationship between heat loss and sleepiness: effects of postural change and melatonin administration. J Appl Physiol. 1997;83:134-9.

la Fleur SE, Kalsbeek A, Wortel J, Fekkes ML, Buijs RM. A daily rhythm in glucose tolerance: a role for the suprachiasmatic nucleus. Diabetes. 2001a;50:1237-43. 
la Fleur SE, Kalsbeek A, Wortel J, van der Vliet J, Buijs RM. Role for the pineal and melatonin in glucose homeostasis: pinealectomy increases night-time glucose concentrations. J Neuroendocrinol. 2001b;13:1025-32.

Lenzen S. The mechanisms of alloxan- and streptozotocin-induced diabetes. Diabetologia. 2008;51(2):216-26.

Lima FB, Machado UF, Bartol I, Seraphim PM, Sumida DH, Moraes SM, Hell NS, Okamoto MM, Saad MJ, Carvalho CR, Cipolla-Neto J. Pinealectomy causes glucose intolerance and decreases adipose cell responsiveness to insulin in rats. Am J Phys. 1998;275(6 Pt 1):934-41.

Lima FB, Matsushita DH, Hell NS, Dolnikoff MS, Okamoto MM, Cipolla-Neto J. The regulation of insulin action in isolated adipocytes. Role of the periodicity of food intake, time of day and melatonin. Braz J Med Biol Res. 1994;27(4):995-1000.

Lin MT, Chuang Jl. Melatonin potentiates $5-\mathrm{HT}(1 \mathrm{~A})$ receptor activation in rat hypothalamus and results in hypothermia. J Pineal Res. 2002;33:14-19.

Lund R. Personality factors and desynchronization of circadian rhythms. Psychomon Med. 1974;36:224-8.

Marques MD, Golombek D, Moreno C. Cronobiologia: Princípios e aplicações. In: Marques N, Menna-Barreto LS, editores. Ed. Fiocruz. São Paulo, 1997. Capítulo 3.

Marques N, Menna-Barreto LS. Cronobiologia: Princípios e aplicações. Ed. Edusp. 3ra ed. São Paulo, 2003.

Matsen ME, Thaler JP, Wisse BE, Guyenet SJ, Meek TH, et al. In uncontrolled diabetes, thyroid hormone and sympathetic activators induce thermogenesis without increasing glucose uptake in brown adipose tissue. Am J Physiol Endocrinol Metab. 2013;304:E734-46.

McArthur A, Gillette M, Prosser P. Melatonin resets the rat suprachiasmatic circadian clock in vitro. Brain Res. 1991;565:158-61.

Mendes C, Lopes AM, do Amaral FG, Peliciari-Garcia RA, Turati AD, Hirabara SM, Scialfa Falcão JH, Cipolla-Neto J. Adaptations of the aging animal to exercise: role of daily supplementation with melatonin. J Pineal Res. 2013; doi:10.1111/jpi.12065.

Minors DS, Folkard S, Waterhouse JM. The shape of the endogenous circadian rhythm of rectal temperature in humans. Chronobiol Int. 1996;13:261-71.

Peschke E, Frese T, Chankiewitz E, Peschke D, Preiss U, et al. Diabetic goto kakizaki rats as well as type 2 diabetic patients show a decreased diurnal serum melatonin level and an increased pancreatic melatonin-receptor status. J Pineal Res. 2006;40:135-43.

Peschke E, Stumpf I, Bazwinsky I, Litvak L, Dralle H, et al. Melatonin and type 2 diabetes - a possible link? J Pineal Res. 2007;42:350-8. 
Peschke E, Wolgast S, Bazwinsky I, Ponicke K, Muhlbauer E. Increased melatonin synthesis in pineal glands of rats in streptozotocin induced type 1 diabetes. J Pineal Res. 2008;45:439-48.

Pevet P. Environmental control of the annual reproductive cycle in mammals. Role of the pineal gland. Comp Physiol Environm Adapt. 1987;3:82-100.

Picinato MC, Haber EP, Carpinelli AR, Cipolla-Neto J. Daily rhythm of glucoseinduced insulin secretion by isolated islets from intact and pinealectomized rat. $\mathrm{J}$ Pineal Res. 2002a;172-7.

Picinato MC, Haber EP, Cipolla-Neto J, Curi R, de Oliveira Carvalho CR, Carpinelli AR. Melatonin inhibits insulin secretion and decreases PKA levels without interfering with glucose metabolism in rat pancreatic islets. J Pin Res. 2002b;33(3):156-60.

Pittendrigh CS. Circadian rhythms and the circadian organization of living systems. Cold Spring Harbor Symp Q nat Biol. 1960;25:159-84.

Rakieten N, Rakieten ML, Nadkarni MV. Studies on the diabetogenic action of streptozotocin. Cancer Chem other Rep. 1963;29:91-108.

Rasmussen DD, Boldt BM, Wilkinson CW, Yellon SM, Matsumoto AM. Daily melatonin administration at middle age suppresses male rat visceral fat, plasma leptin, and plasma insulin to youthful levels. Endocrinology. 1999;140:1009-12.

Rebolledo OR, Redman J, Armstrong S, Ng KT. Free-running activity rhythms in the rat: entrainment by melatonin. Science. 1983; 219:1089-91.

Refinetti R, Menaker M. The circadian rhythm of body temperature. Physiol Behav. 1992;51: 613-37.

Refinetti R. Phase relationship of the body temperature and locomotor activity rhythms in free-running and entrained rats. Biol Rhythm Res. 1997;28.19-24.

Refinetti R. Relationship between the daily rhythms of locomotor activity and body temperature in eight mammalian species. Am J Physiol. 1999;277:R1493-R1500.

Reiter RJ. Pineal gland: an intermediary between the environment and the endocrine system. Psychoneuroendocrinology. 1983;8:31-40.

. The melatonin message: Duration versus coincidence hypotheses. Life Sci. 1987;40:2119-31.

Reiter RJ, Tan DX, Korkmaz A. The circadian melatonin rhythm and its modulation: possible impact on hypertension. J Hypertens Suppl. 2009;27:S17-20.

Reppert SM, Weaver DR, Rivkees SA, Stopa EG. Putative melatonin receptors in a human biological clock. Science. 1988;242:78-81.

Rodgers RL, Davidoff AJ, Mariani MJ. Cardiac function of the diabetic renovascular hypertensive rat: effects of insulin and thyroid hormone treatment. Can J Physiol Pharmacol. 1991;69:346-54. 
Rondeel JM, de Greef WJ, Heide R, Visser TJ. Hypothalamo-hypophysial-thyroid axis in streptozotocin-induced diabetes. Endocrinology. 1992;130: 216-20.

Scheer FA, Pirovano C, Van Someren EJ, Buijs RM. Environmental light and suprachiasmatic nucleus interact in the regulation of body temperature. Neuroscience. 2005;132:465-77.

Schroder-van der Elst JP, van der Heide D. Effects of streptozocin-induced diabetes and food restriction on quantities and source of T4 and T3 in rat tissues. Diabetes. 1992;41:147-52.

Sochor M, Baquer NZ, Ball MR, McLean P. Regulation of enzymes of glucose metabolism and lipogenesis in diabetic rat liver by thyroid hormones. Biochem Int. 1987;15:619-27.

Sundaresan PR, Sharma VK, Gingold SI, Banerjee SP. Decreased beta-adrenergic receptors in rat heart in streptozotocin-induced diabetes: role of thyroid hormones. Endocrinology. 1984;114:1358-63.

Szkudelski T. The mechanism of alloxan and streptozotocin action in B cells of the rat pancreas. Physiol Res. 2001;50:537-46.

Tjälve H, Wilander $\mathrm{E}$, Johansson EB. Distribution of labelled streptozotocin in mice: uptake and retention in pancreatic islets. J Endocrinol. 1976;69:455-6.

Tutuncu NB, Batur MK, Yildirir A, Tutuncu T, Deger A, Koray Z. Melatonin levels decrease in type 2 diabetic patients with cardiac autonomic neuropathy. J Pineal Res. 2005;39:43-9.

Vanecek J, Pavlik A, Illenerová H. Hypothalamic melatonin receptor sites revealed by autoradiography. Brain Res. 1987;435:359-62.

Vollrath L. The Pineal Organ. Berlin, Springer. 1981.

Wever R. Phase-shifts of human circadian rhythms due to shifts of artificial zeitgebers. Chronobiologia. 1980;7:303-27.

Wolden-Hanson T, Mitton DR, McCants RL, Yellon SM, Wilkinson CW, et al. Daily melatonin administration to middle-aged male rats suppresses body weight, intraabdominal adiposity, and plasma leptin and insulin independent of food intake and total body fat. Endocrinology. 2000;141:487-97.

Yang YL, Shen ZL, Tang Y, Wang N, Sun B. Simultaneous telemetric analyzing of the temporal relationship for the changes of the circadian rhythms of brown adipose tissue thermogenesis and core temperature in the rat. Zhongguo Ying Yong Sheng Li Xue Za Zhi. 2011;27: 348-52.

Zanuto R, Siqueira-Filho MA, Caperuto LC, Bacurau RF, Hirata E, Peliciari-Garcia RA,et al. Melatonin improves insulin sensitivity independently of weight loss in old obese rats. J Pineal Res. 2013;doi:10.1111/jpi. 
Zhang L, Parratt JR, Beastall GH, Pyne NJ, Furman BL. Streptozotocin diabetes protects against arrhythmias in rat isolated hearts: role of hypothyroidism. Eur $\mathrm{J}$ Pharmacol. 2002;435:269-76. 


\section{APÊNDICES}

\section{APÊNDICE A - Figuras suplementares}

Figura A1 - Perfis diários dos ritmos de temperatura e de atividade motora de um animal controle

A

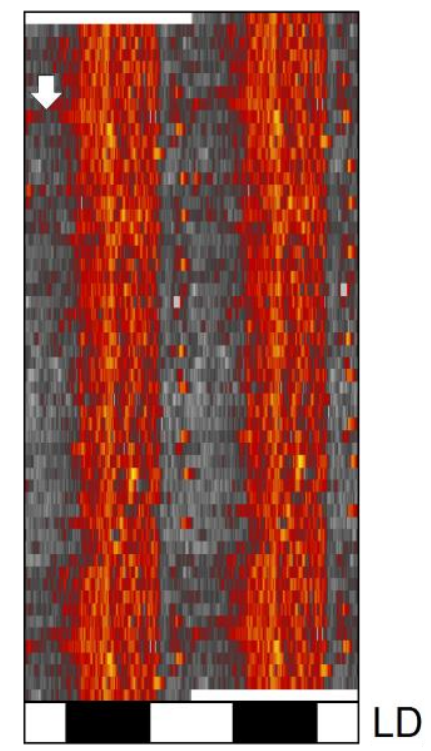

B

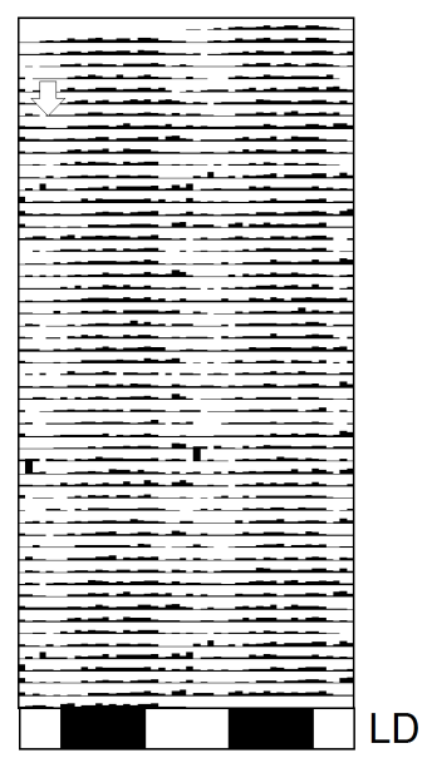

(A) Termograma representado por colorações vermelhas à amarelas indicando temperaturas maiores e gris a preto indicando temperaturas menores. (B) Actograma representado por barras indicando diferentes níveis de atividade obtida por somatória a cada 1 hora. Retângulos brancos e pretos no inferior do termograma indicam o regime de luminosidade durante os experimentos. Seta branca indica o dia da injeção de tampão citrato. 
Figura A2 - Perfis diários dos ritmos de temperatura de animais diabéticos tratados tardiamente.

A
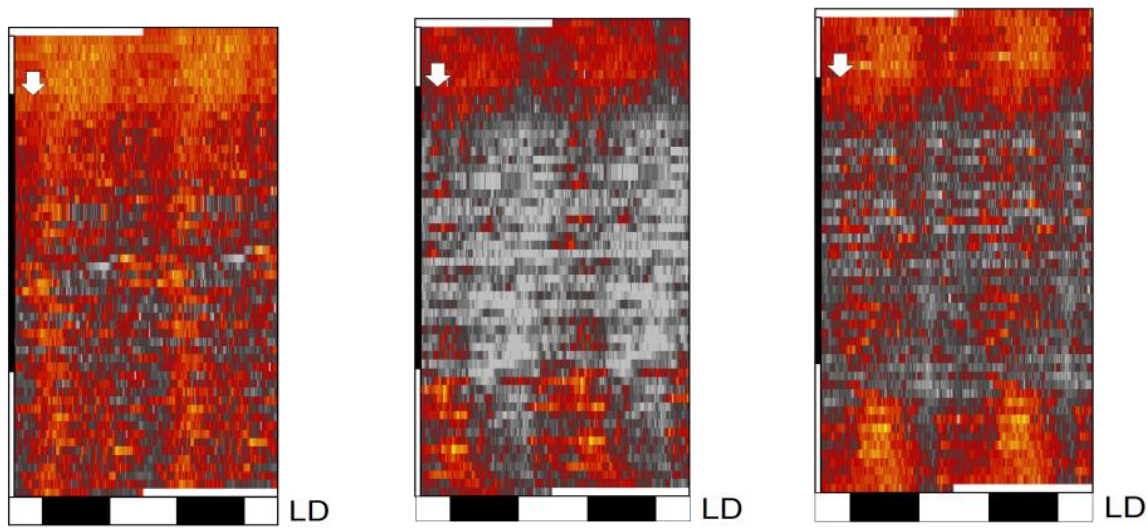

B
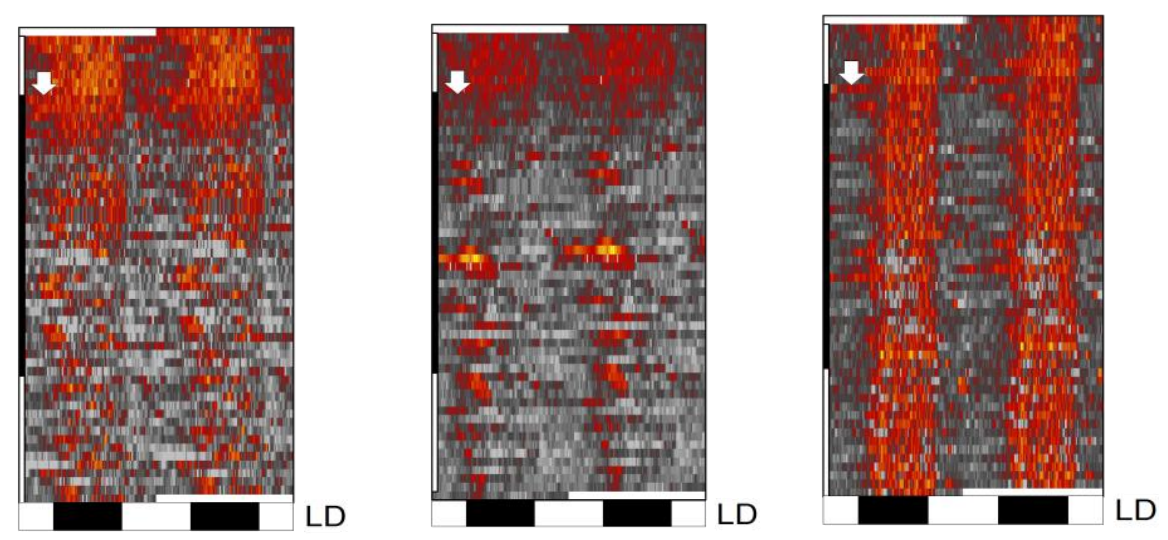

C
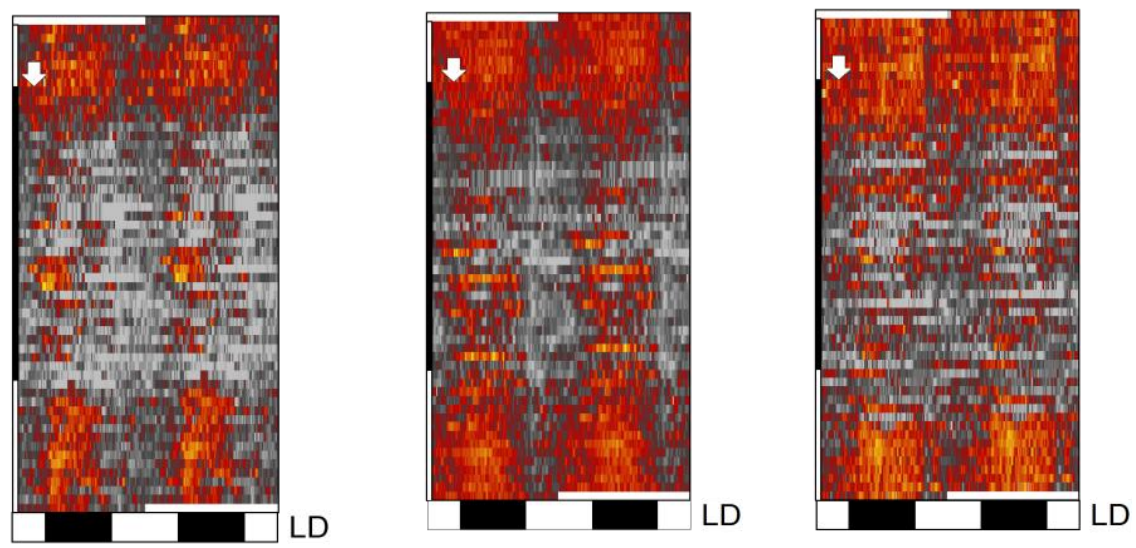

(A) Termogramas dos três animais do grupo diabético tratado tardiamente com insulina. (B) Termogramas dos três animais do grupo diabético suplementado tardiamente com melatonina. (C) Termogramas dos três animais do grupo diabético tratado tardiamente com insulina e melatonina. Gráficos representados por colorações vermelhas à amarelas indicando temperaturas maiores e gris a preto indicando temperaturas menores. Barra lateral branca superior indica o período controle, e a inferior indica o período tratado ou suplementado; a barra preta indica período diabético. Retângulos brancos e pretos no inferior do termograma indicam o regime de luminosidade durante os experimentos. 
Figura A3 - Perfis diários dos ritmos de temperatura de animais diabéticos tratados precocemente.

A

B
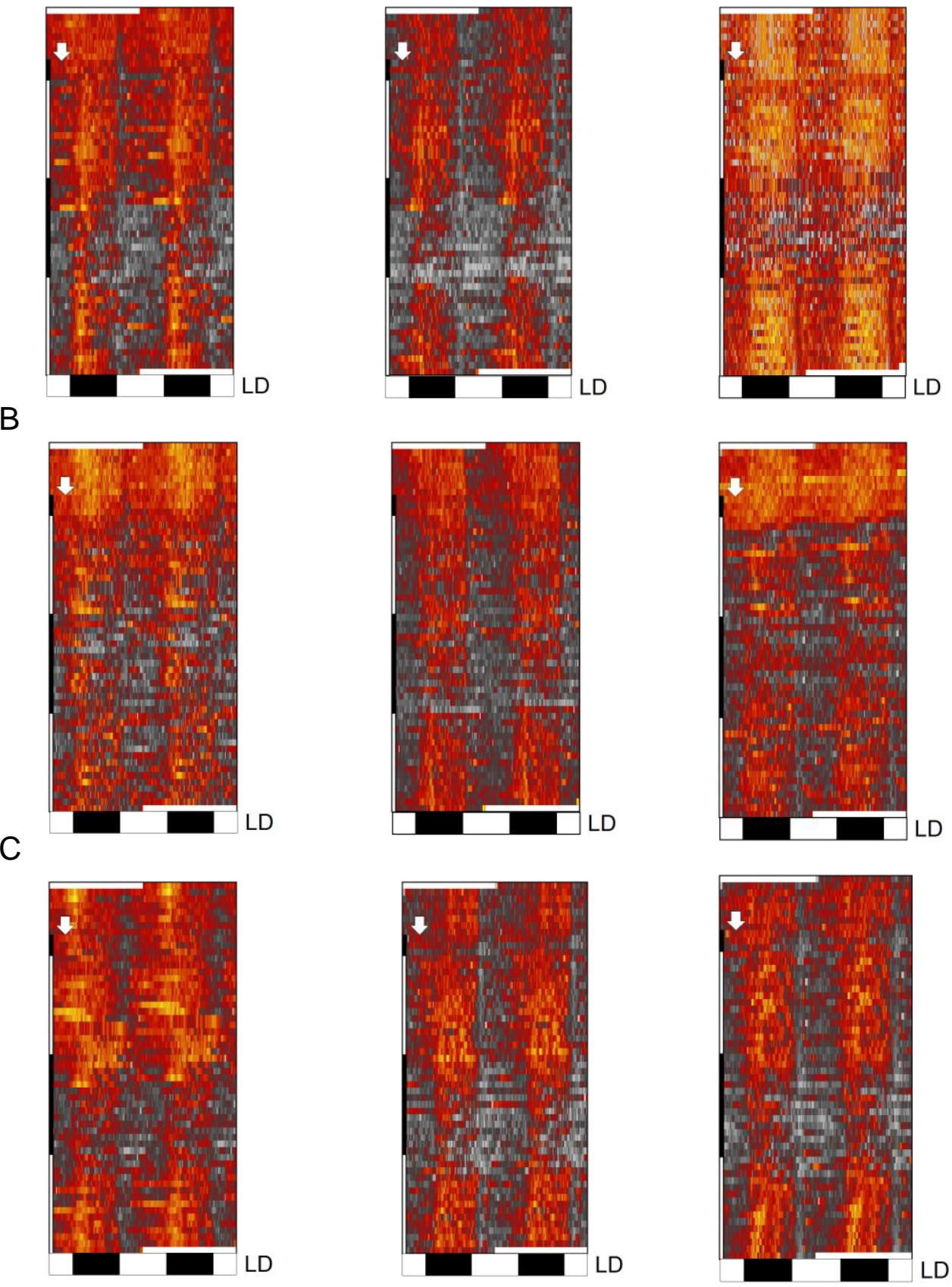

(A) Termogramas dos três animais do grupo diabético tratado precocemente com insulina. (B) Termogramas dos três animais do grupo diabético suplementado precocemente com melatonina. (C) Termogramas dos três animais do grupo diabético tratado precocemente com insulina e melatonina. Gráficos representados por colorações vermelhas à amarelas indicando temperaturas maiores e gris a preto indicando temperaturas menores. Retângulos brancos e pretos no inferior do termograma indicam o regime de luminosidade durante os experimentos. Barra lateral branca superior indica o tratamento ou suplementação precoce e a inferior indica a restituição do tratamento ou suplementação, a barra preta superior indica período diabético e a barra preta inferior indica o período sem tratamento ou suplementação. 
Figura A4 - Perfis diários dos ritmos de atividade motora de animais diabéticos tratados tardiamente.

A

B
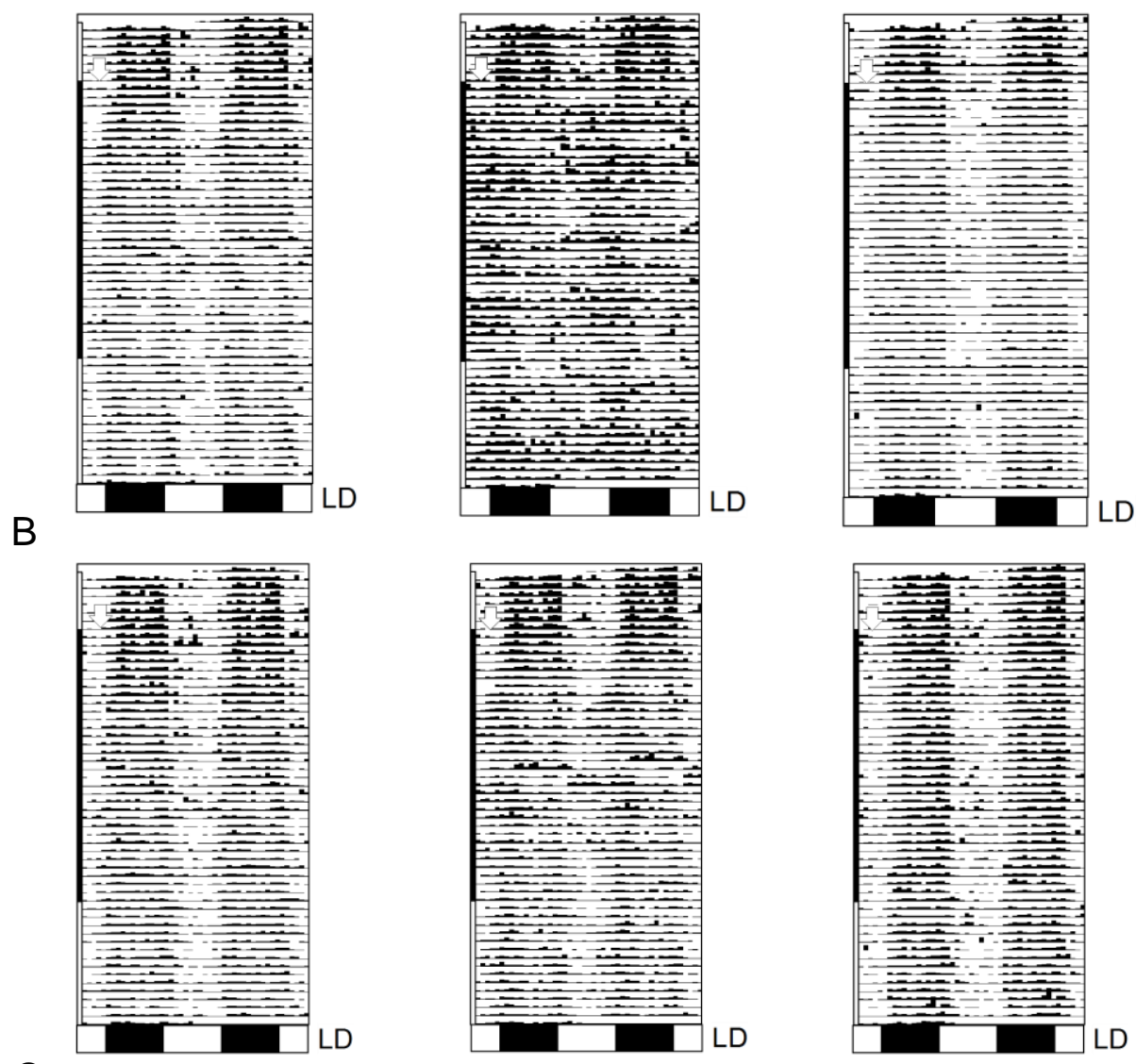

C
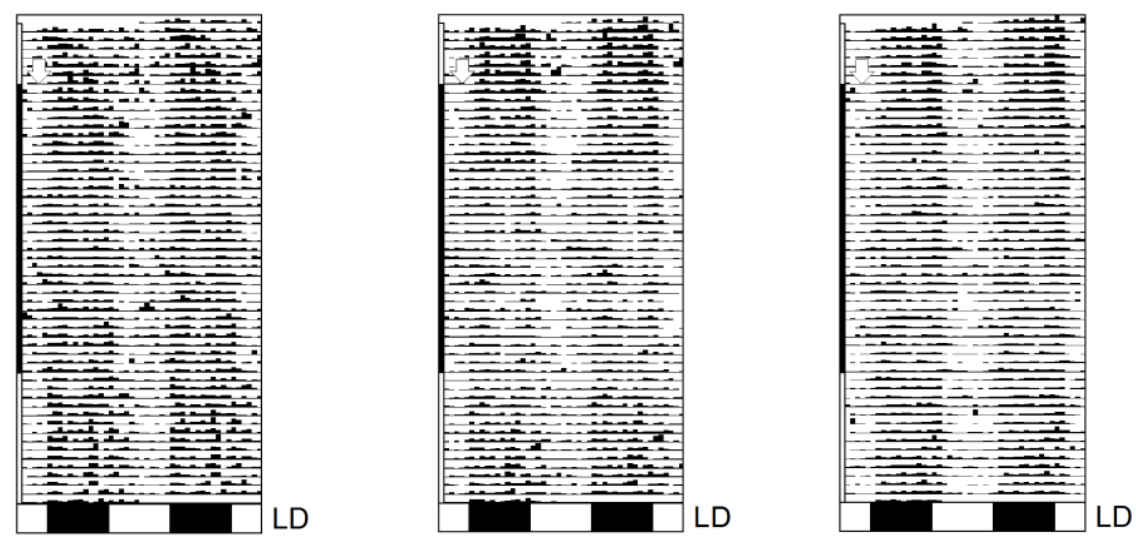

(A) Actogramas dos três animais do grupo diabético tratado tardiamente com insulina. (B) Actogramas dos três animais do grupo diabético suplementado tardiamente com melatonina. (C) Actogramas dos três animais do grupo diabético tratado tardiamente com insulina e melatonina. Gráficos representados por barras indicando diferentes níveis de atividade obtida por somatória a cada 1 hora. Retângulos brancos e pretos no inferior do actograma indicam o regime de luminosidade durante os experimentos. Barra lateral branca superior indica o período controle, barra preta indica período diabético e a barra branca inferior indica o período do tratamento ou suplementação. 

Figura A5 - Perfis diários dos ritmos de atividade motora de animais diabéticos tratados precocemente.

A
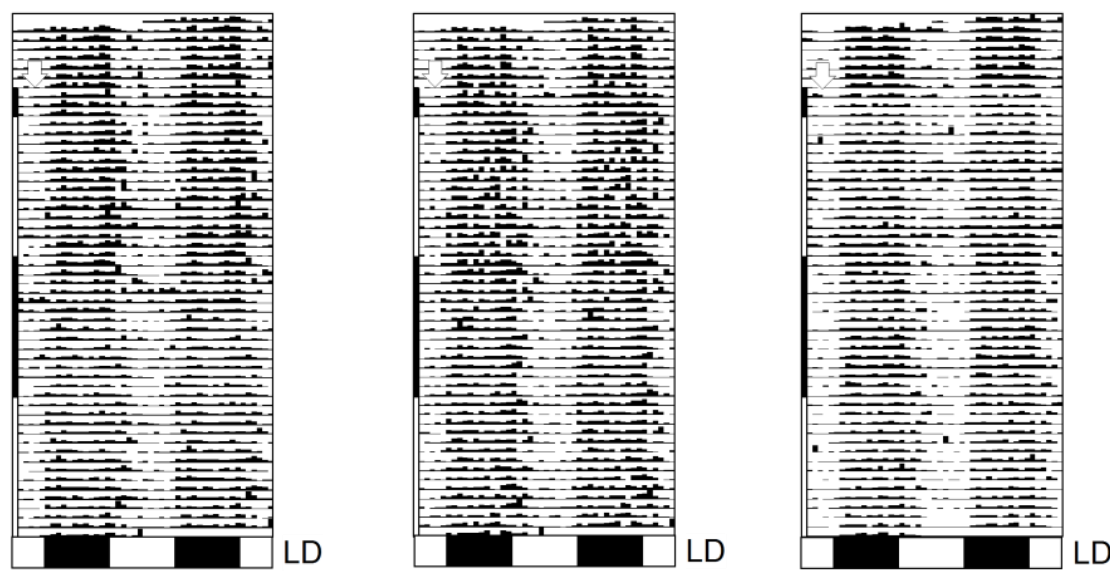

B
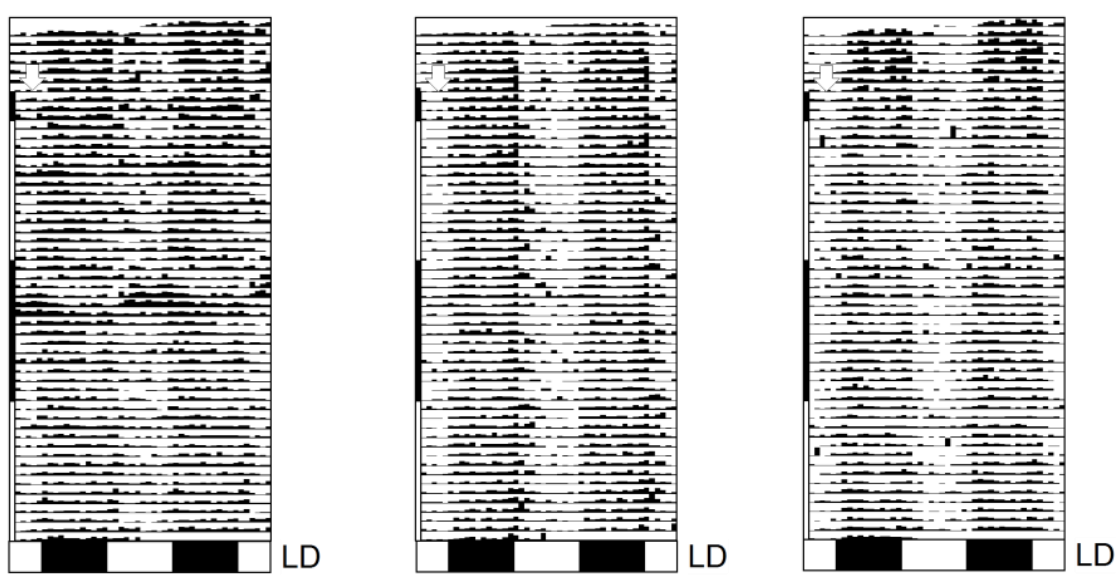

C
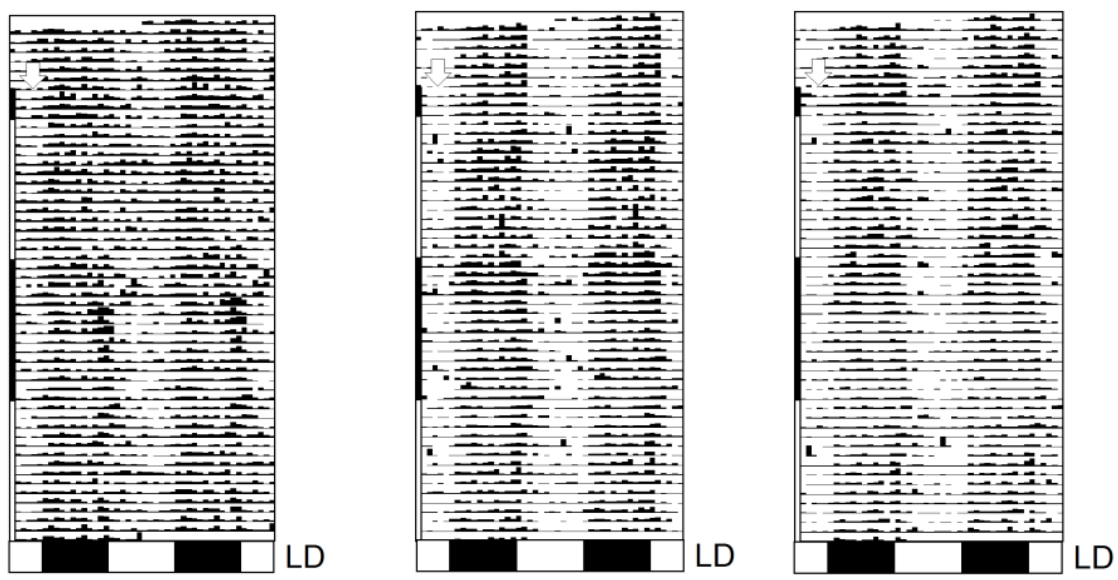

(A) Actogramas dos três animais do grupo diabético tratado precocemente com insulina. (B) Actogramas dos três animais do grupo diabético suplementado precocemente com melatonina. (C) Actogramas dos três animais do grupo diabético tratado precocemente com insulina e melatonina. Gráficos representados por barras indicando diferentes níveis de atividade obtida por somatória a cada 1 hora. Retângulos brancos e pretos no inferior do termograma indicam o regime de luminosidade durante os experimentos. Barra lateral branca superior indica o tratamento precoce e a inferior indica a restituição do tratamento ou suplementação, a barra preta superior indica período diabético e a barra preta inferior indica o período sem tratamento ou suplementação. 


\section{APÊNDICE B - Artigos de periódicos}

Trabalho a ser submetido (em fase de elaboração) na revista PLoS ONE.

TITLE: Streptozotocin-Induced Diabetes Disrupts the Body Temperature Circadian Rhythm in Rats.

AUTHORS: Angela M. Ramos Lobo ${ }^{1}$, Daniella do Carmo Buonfiglio ${ }^{1}$, Luiz S. MennaBarreto $^{2}$, José Cipolla-Neto ${ }^{1}$.

CORRESPONDING AUTHOR:

José Cipolla-Neto, M.D, Ph.D.

Professor of Physiology

Department of Physiology and Biophysics, Institute of Biomedical Sciences, University of São Paulo, Av. Lineu Prestes, 1524, São Paulo, SP, 05508-000, Brazil

Tel +551130917466

Fax +551130917629

Mobile +55 11971695000

Email: cipolla@icb.usp.br

AFFILIATIONS: ${ }^{1}$ Department of Physiology and Biophysics, Institute of Biomedical Sciences, ${ }^{2}$ School of Arts, Sciences and Humanities. ${ }^{1,}{ }^{2}$ University of São Paulo, Brazil. 